

\title{
champagne-ardenne
}

RAPPORT \& AVIS

7 décembre 2012

\section{Le tourisme de mémoire}

« La Champagne-Ardenne : une terre d'histoire qui se tourne vers l'avenir $»$ 



\section{SOMMAIRE}

SOMMAIRE

LA DEMARCHE.

INTRODUCTION : LE TOURISME DE MEMOIRE, LA COMMEMORATION DU CENTENAIRE DE LA GRANDE GUERRE, UN TRAVAIL D'ETAPE

I. LE TOURISME DE MEMOIRE DANS SON CONTEXTE ................................... 8

A) Les prolongements internationaux du tourisme de mémoire ......................................9

B) Le tourisme de mémoire en France....................................................................9

C) Un facteur de développement économique des territoires........................................ 10

II. LE TOURISME DE MEMOIRE EN CHAMPAGNE-ARDENNE............................12



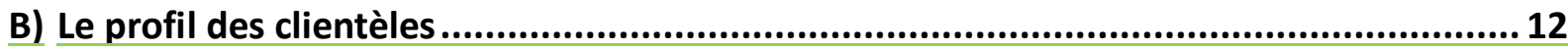

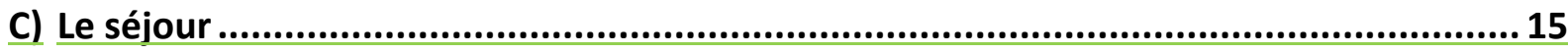

D) La motivation de la visite du site de mémoire ..................................................... 17

E) L'offre touristique en Champagne-Ardenne........................................................ 17

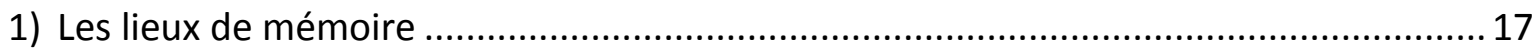

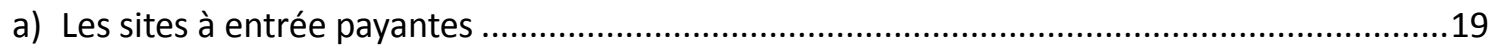

b) Les sites à entrées gratuites (chiffres de 2011) ...................................................................20

c) Une analyse qui montre que le tourisme de mémoire, dans notre région, connaît des



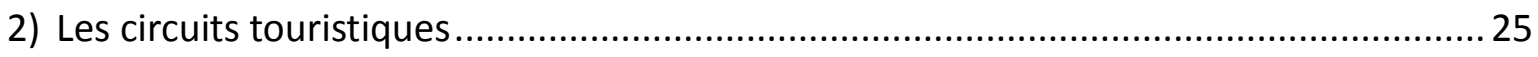

a) Les circuits de mémoire proposés par le Comité Régional du Tourisme - CRT ......................25

b) Les circuits de mémoire proposés par les offices de tourisme ...............................................26

c) Le circuit de mémoire proposé par le syndicat d'initiative d'Esternay ...................................28



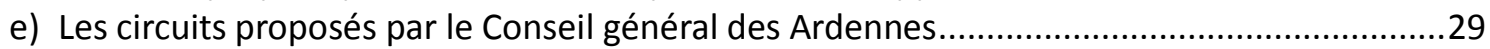

f) Les circuits proposés par le Ministère de la défense ...........................................................30

g) Le circuit proposé par le Centre Régional de Documentation Pédagogique de Champagne-



h) Le circuit proposé par la Communauté de communes du Pays d'Othe Aixois.......................31 
A) Le Centenaire de la Grande Guerre : le passage de la mémoire à l'histoire................... 33

B) La commémoration de la Grande Guerre, le «rapport Zimet» ....................................34

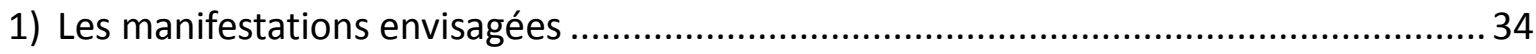

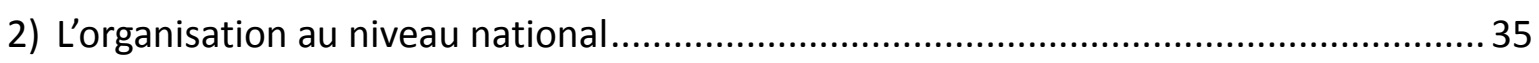

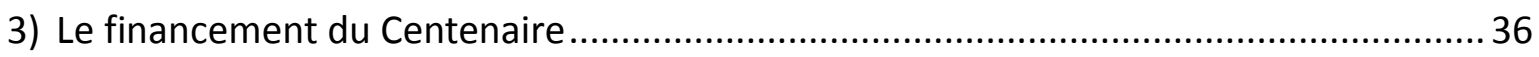

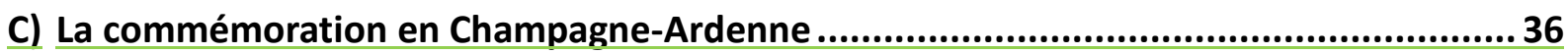







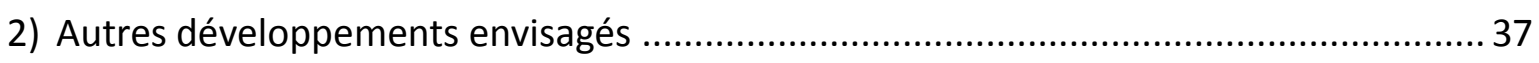

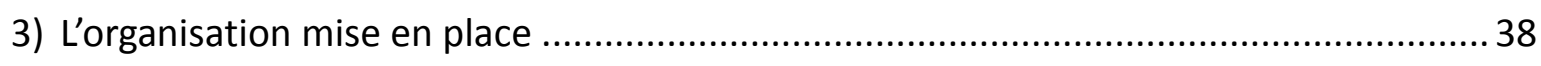

D) La commémoration dans d'autres régions..................................................... 39

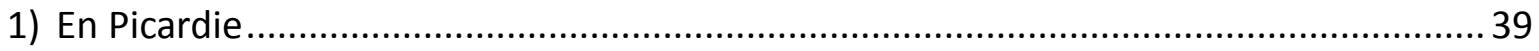

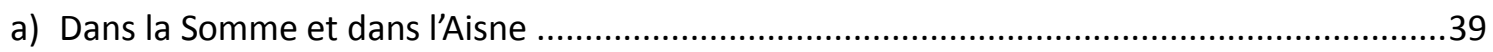



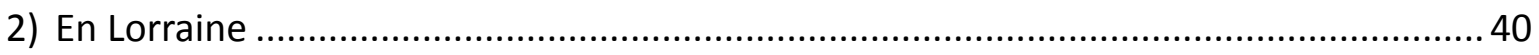

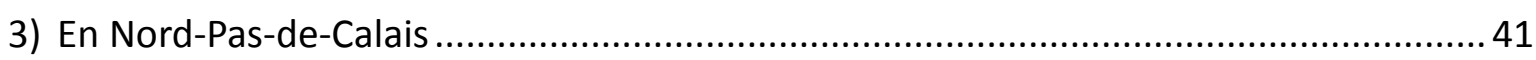

E) La commémoration à l'étranger ........................................................................ 42

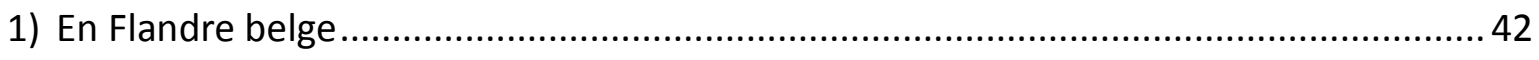



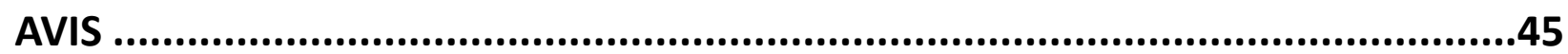

SIGLES ET ABREVIATIONS UTILISES ...........................................................50



ANNEXES..................................................................................................52

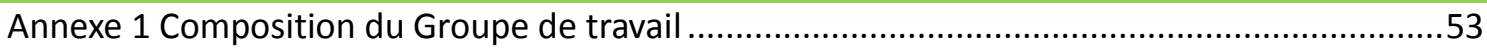

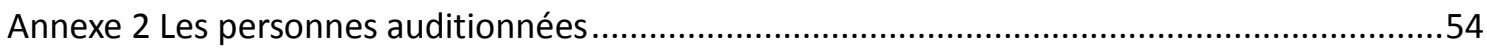

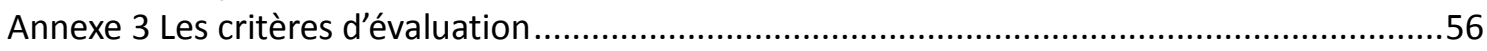

Annexe 4 Fiches descriptives des sites de mémoire de la Grande Guerre ..................................57 


\section{LA DEMARCHE}

Lors de sa réunion du 03 mai 2012, le Bureau du Conseil Économique, Social et Environnemental Régional - CESER - a décidé d'engager une réflexion sur le tourisme en Champagne-Ardenne.

Dans un premier temps, elle portera sur le tourisme de mémoire en s'appuyant sur 2014, année anniversaire des événements de 1914 mais aussi de 1814. Un rapport d'étape sera réalisé, faisant ressortir des préconisations à destination de la Région en rapport avec son rôle dans les célébrations du centenaire de la Grande Guerre en 2014.

Dans un second temps, l'étude portera sur le développement du tourisme de mémoire en Champagne-Ardenne dans l'ensemble de ses dimensions. Notre région présente en effet des atouts, notamment au travers de son patrimoine et de son histoire, pour développer le tourisme.

Ces travaux ont été confiés à un groupe de travail composé de quinze membres (cf. Annexe 1 page 53).

\section{La problématique de l'autosaisine}

En Champagne-Ardenne, le tourisme de mémoire, n'est pas suffisamment valorisé, développé, organisé, ni même perçu comme un axe de développement touristique en tant que tel.

Le constat est assez partagé : il y a des connaissances individuelles de l'histoire de notre région, mais pas assez de connaissances collectives. L'absence de coordination et de politique globale dans ce domaine est un frein au développement du tourisme de mémoire, donc du tourisme en Champagne-Ardenne. Cette absence accentue le manque de relations continues entre les différentes instances existantes (décideurs politiques, professionnels du tourisme, de la culture, historiques, associations et autres spécialistes économiques...). Pour que 2014 soit véritablement un tremplin touristique en Champagne-Ardenne, il parait urgent de créer une synergie entre ces acteurs et de favoriser l'implication des habitants champardennais et leur appropriation de l'histoire de leur région. Clairement, la Région peut être le vecteur de cette synergie, de cette coordination, de cette organisation touristique.

Ainsi l'année 2014 pourrait être l'événement déclencheur du développement organisé du tourisme de mémoire en Champagne-Ardenne pour aller, très rapidement, vers une organisation du tourisme champardennais, dans toutes ses dimensions. 


\section{INTRODUCTION : \\ LE TOURISME DE MEMOIRE, LA COMMEMORATION DU CENTENAIRE DE LA GRANDE GUERRE, UN TRAVAIL D'ETAPE}

La Champagne-Ardenne est une région de passage et de transition. Sa situation géographique et ses vallées de la Meuse, de l'Aisne, de la Marne, et de la Seine, font de cette région, depuis la plus haute antiquité, un carrefour de grands courants d'échanges culturels et commerciaux, amplifiés aujourd'hui par un tissu performant d'infrastructures de transports, tant autoroutières, que ferroviaires, aéroportuaires et fluviales. La ligne à grande vitesse EstEuropéenne et l'Europort de Vatry raccourcissent les distances et facilitent les flux tant commerciaux que touristiques nationaux et européens.

Depuis l'Antiquité, bien des événements de l'Histoire de France ont marqué la région. Par exemple :

- à l'époque romaine, la ville de Reims (Durocortorum) était un carrefour de routes et était une des villes les plus peuplées au nord de Rome (capitale de la Gaule Belgique) ;

- Le 20 juin 451, la bataille des champs catalauniques, localisée aux environs de Châlons-enChampagne (Duro Catalaunum à l'époque gallo-romaine et d'où provient le nom des " champs Catalauniques »), devient le mythe de la victoire contre les Huns avec la défaite d'Attila, qui marque la fin de son incursion en Gaule romaine ;

- au début du Moyen Âge, lors de Noël d'une année comprise entre 496 et 506, Clovis I ${ }^{\text {er }}$ a été baptisé par l'Évêque Remi dans la cathédrale primitive de Reims. C'est la raison pour laquelle Reims est devenue la ville du sacre des rois de France jusqu'à Charles $X$;

- vers I'An mil, l'archevêque de Reims, Gerbert d'Aurillac, est devenu pape sous le nom de Sylvestre II. II était un ami de l'empereur Othon III, créateur du Saint Empire germanique ;

- Né dans la noblesse champenoise en 1042, à Châtillon-sur-Marne, Eudes de Châtillon ou Odon de Lagery, était élu $157^{\mathrm{e}}$ pape sous le nom d'Urbain II (1088-1099).

- Jacques Pantaléon (1195-1264), fils d'un savetier de Troyes, devient pape sous le nom d'Urbain IV le 29 août 1261 ;

- de la fin du XII ${ }^{\mathrm{e}}$ siècle au XIV ${ }^{\mathrm{e}}$ siècle, la Champagne était une région très riche avec ses foires: Lagny-sur-Marne et Provins (dans l'actuelle région administrative d'Île-de-France), Troyes et Bar-sur-Aube, qui étaient sur deux routes de pèlerinage vers Rome ;

- Le Concile de Troyes s'ouvrait le 13 janvier 1129 et reconnaissait officiellement l'Ordre du Temple fondé par Hugues de Payns ;

- Bernard de Clairvaux (1090-1153), fondateur et premier abbé du monastère de Clairvaux laisse une œuvre riche de plusieurs traités, recueils de sermons, une correspondance très étoffée et fonde l'ordre de Cîteaux (cistercien), il est également l'auteur de la règle du temple ;

- Le style gothique apparait en Champagne-Ardenne : Notre-Dame à Reims est l'un des chefsd'œuvre du gothique rayonnant, Saint-Pierre et Saint-Paul à Troyes, Saint-Etienne à Châlonsen-Champagne, Saint-Mammès à Langres... ; 
- Au XVème siècle, Jeanne d'Arc nait à Domremy (Duché de Bar). Michelet, en 1841, élève Jeanne d'Arc au rang d'héroïne nationale. Par ses origines modestes, sa candeur et son bon sens, Jeanne incarne le peuple français et fait émerger le sentiment national en pleine guerre de 100 ans ;

- La bataille de Rocroi a lieu le 19 mai 1643 dans le cadre du conflit franco-espagnol, opposant les armées du roi de France sous les ordres de Louis de Bourbon, duc d'Enghien (le futur Grand Condé) et celles de l'Espagne commandées par Francisco de Melo ;

- le 20 septembre 1792 a lieu la bataille de Valmy, première victoire des révolutionnaires qui précède la création de la République ;

- La campagne de France est la fin de la guerre liée à la Sixième Coalition, qui se déroule de janvier à avril 1814, pendant laquelle Napoléon ${ }^{\text {er }}$ tente d'éviter ou d'arrêter l'invasion de la France et de conserver son trône ;

- en 1870 a eu lieu la bataille de Sedan dans les Ardennes ;

- pendant la Première Guerre mondiale, les Ardennes ont été le lieu de passage de l'invasion ennemie (Charleville était le QG du Kronprinz), la Champagne a été le théâtre des combats après la Première bataille de la Marne près de Paris (6 au 9 septembre 1914 : les taxis de la Marne) puis la seconde bataille de la Marne (1918);

- Le clairon Delaluque, du $415^{\text {ème }}$ Régiment d'Infanterie sonne le "cessez-le-feu » le 11 novembre 1918 à 11 heures. II sera le seul poilu à réellement sonner le cessez-le-feu puisque le secteur où il se trouve, à Vrigne-Meuse, est le seul où l'on se bat encore en cette matinée du 11 novembre ;

- pendant la Seconde Guerre mondiale, les Ardennes ont de nouveau été le lieu de passage de l'armée allemande puis ont fait l'objet d'âpres combats en 1940 puis en 1944 (bataille des Ardennes, maquis...) ;

- le 7 mai 1945 a lieu la capitulation des armées allemandes à Reims ;

- la cérémonie de réconciliation du 8 juillet 1962 entre la France et l'Allemagne a eu lieu à Reims, en présence du président Charles de Gaulle et du chancelier Konrad Adenauer ;

- en 1996, le Pape Jean-Paul II est venu à Reims pour les 1500 ans du baptême de Clovis et de ses soldats.

Des traditions sont à l'origine des grandes filières économiques.

\section{Le fer}

Au Moyen Âge, l'extraction du fer, associée à la présence de forêts et de cours d'eau, a permis l'essor de la métallurgie. Avec la pureté des matériaux, les métiers des arts du fer, fondement de la puissance industrielle de la région, prirent alors un véritable essor.

La définition de la métallurgie a largement évolué à partir du XIX ${ }^{\mathrm{e}}$ siècle. À partir des forgerons et leur accumulation de connaissances empiriques, la métallurgie est devenue au $19^{\mathrm{e}}$ siècle une science et dans le contexte de la révolution industrielle (et dans l'inconscient collectif) devenue synonyme d'acier, de haut fourneaux, de laminoirs, de tréfileries, pour devenir ensuite une activité industrielle intense qui se préoccupe aussi de solutions de pointe, d'alliages spéciaux pour l'aéronautique, l'électronique, le bâtiment, l'automobile, le nucléaire et d'innombrables autres usages. 


\section{Le textile}

L'élevage du mouton et l'exploitation de sa laine ont, dès le Moyen Âge, contribué à la richesse et à la renommée de Troyes. Les foires de Champagne ont favorisé l'expansion du drap de laine, fabriqué dans les villes de Reims et de Troyes. Au $17^{\text {ème }}$ siècle, Sedan a vu s'implanter les manufactures royales de drap et de dentelle. Au $19^{\text {ème }}$ siècle, les villes ardennaises, comme Rethel pour la filature et Mouzon pour le feutre, s'inscrivent dans le mouvement d'industrialisation qui transforme l'artisanat en emplois d'industrie. Reims maintient la tradition du drap de laine de belle facture. Troyes, avec l'Aube, prend la voie de la bonneterie dès le milieu du $18^{\text {ème }}$ siècle, dont elle devient le principal foyer au $20^{\text {ème }}$ siècle.

\section{Le champagne}

Le champagne est apparu sur les tables à la fin du $17^{\text {ème }}$ siècle. Il fut longtemps regardé comme mystérieux, voire dangereux en raison de la méconnaissance du phénomène naturel dit de « la prise de mousse » et de la fragilité des bouteilles, incapables de résister à la pression du vin. II fallut près de deux siècles et les travaux de savants tels que Jean-Baptiste François (mesure du sucre) ou Louis Pasteur (rôle des levures) pour qu'il soit reconnu. Profitant alors d'une conjoncture favorable (prospérité économique, industrialisation, chemin de fer), les négociants fondèrent des Maisons qui, aujourd'hui encore, participent à la notoriété internationale du Champagne. Toutefois, le $20^{\text {ème }}$ siècle s'ouvrit sur des crises : phylloxéra, misère vigneronne, Première Guerre mondiale et récession des marchés. Aussi, en 1941, fut créé le Comité interprofessionnel du vin de Champagne (CIVC) afin de gérer l'appellation Champagne, en renforcer les règles et la défendre contre toute usurpation.

Territoire réputé pour son vin, le premier contact en Champagne-Ardenne est souvent consacré à une visite de cave.

Ainsi, l'ensemble de ces éléments, constitutifs de l'identité de la région Champagne-Ardenne, favorise le tourisme. Ce secteur compte 13500 emplois salariés soit 4,6\% de l'emploi salarié marchand au niveau national et 2550 emplois non salariés. 58,6\% des emplois salariés touristiques dépendent des activités d'hébergement et de restauration. Le solde concerne une multitude d'autres activités dans les loisirs, le sport, le commerce, les banques...

Si la Champagne-Ardenne n'est pas encore une destination de vacances, elle doit pouvoir, dans un premier temps, générer un tourisme de court séjour, qu'il soit culturel, gastronomique, de découverte ou de nature (autour des parcs naturels régionaux et des lacs réservoirs).

Valoriser la Champagne-Ardenne dans toutes ses dimensions, y compris celle de la mémoire et de l'histoire, peut permettre de développer le tourisme.

En 2014, une double opportunité se dessine avec la commémoration du :

Bicentenaire de la Campagne de France de Napoléon $\mathbf{1}^{\mathrm{er}}$, qui se traduira par l'organisation, pendant le premier semestre de l'année, notamment sur les territoires de Brie et de Champagne, d'un programme de manifestations, dont :

- de janvier à juin 2014 : exposition itinérante réalisée par les directions des archives départementales de l'Aisne, de l'Aube, de la Marne, de la Haute-Marne et de la Seine-etMarne dédiée à Napoléon et la Campagne de France ;

- les 25 et 26 janvier 2014 : Concerts de musique militaire et salon de la figurine à Châlonsen-Champagne ; 
- du 7 au 9 février 2014 : Bivouac, exposition, récits de soldats à Nogent-sur-Seine ;

- les $1^{\text {er }}$ et 2 mars : Animations à Chaumont ;

- les 21 et 22 mars 2014 : Animations à Fère-Champenoise ;

- les 28 et 29 mars 2014 : Art lyrique sous l'Empire et reconstitution des combats à SaintDizier ;

- les 12 et 13 avril 2014 : Colloque " Médecine et Sciences sous le Consulat et l'Empire » à Reims ;

- les 17 et 18 mai 2014 : Journées napoléoniennes, reconstitution et bourses aux armes à Brienne-le-Chateau;

- les 24 et 25 mai 2014 : Bivouac, bal de l'époque, exposition sur la vie quotidienne en 1814 et feu d'artifice d'époque à Mormant ;

- à définir : projet de colloque juridique à Troyes.

Centenaire de la Grande Guerre, pour lequel un rapport de préfiguration du centenaire de la Première Guerre Mondiale "Commémorer la Grande Guerre (2014-2020) : propositions pour un centenaire international ", rédigé par Monsieur Joseph Zimet, de la Direction de la mémoire, du patrimoine et des archives au ministère de la Défense et des anciens combattants, laisse une part importante aux collectivités territoriales.

En effet, l'intervention des collectivités locales revêt plusieurs objectifs :

- l'enjeu de la mise en place d'une politique mémorielle volontaire utilisant les lieux de mémoire comme des outils pédagogiques à destination de l'ensemble de la population, mais surtout des jeunes générations,

- un enjeu identitaire pour certaines collectivités qui ont voulu s'appuyer sur les événements " guerriers » pour créer un lien avec les populations,

- un enjeu économique et touristique pour faire venir des visiteurs qui dépensent dans un hébergement, dans la restauration et dans les services de loisirs proposés par les entreprises du territoire.

La commémoration est ponctuelle, alors que des lieux de mémoire peuvent devenir des lieux de tourisme de mémoire, après avoir été des lieux de pèlerinage, soutenus par les collectivités territoriales.

Le tourisme de mémoire a été identifié dans le schéma régional pour l'aménagement, le développement et l'organisation touristique 2006-2010 et plan marketing en ChampagneArdenne comme une filière à développer.

Force est de constater que, à ce jour, très peu d'actions ont été entreprises en termes de coordination régionale pour concrétiser l'identification de la Champagne-Ardenne comme une des grandes régions au cœur de l'histoire de France. 


\section{LE TOURISME DE MEMOIRE DANS SON CONTEXTE}

La Champagne-Ardenne dispose d'atouts incomparables : richesses naturelles, architecturales, culturelles, historiques et patrimoniales qui placent la région aux racines de l'Histoire de France et d'Europe. Le patrimoine religieux y est important et de qualité avec notamment quatre cathédrales, dont celle de Reims, inscrite par l'Unesco au Patrimoine Mondial de l'Humanité, douze abbayes cisterciennes, une statuaire renommée, des églises à pans de bois...

Des personnages illustres ont marqué leurs époques et inspiré les lieux : le Général de Gaulle, Napoléon Bonaparte, Jeanne d'Arc, Clovis, Colbert, Rimbaud, Verlaine, Louvois, Diderot, Robert de Sorbon, Louise Michel, Nicolas Appert, Pierre Dac, Thibaut de Champagne, les Templiers...

De nombreux sites témoignent de l'histoire militaire de la région : châteaux forts, fortifications, bataille de la Marne, maquis des Ardennes...

Le patrimoine social, industriel est également important en région : mouvement coopératif à succursale, le musée de l'outil et de la pensée ouvrière de Troyes, Metallurgic Parc dans la Vallée de la Blaise, la cité du Chemin vert à Reims...

Au regard du calendrier, faisant de l'année 2014 une année anniversaire des événements de 1814 et 1914 , de nature internationale touchant tout particulièrement notre région, il semble judicieux de s'intéresser au tourisme de mémoire, sous réserve de considérer l'année 2014 comme un tremplin pour le tourisme au sens large incluant le tourisme historique et de mémoire.

Le " tourisme de mémoire " peut surprendre par les contradictions possibles entre les deux termes. Le tourisme évoque plutôt des activités de loisirs et la mémoire peut être empreinte de gravité, voire de recueillement lorsqu'il s'agit d'événements appartenant au passé relativement proche dans les mémoires familiales. Le concept de tourisme de mémoire a été forgé dans les années 2000 et témoigne de la volonté de rénover et moderniser la politique menée dans le domaine de la mémoire combattante.

Ce concept est défini par ses auteurs (ministère de la Défense) comme une "démarche incitant le public à explorer les éléments du patrimoine mis en valeur pour y puiser l'enrichissement civique et culturel que procure la référence au passé».

Le tourisme de mémoire doit aussi répondre à une triple ambition : civique et pédagogique ; culturelle et touristique ; économique et commerciale.

Ambition civique et pédagogique, tout d'abord, parce que la préservation de l'héritage combattant et sa transmission aux jeunes générations satisfont l'intérêt croissant pour la mémoire collective et contribuent à maintenir le lien entre la société et son armée après la disparition du service national.

Ambition culturelle et touristique, ensuite, en ce que l'exploration des lieux de mémoire permet de valoriser l'exceptionnel patrimoine civil et militaire dont dispose la France, de le replacer dans I'histoire nationale, européenne voire mondiale, et constitue une composante complémentaire de l'offre touristique traditionnelle. 
Ambition économique et commerciale, enfin, puisque la démarche contribue au développement de régions, dont le patrimoine mémoriel devient un facteur direct de création de richesse ${ }^{1}$.

\section{A) LES PROLONGEMENTS INTERNATIONAUX DU TOURISME DE MEMOIRE}

Une des particularités du tourisme de mémoire est la forte internationalisation des clientèles qu'il génère. Ainsi, le centre de la mémoire d'Oradour-sur-Glane, inauguré en 1999, accueille un public constitué pour moitié d'étrangers ; les musées et mémoriaux de la Somme attirent, chaque année, 200000 touristes étrangers, en majorité britanniques ; de même, certains forts de la ligne Maginot, comptent 40 \% d'étrangers parmi leurs clients. En Champagne-Ardenne citons comme exemples:

- les manifestations (séminaires, colloques, expositions) organisées par l'association 1814 V4 au château de Montmirail, qui accueille environ 500 étrangers de nationalité allemande, américaine, coréenne, japonaise... par an,

- le Mémorial Charles de Gaulle à Colombey les deux Eglises qui reçoit 7\% d'étrangers.

Par ailleurs, on observe que, parmi cette clientèle internationale dont le flux grossit lors des événements anniversaires et des commémorations, la part des jeunes publics tend à s'accroître par rapport à celle des «seniors». Certains sites, comme le Mémorial de Caen, reçoivent 30 à $35 \%$ de publics scolaires. De même, la cérémonie célébrant le $90^{\mathrm{ème}}$ anniversaire de la bataille de Vimy, le 9 avril 2007, a réuni 25000 personnes, dont 10000 Canadiens, âgés de moins de vingt-cinq ans pour la moitié d'entre eux. En région, le Château de Montmirail accueille 1000 jeunes par an.

\section{B) Le TOURISME DE MEMOIRE EN FRANCE}

Au niveau national, les données sont issues d'une enquête sur l'évaluation du poids économique de la filière du "Tourisme de mémoire ", commandée, en 2010, par le ministère de la Défense et par Bercy, réalisée par l'agence nationale de développement touristique Atout France. Les données ont été collectées auprès de 155 sites mémoriels disposant de données de fréquentation. 85 questionnaires exploitables ont été collectés. L'échantillon des répondants ayant été représentatif de la population globale des sites interrogés, des extrapolations ont pu être réalisées.

Cette filière se développe particulièrement depuis 40 ans : $80 \%$ des sites payants ont été ouverts en France après 1980 (25\% l'ont été dans les années 2000).

En 2010 :

-6,2 millions de visites ont été enregistrés dans l'ensemble des sites mémoriels payants ou avec services annexes payants.

- Le chiffre d'affaires global direct, généré au sein des sites de la filière, est de 45 millions d'euros. La billetterie représente $65 \%$, les boutiques $30 \%$ et les services annexes $5 \%$.

\footnotetext{
${ }^{1}$ Veille Info Tourisme - René Ressouches, Direction du tourisme, 17 juillet 2008
} 
Le chiffre d'affaires moyen par visite est de 5,70€ dont 1,70€ pour la boutique.

- 17 sites totalisent 4 millions d'entrées, principalement répartis de la Normandie à l'Alsace où sont concentrés les sites des deux conflits mondiaux.

- $60 \%$ des visites sont effectués par une clientèle individuelle.

- La clientèle étrangère, principalement anglaise, allemande, belge, néerlandaise et américaine, génère plus de 2,7 millions de visites.

- Les militaires et les anciens combattants représentent $4 \%$ du volume total des visites.

- Les sites mémoriels payants ont directement généré 1050 équivalents temps plein. L'activité de ces sites a mobilisé au total 3000 personnes dont 1000 bénévoles. D'une manière générale, $48 \%$ des postes sont dédiés aux fonctions d'accueil et d'animation.

\section{C) UN FACTEUR DE DEVELOPPEMENT ECONOMIQUE DES TERRITOIRES}

Le tourisme de mémoire est parfois le premier vecteur de fréquentation de départements, comme en Meuse, où le Mémorial de la Paix à Verdun accueille, à lui seul, environ 500000 touristes par an. En Champagne-Ardenne, la fréquentation des sites de mémoire a été évaluée, en 2007, à 340000 visiteurs (+13\% par rapport à 2000), 10 sites de plus de 30000 visiteurs soit 300000 visiteurs accaparent plus de $88 \%$ de visites (Source ORT).

Mais cette fréquentation reste très inférieure aux autres régions comparables en termes de tourisme de mémoire : Normandie (4 430000 visiteurs), Lorraine (près d'un million), Picardie (637 000) et Nord-Pas-de-Calais (740 000).


Source enquête tourisme de mémoire - Cabinet Planeth - 2009 


\section{À RETENIR}

\section{4 : ANNEE DE COMMEMORATIONS QUI TOUCHENT PARTICULIEREMENT NOTRE REGION}

- doit être considérée comme un tremplin pour le développement du tourisme historique en Champagne-Ardenne mais surtout pour le tourisme de mémoire.

\section{LE CONCEPT DE « TOURISME DE MEMOIRE »}

- mêle deux notions a priori antinomiques : les activités de loisirs et la mémoire qui peut être empreinte de gravité voire de recueillement ;

- répond à une triple ambition :

- civique et pédagogique : préservation de l'héritage combattant et sa transmission aux jeunes générations,

- culturelle et touristique : valorisation du patrimoine civil et militaire de la France par la visite des lieux de mémoire, en complément de l'offre touristique traditionnelle,

- économique et commercial : contribution au développement des territoires avec création de richesses issues directement de leur patrimoine mémoriel.

\section{LE TOURISME DE MEMOIRE EN FRANCE, EN 2010, C'EST :}

- 6,2 millions de visites dont 2,7 millions correspondant à la clientèle étrangère ;

- un chiffre d'affaires global de 45 millions d'euros ;

- 1050 emplois équivalents temps plein générés par les sites payants ;

- $60 \%$ de visites individuelles, dont $4 \%$ dus aux militaires et anciens combattants. 


\section{Le tourisme DE MEMoIRE en ChAMpagne-ARDEnNe}

En Champagne-Ardenne, le Comité Régional du Tourisme a commandé une étude sur le tourisme de mémoire dans la région. Elle a été réalisée par le Cabinet d'études Planeth en 2009.

\section{A) LES SITES ENQUETES}

25 sites ont été retenus : sites militaires, patrimoine (tourisme de court séjour, fortifications, mémoire vive), répartis de façon homogène sur la région Champagne-Ardenne (Cf. carte page suivante).

\section{B) LE PROFIL DES CLIENTELES}

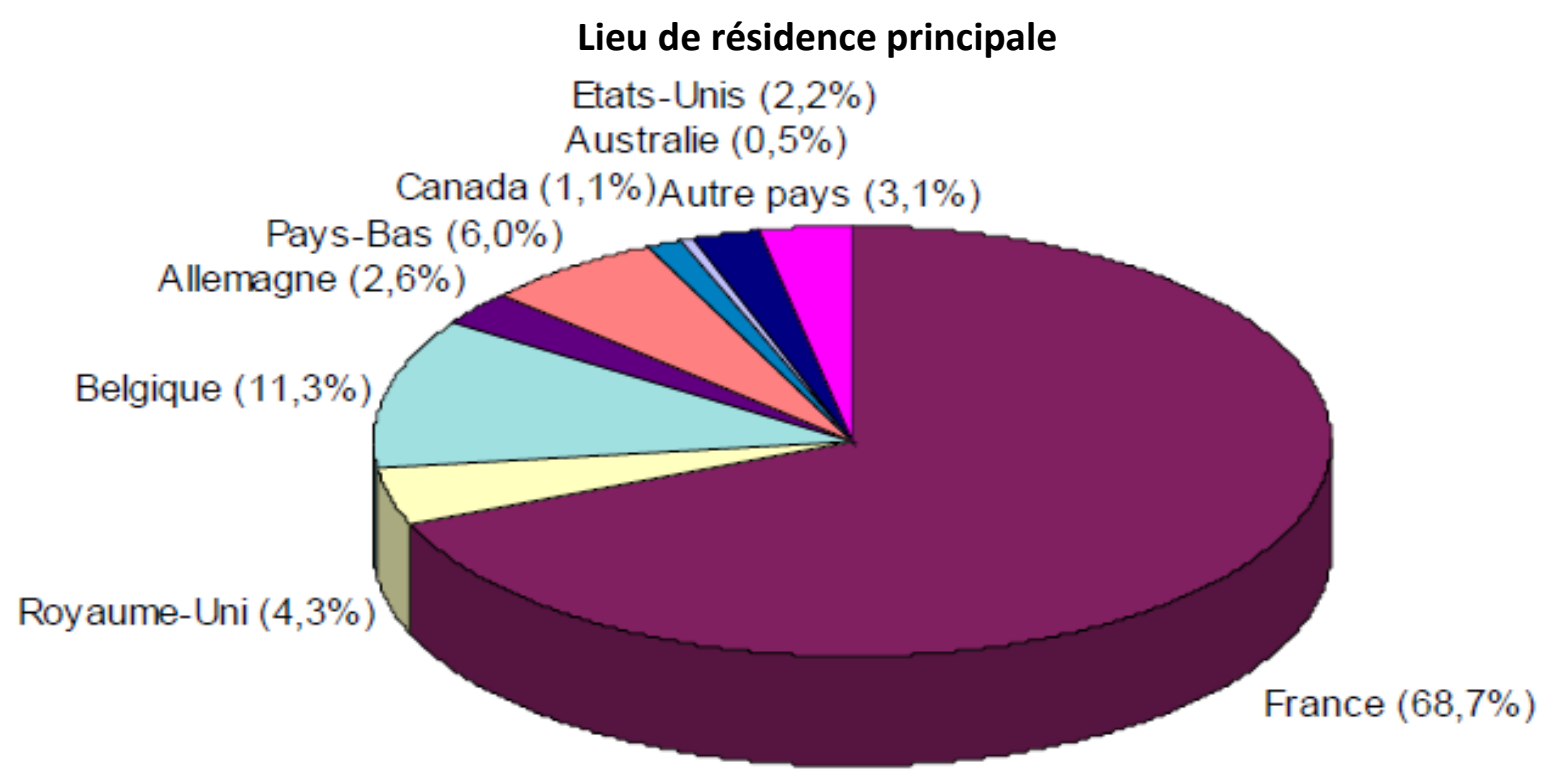

Source : enquête tourisme de mémoire - Cabinet Planeth - 2009

En Champagne-Ardenne, les sites de mémoire sont visités très majoritairement par les Français (près de 69\%; $55 \%$ au niveau national). L'histoire de la Champagne-Ardenne s'inscrit dans I'histoire de France et participe très fortement à la construction de l'identité nationale. L'identité des territoires se développe et se fonde désormais sur l'accueil, sur l'ouverture aux autres, l'échange et sur l'enrichissement mutuel.

Le tourisme de mémoire participe ainsi à la construction, à la reconstruction d'une nouvelle identité de ces territoires meurtris, où le sol contient le monde entier (des soldats allemands, russes, sénégalais, anglais, américains... sont inhumés en Champagne-Ardenne par exemple). 


\section{Sites de visite - Tourisme de mémoire en Champagne Ardenne}

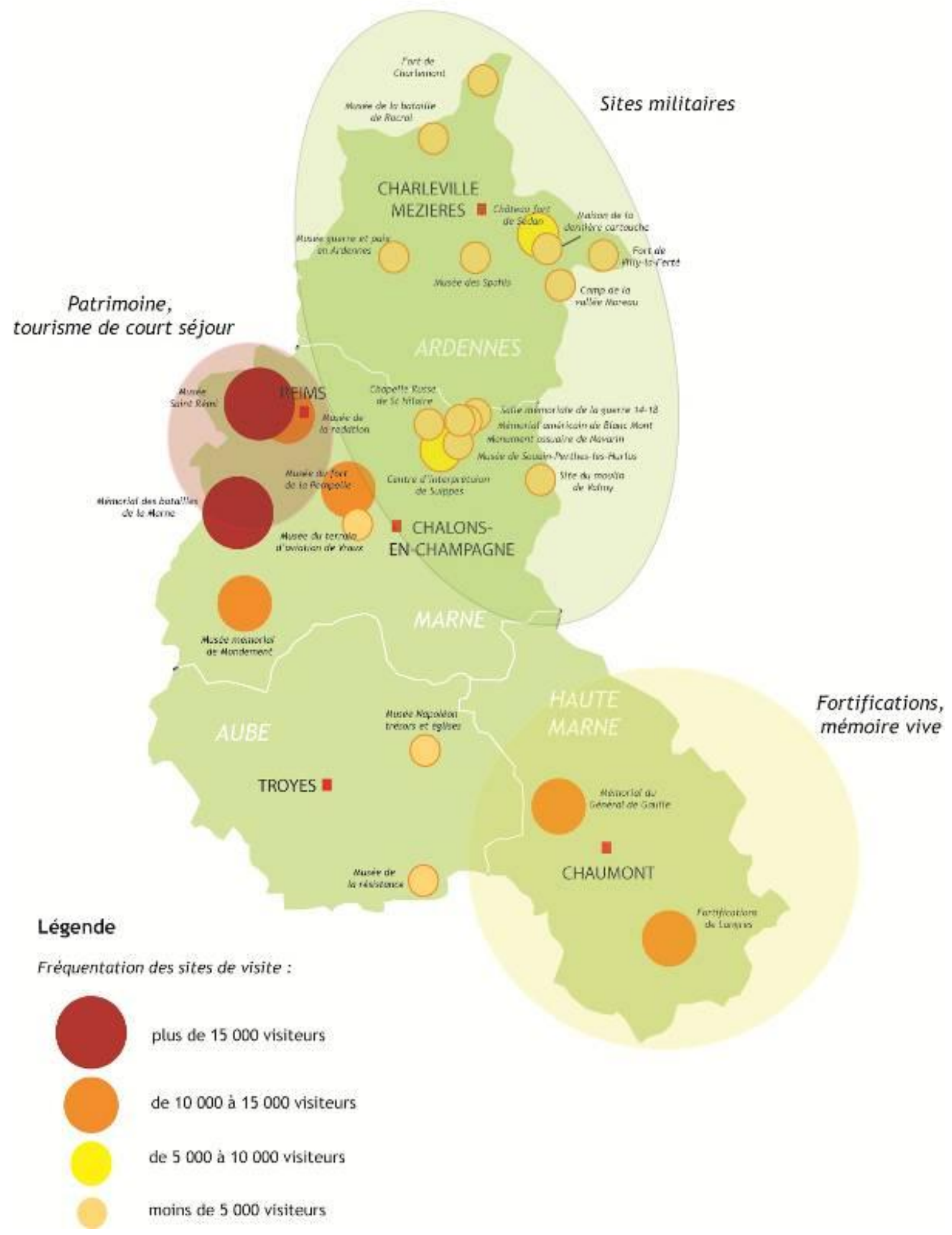

Source enquête tourisme de mémoire - Cabinet Planeth - 2009 
La part des visiteurs locaux est difficile à mesurer. Seuls certains sites, comme le Mémorial Charles de Gaulle, les recensent. En moyenne, 30000 champardennais ont visité, en 2010, ce site. Ceci traduit, de leur part, une certaine curiosité et la volonté de s'intéresser à l'histoire.

Selon Madame Catherine Martin ${ }^{2}$, "l'appropriation de l'histoire par l'habitant est primordiale ", c'est la condition sine qua non du devoir d'histoire.

Les étrangers représentent un peu plus de $31 \%$; parmi eux, ce sont les Belges qui s'intéressent le plus aux sites de mémoire (11,3\%). On remarque le potentiel du développement des visiteurs européens (Royaume-Uni, Allemagne) mais aussi au-delà des océans: États-Unis, Chine, Australie.



Source enquête tourisme de mémoire - Cabinet Planeth - 2009

Parmi les touristes de mémoire en Champagne-Ardenne, on note une forte proportion de retraités (28\%), d'employés $(15,7 \%)$ et de cadres supérieurs et professions libérales $(12,6 \%)$.

Les scolaires représentent $6,6 \%$ de la clientèle contre $24 \%$ (français et étrangers confondus) au niveau national. Ce sont principalement des collégiens et des lycéens qui visitent ces sites, d'autant que, en France, les programmes d'histoire et de géographie intègrent respectivement la première guerre mondiale : l'expérience du combattant dans une guerre totale et l'étude du territoire régional où est situé le lycée.

\footnotetext{
${ }^{2}$ Chargée de mission à la Ville de Reims, auditionnée le $1^{\mathrm{er}}$ juin 2012
} 




Source enquête tourisme de mémoire - Cabinet Planeth - 2009

Outre le tourisme de mémoire, les visiteurs s'intéressent aux sites touristiques pour $43,3 \%$ et aux villes champardennaises pour $42,7 \%$ d'entre eux.

Près de $33 \%$ effectuent une promenade ou une randonnée. Seulement $15 \%$ visitent une des caves. On s'aperçoit que les centres d'intérêt des touristes sont multiples.

\section{C) LE SEJOUR}

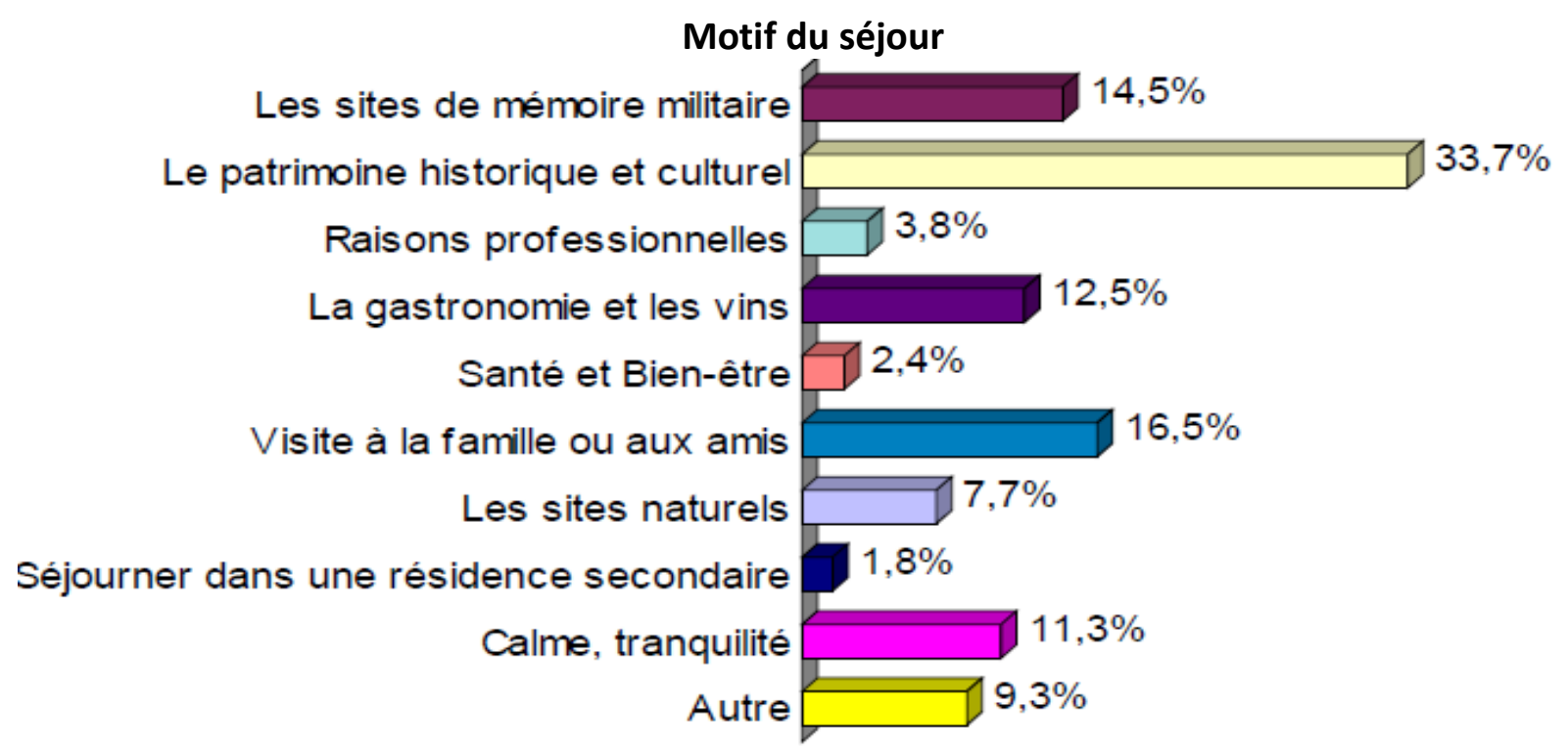

Source enquête tourisme de mémoire - Cabinet Planeth - 2009 


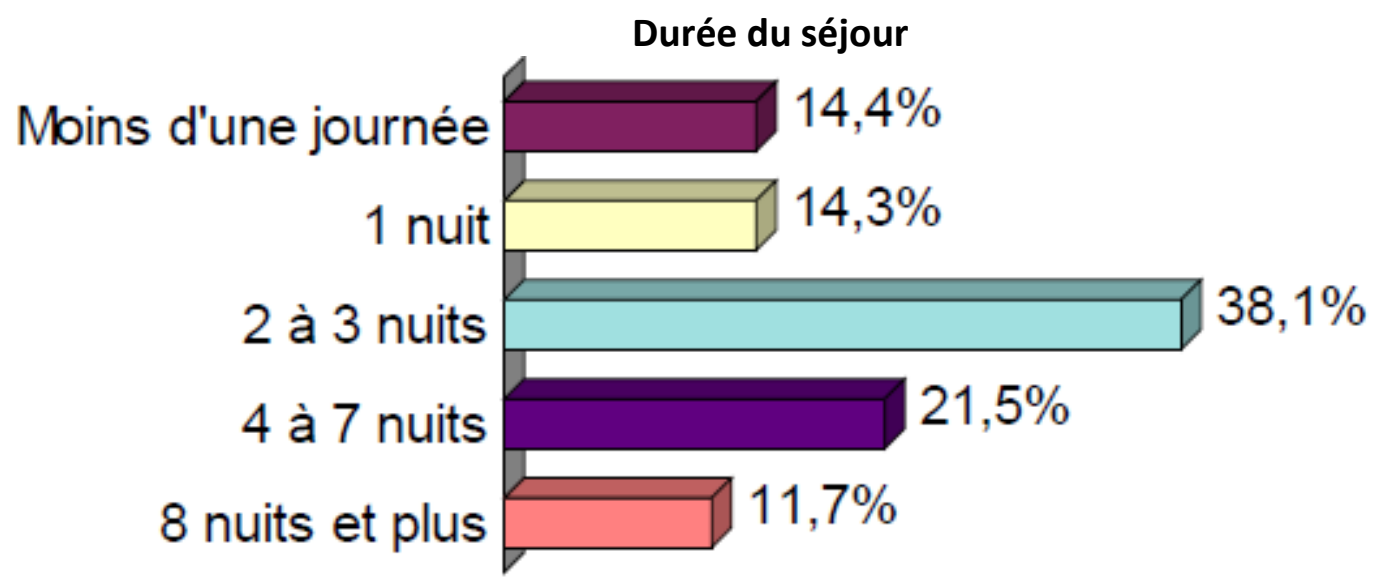

Source enquête tourisme de mémoire - Cabinet Planeth - 2009

Le logement

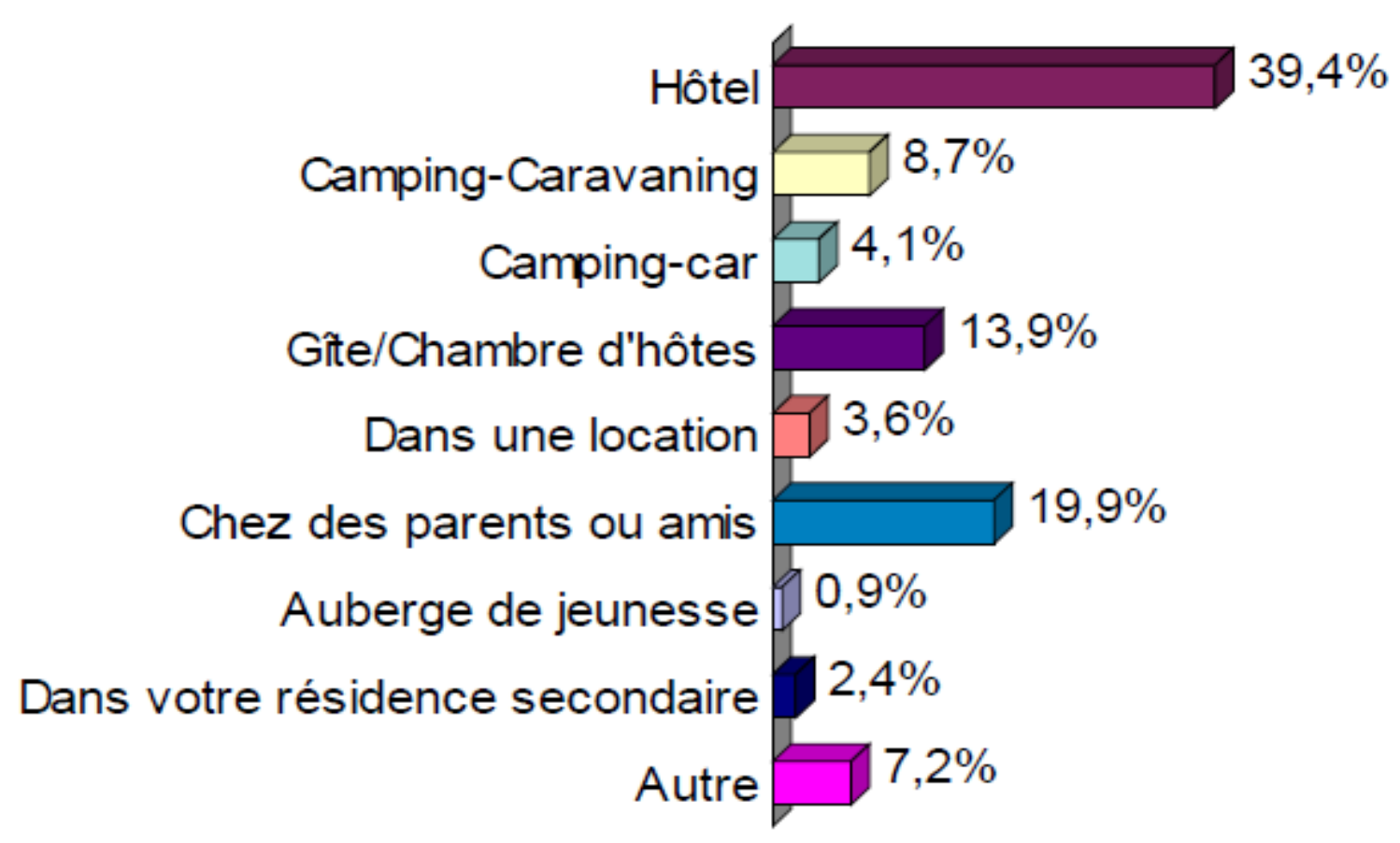

Source enquête tourisme de mémoire - Cabinet Planeth - 2009

14\% des répondants citent les sites de mémoire militaire comme ayant participé au motif du séjour.

Pour la majorité, les séjours sont de courte durée (moins d'une journée à 3 nuits).

39,4\% des touristes de mémoire privilégient les séjours à l'hôtel. Les séjours chez des parents et amis $(19,9 \%)$ et en gîtes et chambres d'hôtes $(13,9 \%)$ revêtent une importance notable. 


\section{D) LA MOTIVATION DE LA VISITE DU SITE DE MEMOIRE}

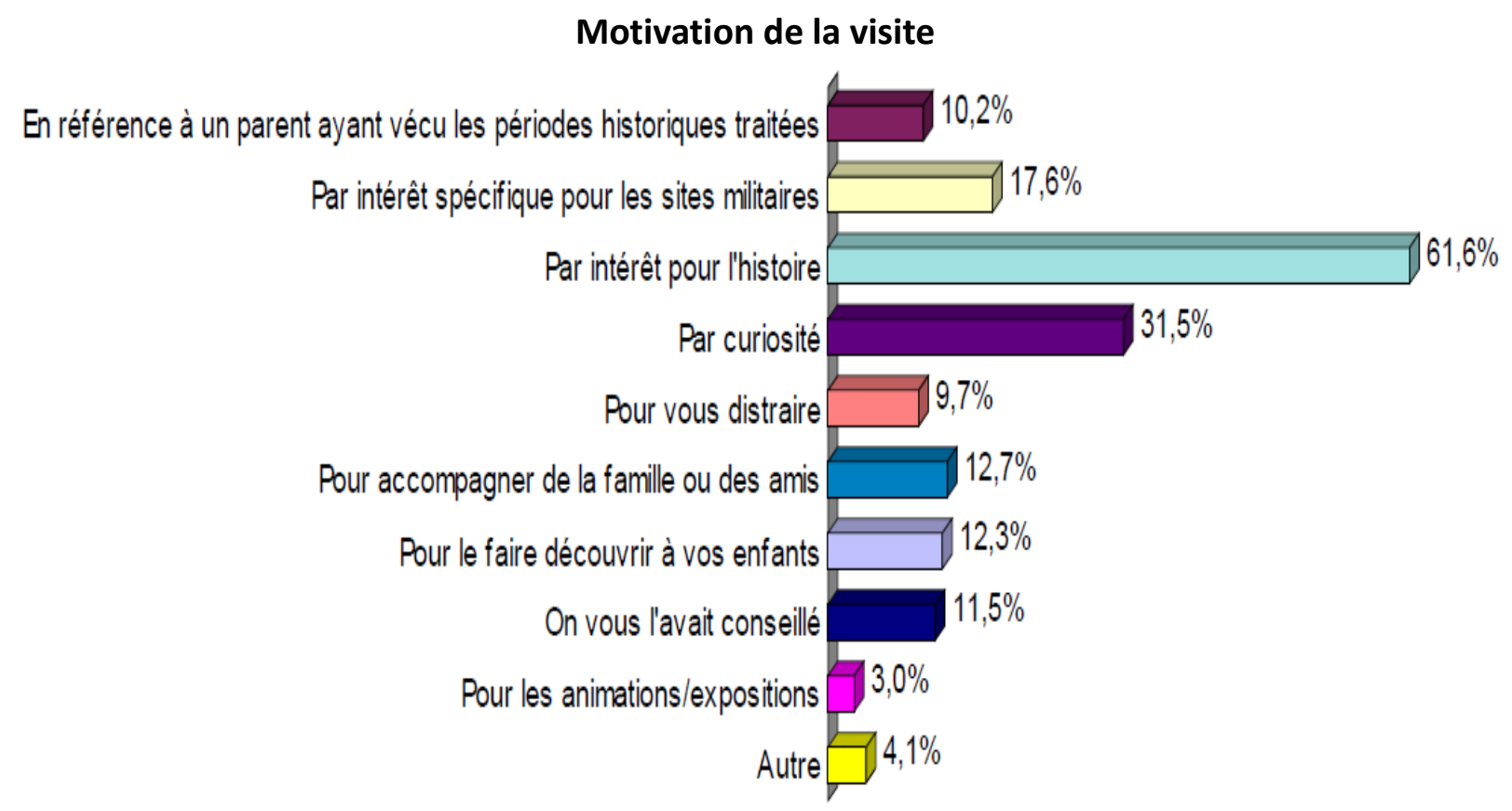

Source enquête tourisme de mémoire - Cabinet Planeth - 2009

Les touristes de mémoire mettent en avant leur intérêt pour l'histoire $(61,6 \%)$ puis la curiosité pour $31,5 \%$ d'entre eux; enfin $17,6 \%$ déclarent porter un intérêt spécifique pour les sites militaires.

II est intéressant de noter que seulement 10,2\% des sondés affirment que la référence à un parent proche a joué un rôle dans leur visite.

Cela tend à montrer le passage de la mémoire familiale à l'histoire nationale.

\section{E) L'offre touristique en Champagne-ARDENNE}

\section{1) Les lieux de mémoire}

Les sites de mémoire et d'histoire en Champagne-Ardenne sont disséminés sur l'ensemble du territoire régional et couvrent toutes les périodes historiques. 


\section{Sites touristiques en Champagne Ardenne}

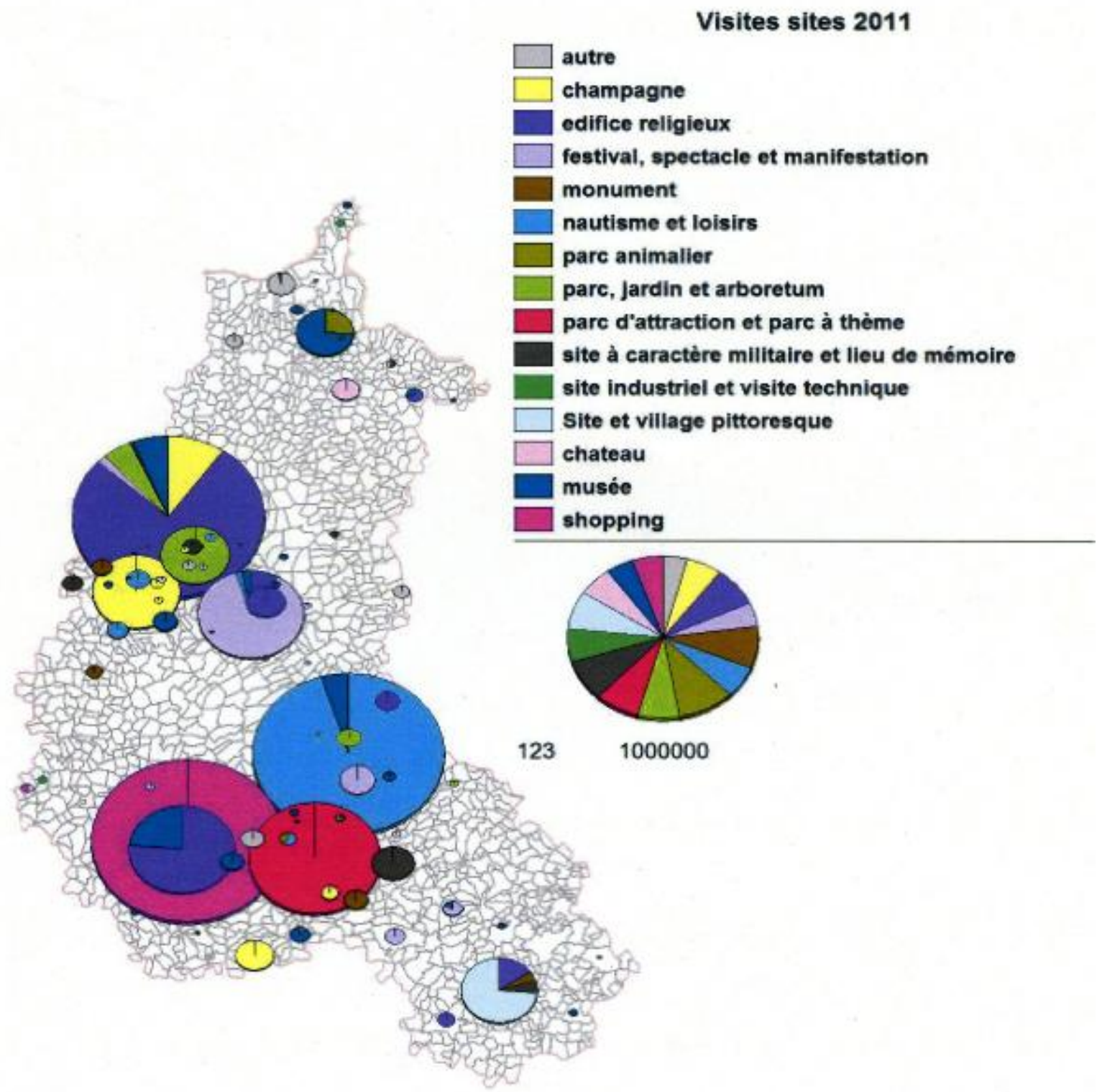

Source : Comité Régional du Tourisme de Champagne-Ardenne - Bulletin de l'Observatoire Régional du Tourisme de Champagne-Ardenne juin 2011 
a) Les sites à entrée payantes

En 2000, la Champagne-Ardenne a accueilli 300293 touristes sur les sites de mémoire ${ }^{3}$ à entrées payantes répartis entre :

\begin{tabular}{|c|c|c|c|}
\hline Département & Office de tourisme & Sites de mémoire & Visiteurs \\
\hline \multirow[t]{14}{*}{ Marne } & Dormans & $\begin{array}{l}\text { Mémorial batailles de la } \\
\text { Marne }\end{array}$ & 10000 \\
\hline & \multirow[t]{2}{*}{ Reims } & Musée de la Rédition & 8000 \\
\hline & & Fort de la Pompelle & 24000 \\
\hline & \multirow[t]{3}{*}{ Ste Menehould } & Chapelle St Hilaire & 4000 \\
\hline & & Vraux : musée de l'aviation ${ }^{4}$ & 3500 \\
\hline & & Musée de Ste Menehould & 1200 \\
\hline & \multirow[t]{8}{*}{ Suippes } & Valmy : Maison du meunier & 2500 \\
\hline & & Musée de Mondement & 1200 \\
\hline & & Musée de Varennes & \\
\hline & & Mémorial & 1300 \\
\hline & & Ferme de Navarin & 3500 \\
\hline & & Les Hurlus & 500 \\
\hline & & Monument US Tahure & 20000 \\
\hline & & Musée Sommepy Tahure & 150 \\
\hline \multirow[t]{6}{*}{ Ardennes } & Vouziers & Musée de Semuy & \\
\hline & Sedan $^{5}$ & Musée dernière cartouche & 18000 \\
\hline & Givet & Château Fort & 57000 \\
\hline & \multirow[t]{3}{*}{ Rocroi } & Fort de Charlemont & 1478 \\
\hline & & Tour Victoire & 589 \\
\hline & & Musée bataille de Rocroi & 2876 \\
\hline \multirow[t]{3}{*}{ Haute-Marne } & Langres & Cognelot & 500 \\
\hline & \multirow{2}{*}{$\begin{array}{l}\text { Colombey les deux } \\
\text { Eglises }\end{array}$} & Mémorial $^{6}$ & 80000 \\
\hline & & La Boisserie & 60000 \\
\hline Aube & Mussy sur Seine & Musée de la Résistance & \\
\hline \multicolumn{3}{|c|}{ TOTAL } & 300293 \\
\hline
\end{tabular}

*Le Centre d'Interprétation de Suippes qui a reçu 6000 visiteurs en 2011 n'est pas répertorié. II est ouvert depuis 2006.

\footnotetext{
${ }^{3}$ Etude Tourisme de mémoire Région Champagne-Ardenne Schéma de développement du tourisme de mémoire en Champagne-Ardenne - Mérimée Conseil - Novembre 2001

${ }^{4}$ L'entrée du musée est gratuite depuis son ouverture en 1994

${ }^{5}$ Le musée de la dernière cartouche se situe à Bazeilles

${ }^{6}$ Musée dit « mémorial » situé au pied de la Croix de Lorraine
} 


\section{b) Les sites à entrées gratuites (chiffres de 2011)}

Ces listes se veulent les plus exhaustives possibles. Cependant, il est difficile d'avoir un recensement absolument fiable.

- Musées, sites religieux, monuments, ...

\begin{tabular}{|c|c|c|c|c|}
\hline Département & Ville & Site de mémoire & Visiteurs/an & Période historique \\
\hline \multirow[t]{13}{*}{ Marne } & \multirow[t]{2}{*}{ Reims } & Cathédrale de Reims & 1500000 & $\begin{array}{l}\text { Vème/ XIllème s. } \\
\text { Sacre des rois de } \\
\text { France }\end{array}$ \\
\hline & & Basilique Saint Remi & 150000 & X/XIllème s. \\
\hline & L'Épine & Basilique de l'Epine & 45000 & XIV/XVIème s. \\
\hline & Dormans & $\begin{array}{l}\text { Mémorial des batailles de } \\
\text { la Marne }\end{array}$ & 15609 & 1914/1918 \\
\hline & Massiges & $\begin{array}{l}\text { Tranchées de la Main de } \\
\text { Massiges }\end{array}$ & & 1914/1918 \\
\hline & \multirow[t]{2}{*}{ Mondement } & $\begin{array}{l}\text { Monument national } \\
\text { Première bataille de la } \\
\text { Marne }\end{array}$ & 12000 & 1914/1918 \\
\hline & & Musée de Mondement & 1200 & $1914 / 1918$ \\
\hline & $\begin{array}{l}\text { Châlons-en- } \\
\text { Champagne }\end{array}$ & Cathédrale Saint-Etienne & 10285 & XII/XIIlème s. \\
\hline & La Cheppe & Camp d'Attila & 5000 & 451 \\
\hline & Sommepy-Tahure & $\begin{array}{l}\text { Monument américain de } \\
\text { Blanc Mont }\end{array}$ & 20000 & 1914/1918 \\
\hline & $\begin{array}{l}\text { Souain-Perthe-les- } \\
\text { Hurlus }\end{array}$ & Ossuaire de Navarin & 3500 & 1914/1918 \\
\hline & Verzy & Observatoire du Mont Sinaï & & $1914 / 1918$ \\
\hline & Vraux & Musée de l'aviation & 3500 & 1939/1945 \\
\hline \multirow[t]{3}{*}{ Ardennes } & Rocroi & Fortifications & 26984 & XVIème siècle \\
\hline & Brienne-sur-Aisne & $\begin{array}{l}\text { Musée des guerres } \\
1914 / 1918 \text { et } 1935 / 1945\end{array}$ & & $\begin{array}{c}1914 / 1918 \text { et } \\
1939 / 1945\end{array}$ \\
\hline & Chagny & Musée des deux guerres & 300 & $\begin{array}{c}1914 / 1918 \text { et } \\
1939 / 1945\end{array}$ \\
\hline Aube & Troyes & Cathédrale & 147802 & XI/XVIlème s. \\
\hline \multirow{3}{*}{$\begin{array}{l}\text { Haute- } \\
\text { Marne }\end{array}$} & \multirow[t]{2}{*}{ Langres } & Cathédrale & 25000 & XIlème siècle \\
\hline & & $\begin{array}{l}\text { Visite de la ville et de ses } \\
\text { fortifications }\end{array}$ & 122515 & $\begin{array}{c}\text { Première } \\
\text { enceinte au } \\
\text { IIlème s. puis en } \\
\text { mouvement } \\
\text { perpétuel }\end{array}$ \\
\hline & $\begin{array}{l}\text { Soulaucourt-sur- } \\
\text { Mouzon }\end{array}$ & $\begin{array}{l}\text { Ruines de la Mothe-en } \\
\text { Bassigny }\end{array}$ & & $1644-1645$ \\
\hline \multicolumn{3}{|l|}{ TOTAL } & 2088695 & \\
\hline
\end{tabular}


Le territoire champardennais possède un patrimoine funéraire important. Ce dernier se compose de nécropoles nationales (le ministère de la défense est responsable de la conservation et veille à la pérennité des sépultures), de cimetières militaires qui honorent et reconnaissent le service et le sacrifice des militaires, ainsi que d'ossuaires, où sont rassemblés des ossements humains qui n'ont pas eu de sépulture individuelle.

\section{- Les nécropoles nationales}

Rien que dans le département de la Marne, on comptabilise $\mathbf{3 4}$ nécropoles nationales qui sont toutes liées à la Première Guerre mondiale même si, depuis, y reposent des Morts pour la France de la Seconde Guerre mondiale.

\begin{tabular}{|c|c|c|c|}
\hline Lieu & Superficie & $\begin{array}{l}\text { Nombre de } \\
\text { corps }\end{array}$ & Nationalité \\
\hline Aubérive " Le Bois du Puits» & $23461 m^{2}$ & 3901 & Français et Polonais \\
\hline Bligny « La Croix Ferlin » & 1 hectare & 2145 & Français et Russes \\
\hline Châlons-en-Champagne & $\begin{array}{c}\text { Inclus dans } \\
\text { le cimetière } \\
\text { communal }\end{array}$ & 4500 & Français \\
\hline $\begin{array}{l}\text { Chatillon sur Marne "Le Prieuré de } \\
\text { Binson" }\end{array}$ & $12500 \mathrm{~m}^{2}$ & 2109 & Français \\
\hline Cormicy " La Maison Bleue » & $44213 \mathrm{~m}^{2}$ & 7453 & Français et Britanniques \\
\hline Courgivaux & $245 \mathrm{~m}^{2}$ & 32 & Français et Britannique \\
\hline Dormans & $11271 \mathrm{~m}^{2}$ & 1290 & Français et Britanniques \\
\hline Fère Champenoise & $16480 \mathrm{~m}^{2}$ & 2657 & $\begin{array}{l}\text { Français, Britanniques, } \\
\text { Tchèques et Belges }\end{array}$ \\
\hline Floing & $19112 \mathrm{~m}^{2}$ & 1952 & Nord-Africains \\
\hline Florent-en-Argonne & $10219 \mathrm{~m}^{2}$ & 2061 & Français \\
\hline Hermonville "Le Luxembourg" & $220 m^{2}$ & 12 & Français \\
\hline Jonchery-sur-Suippe & $26120 m^{2}$ & 4901 & Français et Tchèques \\
\hline La Cheppe "Le Mont Frenet» & $8485 \mathrm{~m}^{2}$ & 2307 & $\begin{array}{l}\text { Français, Britanniques, } \\
\text { Tchèques et Américains }\end{array}$ \\
\hline Maurupt-le-Montois & $800 \mathrm{~m}^{2}$ & 71 & Français \\
\hline $\begin{array}{l}\text { Minaucourt-le-Mesnil-les-Hurlus "Le } \\
\text { Pont du Marson » }\end{array}$ & $43944 \mathrm{~m}^{2}$ & 9096 & $\begin{array}{l}\text { Français, Tchèques et } \\
\text { Serbes }\end{array}$ \\
\hline Mourmelon-le-Grand & $13580 \mathrm{~m}^{2}$ & 2644 & Français \\
\hline Mourmelon-le-Petit & $8230 \mathrm{~m}^{2}$ & 1496 & Français \\
\hline Noyers-Pont-Maugis "La Marfée " & $4771 \mathrm{~m}^{2}$ & 521 & Allemands et Français \\
\hline Pargny-Sur-Saulx & $1459 \mathrm{~m}^{2}$ & 288 & Français et Britannique \\
\hline Rethel & $12100 \mathrm{~m}^{2}$ & 2253 & Français \\
\hline Saint-Jean-sur-Tourbe & $12680 \mathrm{~m}^{2}$ & 2222 & Français \\
\hline Saint-Thomas-en-Argonne & $23820 \mathrm{~m}^{2}$ & 4849 & Français \\
\hline Sainte-Menehould & $21900 \mathrm{~m}^{2}$ & 5700 & Français \\
\hline Sedan-Torcy & $3945 \mathrm{~m}^{2}$ & 805 & Français \\
\hline Semide "Orfeuil» & $7510 \mathrm{~m}^{2}$ & 1083 & Français \\
\hline
\end{tabular}




\begin{tabular}{|c|c|c|c|}
\hline Sept-Saulx & $16478 m^{2}$ & 3045 & Français \\
\hline Sillery-Bellevue & $24966 m^{2}$ & 5711 & Français et Tchèques \\
\hline Somme-Suippe & $20160 \mathrm{~m}^{2}$ & 3574 & Français \\
\hline Sommepy-Tahure & $10968 \mathrm{~m}^{2}$ & 1.480 & Français \\
\hline Souain-Perthe-les-Hurlus "L'opéra" & $3460 \mathrm{~m}^{2}$ & 144 & Français \\
\hline $\begin{array}{l}\text { Souain-Perthe-les-Hurlus } \\
\text { " } 28^{\text {ème }} \text { Brigade " }\end{array}$ & $3340 \mathrm{~m}^{2}$ & 147 & Français \\
\hline $\begin{array}{l}\text { Souain-Perthe-les-Hurlus } \\
\text { "La Crouée " }\end{array}$ & $60384 \mathrm{~m}^{2}$ & 9047 & Français \\
\hline Suippes " La Ferme de Suippes" & $47708 \mathrm{~m}^{2}$ & 8833 & Français, Russes et Belges \\
\hline Suippes « Ville » & $20623 \mathrm{~m}^{2}$ & 4853 & Français \\
\hline Vienne le Château "La Harazée » & $5530 \mathrm{~m}^{2}$ & 1231 & Français \\
\hline Villers-Marmery & $3963 \mathrm{~m}^{2}$ & 523 & Français \\
\hline Vitry-le-Francois & $8612 \mathrm{~m}^{2}$ & 1809 & Français et Britanniques \\
\hline Villy-la-Ferte & $317 \mathrm{~m}^{2}$ & 64 & Soldats inconnus \\
\hline Vouziers & $10268 \mathrm{~m}^{2}$ & 1443 & $\begin{array}{l}\text { Français, Belges, Russes et } \\
\text { Tchèques }\end{array}$ \\
\hline & Total & 108252 & \\
\hline
\end{tabular}

- Parmi le patrimoine funéraire, on compte également de nombreux cimetières militaires

\begin{tabular}{|c|c|c|c|}
\hline Lieu & $\begin{array}{l}\text { Nombre de } \\
\text { corps }\end{array}$ & Nationalité & Période \\
\hline \multirow[t]{2}{*}{ Aubérive } & 385 & Polonais & $\begin{array}{c}1914 / 1918 \text { et } \\
1939 / 1945\end{array}$ \\
\hline & 2235 & Allemands & $1914 / 1918$ \\
\hline Berru & 17000 & Allemands & $1914 / 1918$ \\
\hline Bligny & 3062 & Allemands & $1914 / 1918$ \\
\hline Bouilly & 203 & Britanniques & $1914 / 1918$ \\
\hline Chambrecy & 435 & Britanniques et 1 Indien & $1939 / 1945$ \\
\hline Connantre & 8368 & Allemands & $1914 / 1918$ \\
\hline $\begin{array}{l}\text { Cormicy "La Maison } \\
\text { Bleue " }\end{array}$ & 6945 & Français & $1914 / 1918$ \\
\hline Courmas & 207 & Britanniques & $1914 / 1918$ \\
\hline Hermonville & 244 & Britanniques & $1914 / 1918$ \\
\hline La Neuville aux Larris & 98 & Britanniques & $1914 / 1918$ \\
\hline Laval-sur-Tourbe & 40 & Français & $1914 / 1918$ \\
\hline Loivre & 2236 & Allemands & $1914 / 1918$ \\
\hline Marfaux «Chambrecy» & 1129 & $\begin{array}{l}\text { Britanniques et } \\
\text { Néo-Zélandais }\end{array}$ & $1914 / 1918$ \\
\hline Marfaux & 1697 & Allemands & $1914 / 1918$ \\
\hline $\begin{array}{l}\text { Minaucourt-Le-Mesnil-Les- } \\
\text { Hurlus }\end{array}$ & 21319 & $\begin{array}{l}\text { Français, Serbes, et } \\
\text { Tchèques }\end{array}$ & $\begin{array}{c}1914 / 1918 \text { et } \\
1939 / 1945\end{array}$ \\
\hline Montmirail & 120 & Français et Belges & $1914 / 1918$ \\
\hline
\end{tabular}




\begin{tabular}{|c|c|c|c|}
\hline \multirow[t]{2}{*}{ Orfeuil } & 1436 & Français & $1914 / 1918$ \\
\hline & 3088 & Allemands & $1914 / 1918$ \\
\hline Saint-Hilaire-le-Grand & 915 & Russes & $1914 / 1918$ \\
\hline Saint-Imoges & 91 & Français et Britanniques & $1914 / 1918$ \\
\hline Sechault & 6000 & Allemands & $1914 / 1918$ \\
\hline Servon-Melzicourt & 3621 & Allemands & $1914 / 1918$ \\
\hline Sezanne & 451 & Français et Britanniques & $1914 / 1918$ \\
\hline Souain-Perthe-les-Hurlus & 2464 & Allemands & $1914 / 1918$ \\
\hline Warmeriville & 2658 & Allemands & $1914 / 1918$ \\
\hline Total & 87937 & & \\
\hline
\end{tabular}

- Sur le territoire régional, nombreux sont les ossuaires dont la plupart se situent au sein même des nécropoles nationales ou des cimetières militaires

\begin{tabular}{|c|c|c|c|}
\hline Lieu & $\begin{array}{l}\text { Nombre de } \\
\text { corps }\end{array}$ & Nationalité & Période \\
\hline Aubérive "Le Bois du Puits » & 2908 & Français et Polonais & $1914 / 1918$ \\
\hline $\begin{array}{ll}\text { Aubérive } & \text { Cimetière } \\
\text { Allemand } & \end{array}$ & 3124 & Allemands & $1914 / 1918$ \\
\hline Berru & 4500 & Allemands & $1914 / 1918$ \\
\hline Bligny & 1670 & Allemands & $1914 / 1918$ \\
\hline Bligny " La Croix Ferlin » & 2506 & Français & $1914 / 1918$ \\
\hline $\begin{array}{l}\text { Chatillon-sur-Marne } \\
\text { "Le Prieuré-de-Binson" }\end{array}$ & 562 & Français & $1914 / 1918$ \\
\hline Connantre & 8368 & Allemands & $1914 / 1918$ \\
\hline Cormicy « La Maison Bleue » & 6965 & Français & $1914 / 1918$ \\
\hline Courgivaux & 193 & Français & $1914 / 1918$ \\
\hline Dormans & 661 & Toutes nationalités & $1914 / 1918$ \\
\hline Fère-Champenoise & 3329 & Français & $1914 / 1918$ \\
\hline Jonchery-sur-Suippe & 3009 & Français & $1914 / 1918$ \\
\hline Loivre & 1913 & Allemands & $1914 / 1918$ \\
\hline Marfaux & 2760 & Allemands & $1914 / 1918$ \\
\hline Maurupt-Le-Monthois & 444 & Soldats inconnus & $1914 / 1918$ \\
\hline $\begin{array}{l}\text { Minaucourt-le-Mesnil-les- } \\
\text { Hurlus }\end{array}$ & 2223 & Français & $1914 / 1918$ \\
\hline Mourmelon-le-Grand & 41 & Français & $1914 / 1918$ \\
\hline Noyer-Pont-Maugis & 1202 & Allemands & $\begin{array}{c}1914 / 1918 \text { et } \\
1939 / 1945\end{array}$ \\
\hline Pontfaverger-Moronvilliers & 123 & Allemands & $1914 / 1918$ \\
\hline Rethel & 1202 & Français & $1914 / 1918$ \\
\hline Saint-Thomas-en-Argonne & 3324 & Français & $1914 / 1918$ \\
\hline Sedan-Torcy & 2104 & Français & $1914 / 1918$ \\
\hline Semide & 259 & Français & $1914 / 1918$ \\
\hline Servon-Melzicourt & 6524 & Allemands & $1914 / 1918$ \\
\hline Sillery & 5548 & Français & $\begin{array}{c}1914 / 1918 \text { et } \\
1939 / 45\end{array}$ \\
\hline
\end{tabular}




\begin{tabular}{|c|c|c|c|}
\hline Soizy-aux-Bois & 1692 & Français & $1914 / 1918$ \\
\hline Somme-Suippe & 1388 & Français & $1914 / 1918$ \\
\hline Sommepy-Tahure & 721 & Français & $1914 / 1918$ \\
\hline $\begin{array}{l}\text { Souain-Perthes-les-Hurlus } \\
\text { "Ossuaire De Navarin" }\end{array}$ & 10000 & $\begin{array}{l}\text { Français, Russes, Polonais, } \\
\text { Américains et Tchécoslovaques }\end{array}$ & $1914 / 1918$ \\
\hline $\begin{array}{l}\text { Souain-Perthes-les-Hurlus } \\
\text { "Légion Étrangère " }\end{array}$ & 128 & Français & $1914 / 1918$ \\
\hline $\begin{array}{l}\text { Souain-Perthes-les-Hurlus } \\
\text { "La Crouée " }\end{array}$ & 21688 & Français & $1914 / 1918$ \\
\hline $\begin{array}{l}\text { Souain-Perthes-les-Hurlus } \\
\text { Cimetière Militaire }\end{array}$ & 11322 & Allemands & $1914 / 1918$ \\
\hline $\begin{array}{l}\text { Suippes } \\
\text { "La Ferme de Suippes » }\end{array}$ & 528 & Français & $1914 / 1918$ \\
\hline $\begin{array}{l}\text { Vienne-le-Château } \\
\text { "La Gruerie » }\end{array}$ & 10000 & Corps de soldats inconnus & $1914 / 1918$ \\
\hline $\begin{array}{l}\text { Vienne-le-Château } \\
\text { «La Harazée » }\end{array}$ & 442 & Français & $1914 / 1918$ \\
\hline Villy-la-Ferte & 44 & Inconnus & $1914 / 1918$ \\
\hline Vitry-le-Francois & 2258 & Français & $1914 / 1918$ \\
\hline Vouziers & 1459 & Français & $1914 / 1918$ \\
\hline Warmeriville & 439 & Allemands & $1914 / 1918$ \\
\hline Total & 127571 & & \\
\hline
\end{tabular}

\section{c) Une analyse qui montre que le tourisme de mémoire, dans notre région, connaît des faiblesses}

Tout d'abord, la plupart des zones géographiques où sont présents les sites de mémoire, constituent de véritables déserts touristiques et présentent une faiblesse en termes d'accueil touristique. On peut citer l'exemple de la région de Suippes. Ce secteur offre un foisonnement de lieux de mémoire; pour autant, ce territoire est très pauvre en termes de restauration ou d'hostellerie. Ce déficit existe, de manière plus générale partout, excepté pour les villes. Cela constitue une problématique importante qui empêche les touristes de séjourner plus longtemps sur place. D'où un tourisme de passage et de très courte durée important dans notre région. II est donc important, en vue du centenaire de la Grande Guerre, de palier le problème des conditions d'accueil insuffisantes tout en donnant envie aux gens de revenir. "L'essor d'un site ne se réalise que si les visiteurs peuvent être accueillis ${ }^{7}$ ».

Ensuite il n'y a pas de lisibilité historique forte. En effet, la région est paradoxalement vide d'endroits très connus tels que Verdun ou encore le Chemin des Dames qui se situent en périphérie du territoire et qui concentrent un flux touristique important.

De plus, à l'inverse de la Picardie ou encore de la Lorraine, la Champagne-Ardenne ne dispose pas de sites centraux qui concentrent les flots touristiques tout en les diffusant par la suite sur les lieux de mémoire proches. Des " micro-sites » se répartissent sur l'ensemble du territoire. L'absence de sites majeurs entraîne alors un déficit d'image. Il est donc difficile de symboliser

\footnotetext{
${ }^{7}$ Monsieur Alexandre MORA - Directeur Général du Mémorial Charles de Gaulle
} 
quelque chose puisqu'il n'y a pas " un endroit mais des endroits ${ }^{8}$ ". Même si certains sites bénéficient d'une certaine notoriété, pour d'autres, la situation géographique et le manque de signalétique influent négativement sur eux. Le travail sur la signalétique est donc un enjeu majeur pour être prêt pour le grand rendez-vous du centenaire de la Grande Guerre.

Aujourd'hui, les touristes, en Champagne-Ardenne, ne sont pas principalement attirés par le tourisme de mémoire mais plutôt par des thématiques telles que le champagne, la cathédrale (1500000 à 2000000 de visiteurs) et la ville de Reims, les magasins de marques (environ 1000000 de personnes) et la ville de Troyes, les grands lacs (1 110000 pour le lac du Der) et le parc naturel régional de la Forêt d'Orient.

Pourtant, la région offre une grande variété de sites de mémoire qui s'inscrivent dans une continuité temporelle large.

Un véritable " territoire de mémoire " reste donc à construire en Champagne-Ardenne.

Le Comité Régional du Tourisme de Champagne-Ardenne (CRT) a lancé l'opération " devenez ambassadeur de votre région ". L'objectif de cette initiative est de faire découvrir ou redécouvrir les richesses du territoire aux champardennais. Pour cela le « Pass Ambasseur » mis en place permet d'avoir accès à des tarifs préférentiels pour des événements ainsi qu'une quarantaine de sites à travers la région. Le but second du CRT est de rendre les ambassadeurs fiers de leur région et, par la suite, la faire découvrir à d'autres.

Le tourisme de mémoire reste clairement un enjeu colossal pour la région.

\section{2) Les circuits touristiques}

Les sites étant disséminés sur le territoire régional, il semble impossible de les relier tous dans un seul et même itinéraire qui serait trop long. Toutefois, il a été judicieux de créer des circuits thématiques.

\section{a) Les circuits de mémoire proposés par le Comité Régional du Tourisme - CRT}

Le Comité Régional du Tourisme propose différents itinéraires intitulés "Votre prochaine conquête » à faire sur plusieurs jours.

Circuit Napoléon et la Campagne de France de 1814

Cet itinéraire entretient le souvenir de la Campagne de France de 1814 en empruntant les pas de Napoléon. Le circuit est extra régional puisqu'il passe par Paris ou encore Fontainebleau.

http://www.tourisme-champagne-ardenne.com/wpFichiers/Documentation/130/Napoleon 1814 FR.pdf

$\rightarrow$ Circuit 1914-1918 : La Grande Guerre dans la Marne

Cet itinéraire a pour vocation de comprendre la Grande Guerre dans la Marne en partant du monument de la victoire de la Marne de Mondement et pour finir par la visite du camp de la Vallée Moreau à Vienne-le-Château.

http://www.tourisme-champagne-ardenne.com/wpFichiers/Documentation/58/Circuit 14182012 FR.pdf

$\rightarrow$ Circuit des sites de mémoire 1939-1945 : La seconde Guerre mondiale de ChampagneArdenne

12 sites historiques, mémoriaux et musées régionaux sont intégrés dans cet itinéraire. http://www.tourisme-champagne-ardenne.com/wpFichiers/Documentation/67/Brochure-Sites39-45 2011.pdf

\footnotetext{
${ }^{8}$ Monsieur Bruno DUPUIS - Directeur départemental de l'Office National des Anciens Combattants - ONAC
} 
Le parcours histoire \& patrimoine

Cathédrales, forteresses, musées et champs de batailles font partie de ce parcours à travers la Champagne-Ardenne. Le voyage débute par la cathédrale de Reims pour s'achever avec une partie du patrimoine industriel comme la cristallerie et le musée du cristal de Bayel ou encore le musée de la coutellerie de Nogent.

http://www.tourisme-champagne-ardenne.com/wpFichiers/Documentation/116/CRT-Brochure-Histoire-2012-FR.pdf

Le Comité Régional du Tourisme de Champagne-Ardenne (CRT) a développé l'activité de géocaching sur le Circuit 1914-1918 : la Grande Guerre dans la Marne.

Il s'agit de chemins dédiés à la Première Guerre mondiale, qui offrent des "caches " dissimulées à proximité des monuments, ruines et musées de Mondement à l'Argonne, en passant par Reims, Suippes et Massiges.

\section{b) Les circuits de mémoire proposés par les offices de tourisme}

L'office de tourisme de Brienne-le-Château propose un circuit sur les traces de Napoléon. Tout au long du parcours, on découvre vingt-cinq pupitres sur les hauts-lieux de la Campagne de 1814, dont les batailles de Brienne-le-Château ou encore La Rothière. Chaque pupitre est traduit en français, anglais et allemand.

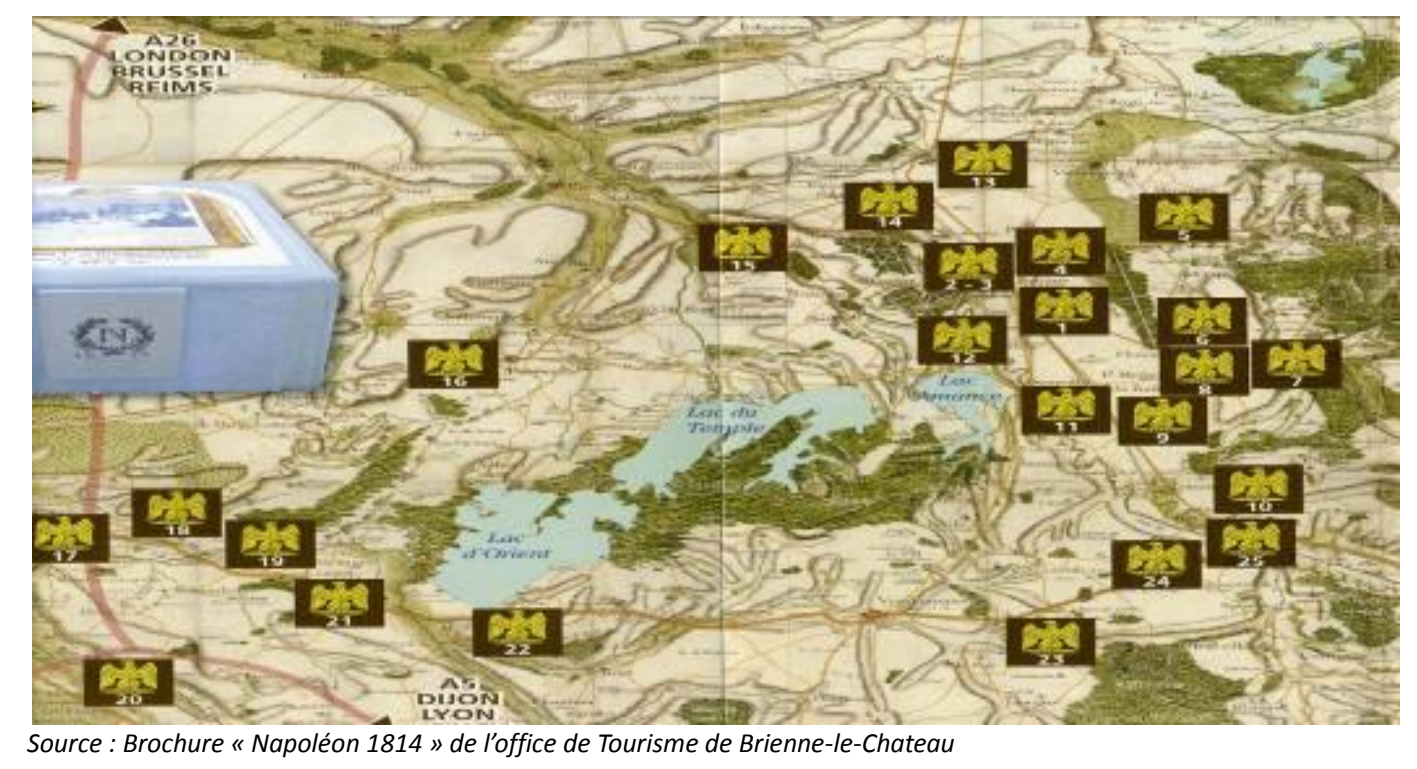

L'office de tourisme de Reims propose le Pass Mémoire :

Cette formule permet d'accéder à quatre musées consacrés aux Première et Seconde Guerres mondiales. Le Pass mémoire comprend la visite :

- du Musée du Fort de la Pompelle ;

- du Centre d'interprétation Marne 14/18 à Suippes ;

- du Musée Saint-Remi ;

- du Musée de la Reddition.

L'office de tourisme des trois cantons propose le circuit historique de la bataille de Stonne (dans les Ardennes françaises):

Le circuit de 50 kms est entièrement balisé et agrémenté de totems informatifs concernant la bataille du 15 mai 1940. 


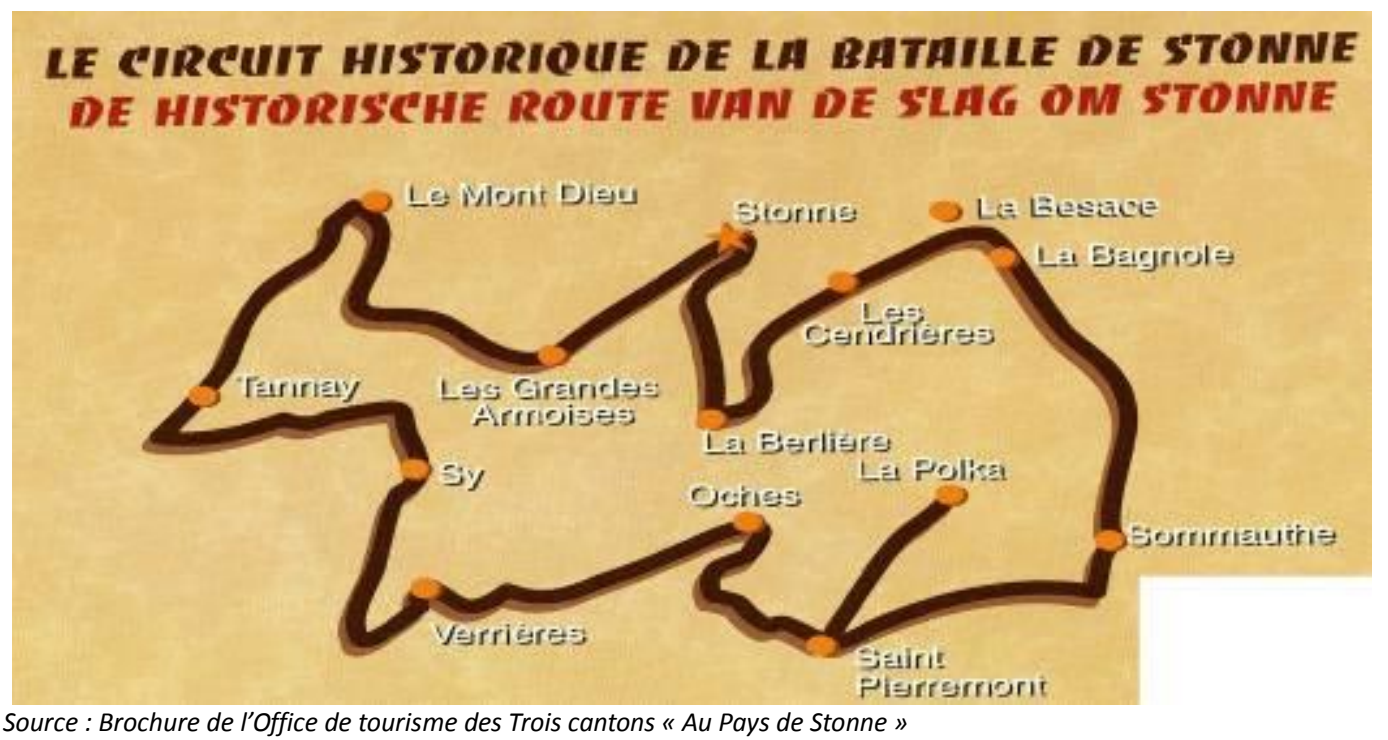

L'Office de tourisme de Sedan et du Pays sedanais a élaboré un itinéraire " Mémoire ":



Source : Site internet de l'Office de tourisme de Sedan www.tourisme-sedan.fr

L'office de tourisme de l'Argonne Ardennaise organise la journée "La Grande Guerre: des combats à la reconstitution " :

Cette excursion inclut une balade commentée de la ville de Vouziers (reconstruite dans les années 1920-30), suivie d'une randonnée accompagnée en forêt d'Argonne, sur les traces du Sergent York à Châtel-Chéhéry avec un déjeuner prévu au relais de Bagot à Savigny-sur-Aisne. 
L'office de tourisme de Pays d'Argonne propose une brochure "Les sites de mémoire en 1914-1918 » :

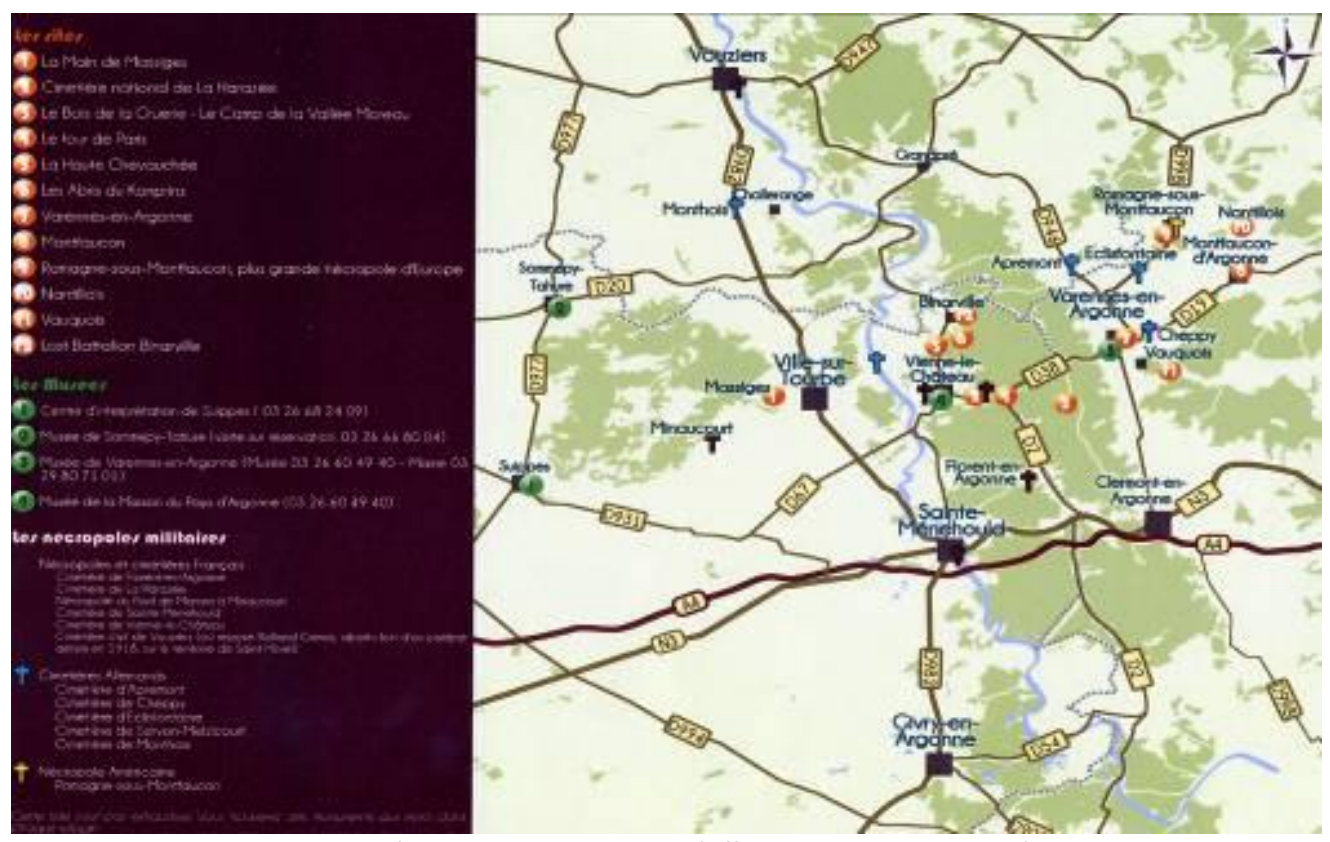

Source : Brochure "Les sites de mémoire en 1914-1918 » de l'Office de tourisme du Pays d'Argonne champenoise

\section{c) Le circuit de mémoire proposé par le syndicat d'initiative d'Esternay}

Le syndicat d'initiatives d'Esternay a élaboré un chemin de la mémoire :

Ce périple a été mis en place pour découvrir les lieux et les villages où se sont déroulés les combats de la première bataille de la Marne ainsi que celui du 13 juin 1940.

\section{d) Le circuit proposé par le centre d'interprétation de Suippes}

> Le circuit de mémoire : "Sur les pas des armées de Champagne » :

Le centre d'interprétation Marne 14-18 de Suippes propose un parcours à travers les hauts lieux des batailles qui s'y livrèrent. Des musées, monuments, stèles, plaques ou encore nécropoles parsèment les routes empruntées par les soldats des Armées de Champagne.

Un audio guide est téléchargeable sur le site internet du Centre d'interprétation afin d'accompagner au mieux la visite des différents sites présents sur le circuit.



Source : Brochure "Sur les pas des Armées de Champagne 1914-1918 》 


\section{e) Les circuits proposés par le Conseil général des Ardennes}

Le Conseil général des Ardennes a mis en place six routes touristiques à thème dont la route des fortifications : ce circuit, long de 140 kms, fait revivre 2000 ans d'histoire. Le musée mai juin 40 de Margut, le fort de la Ligne Maginot de Villy-La-Ferté et les remparts de Carignan sont les points forts de cet itinéraire.



Source : Brochure du Conseil Général des Ardennes « Les itinéraires ardennais »

Sites de mémoire en terre ardennaise : Le Conseil général des Ardennes a rassemblé huit sites dans une brochure. Tous proposent de découvrir l'histoire des Ardennes, en partant de la défaite de la France à Sedan en 1870 jusqu'à la percée allemande de 1940.



Source : Brochure «Sites de mémoire en terre ardennaise

- Musée Guerre et Paix en Ardennes à Novion-Porcien [actuellement fermé]

- Château fort de Sedan

- Maison de la dernière cartouche à Bazeilles

- Circuit historique de la bataille mai-juin 1940 à Stonne

- Musée des Spahis à La Horgne 
- Musée des deux guerres mondiales à Chagny

- L'ouvrage de Villy-La-Ferté

- Musée de la batille de mai-juin 40 à Semuy

\section{f) Les circuits proposés par le Ministère de la défense}

Sur le site www.cheminsdememoire.gouv.fr différents parcours thématiques sont disponibles :

$\rightarrow$ Les troupes russes en France : excursion de 26 kms dans la Marne à la nécropole russe de Saint-Hilaire-le-Grand puis visite du musée du Fort de la Pompelle.

$\rightarrow \underline{\text { Visiter la Marne }}$ : Mémorial des batailles de la Marne à Dormans, monument national de la victoire de la Marne de Mondement, musée du Fort de la Pompelle et nécropole russe à Saint-Hilaire-le-Grand.

$\rightarrow$ Chemins de mémoire de 1870/1871 : Maison de la dernière cartouche à Bazeilles, Château fort de Sedan, Musée Saint Remi à Reims et système défensif et les fortifications de Langres.

$\rightarrow$ Chemins de mémoire de 1939/1945 : fort de Villy-la-Ferté, mémorial et musée des Spahis à La Horgne, musée mai - juin 40 à Margut, musée de la reddition à Reims, musée de la résistance à Mussy-sur-Seine, Mémorial Charles De Gaulle et la Boisserie à Colombey-lesDeux-Eglises.

\section{g) Le circuit proposé par le Centre Régional de Documentation Pédagogique de Champagne-Ardenne}

Le centre Régional de Documentation Pédagogique - CRDP - de Champagne-Ardenne propose un périple afin de découvrir quelques lieux de mémoire de la Grande Guerre à l'est de Reims. L'excursion d'une cinquantaine de kilomètres nécessite une journée complète, même s'il est possible de la décomposer.

Huit étapes sont prévues au cours de cette promenade qui conduit le visiteur du monument de l'Armée Noire de Reims jusqu'au Monument-ossuaire de Navarin.

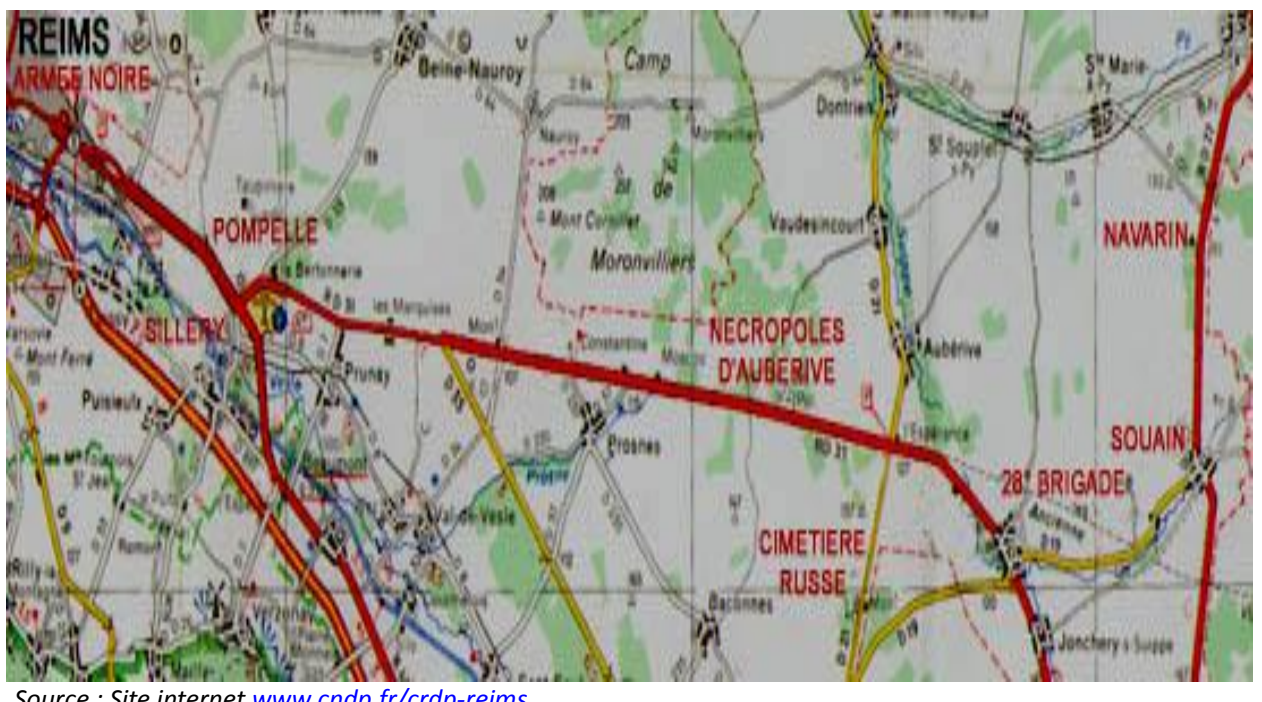

Source : Site internet www.cndp.fr/crdp-reims 
h) Le circuit proposé par la Communauté de communes du Pays d'Othe Aixois

La Communauté de communes du Pays d'Othe Aixois propose un circuit de 4,5 kms sur les pas de maquisards et retrace les événements qui se sont déroulés au bois de Villiers, théâtre des actes de la résistance en Pays d'Othe.

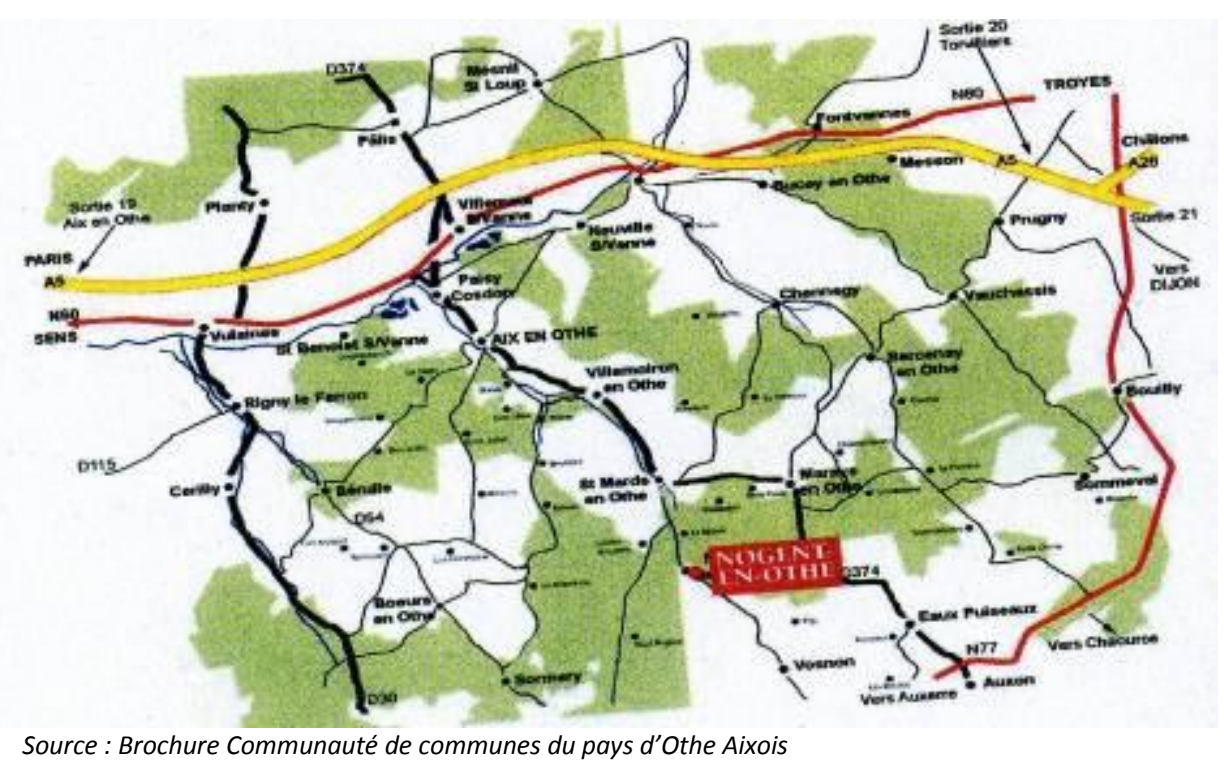

Afin de développer le tourisme de mémoire, il semble important de proposer des offres en synergie avec les thèmes et offres touristiques forts comme le champagne, les parcs naturels, les lacs, les sites patrimoniaux incontournables (on peut penser à la cathédrale de Reims), les magasins de marques et la vieille ville de Troyes...

Néanmoins, l'approche des sites de mémoire et d'histoire doit se faire par des circuits d'une longueur courte en partant toujours d'un site majeur de la région. 


\section{À RETENIR}

\section{En 2007 : 340000 touristes de MEMOIRE En ChAMPAGNE-ARDENNE}

- $+13 \%$ par rapport à 2000 ;

- Mais une fréquentation très inférieure aux autres régions.

\section{LE PROFIL DES TOURISTES DE MEMOIRE EN CHAMPAGNE-ARDENNE}

- $69 \%$ sont de nationalité française ( $55 \%$ au niveau national) ;

- Pour la clientèle étrangère, la nationalité belge prédomine (11,3\%);

- Les sites de mémoire sont d'abord visités par des retraités $(27,9 \%)$;

- Les scolaires représentent $6 \%$ de la clientèle contre $24 \%$ au niveau national.

\section{LA MOTIVATION DU SEJOUR DES VISITEURS DES SITES DE MEMOIRE}

- $33,7 \%$ : le patrimoine historique et culturel ;

- $16,5 \%$ : la visite à la famille ou aux amis ;

- $14,5 \%$ : les sites de mémoire militaire.

\section{LA MOTIVATION DE LA VISITE DU SITE DE MEMOIRE}

- Majoritairement : par intérêt pour l'histoire $(61,6 \%)$;

- Pour $1 / 3$ des visiteurs : par curiosité $(31,5 \%)$;

- Pour seulement un dixième : par référence à la mémoire familiale $(10,2 \%)$.

\section{UNE FAIBLESSE AVEREE EN TERMES D'ACCUEIL TOURISTIQUE}

- En dehors des villes, la pauvreté de l'offre en termes de restauration ou d'hôtellerie est une réalité qui conduit de fait à un tourisme de passage ou de court séjour (2 à 3 nuits pour $38,1 \%$ des touristes). 


\section{1914-1918 DE LA MEMOIRE A L'HISTOIRE}

\section{A) Le Centenaire de la Grande Guerre : le passage de la memoire a L'HISTOIRE}

"Le Centenaire de la Grande Guerre va marquer son entrée dans I'histoire " ${ }^{9}$.

Monsieur Serge Barcellini, lors d'une intervention présentée à l'Assemblée Nationale le 21 mars 2009 sur le thème "Réflexions sur la politique de mémoire de la Grande Guerre ", a développé les trois thèmes qui structurent la politique de mémoire : le Souvenir, la Mémoire et l'Histoire.

Le temps du Souvenir : c'est le temps des deux générations qui suivent la Grande Guerre (environ 50 ans, 1918-1968).

Il est marqué par :

- la connaissance de l'événement qui est enracinée dans l'opinion publique. Les noms des batailles et des chefs militaires sont connus de tous. Le monument aux Morts est inscrit dans la quotidienneté du vécu des villageois et des citadins.

- la Grande Guerre qui est une référence dans le débat politique français et les acteurs sont nombreux.

En 1968, lors du $50^{\text {ème }}$ anniversaire de Verdun, c'est entre trois ou quatre millions d'anciens combattants qui sont présents.

Le temps de la Mémoire : c'est le temps des deux générations qui suivent. L'événement est de moins en moins connu. Sa place est de plus en plus réduite dans l'enseignement. Le monument aux morts devient un lieu de mémoire. L'utilisation de la mémoire n'entre plus dans le champ politique. Les anciens combattants disparaissent : le dernier Poilu, Lazare Ponticceli, décède le 12 mars 2008. Leurs descendants prennent le relais mais leur légitimité mémorielle est moins marquée.

- Le temps de l'Histoire : c'est le temps qui s'ouvre avec la cinquième génération d'après guerre (à partir de 2010/2020). Cette période n'est connue qu'à travers les livres ou les films. 1914-1918 est totalement hors du champ politique et idéologique. Des associations mémorielles entretiennent le souvenir des sites.

Ainsi la mémoire devient un vecteur économique à travers le tourisme. Les champs de bataille deviennent des lieux de tourisme de mémoire. La mémoire partagée reste une des bases déterminantes des relations internationales et le ré-enracinement familial est fourni par la généalogie, qui favorise la redécouverte de la Grande Guerre.

\footnotetext{
${ }^{9}$ Propos de M. Serge Barcellini, Directeur de la mission « Histoire » au Conseil Général de la Meuse, recueilli lors de son audition du 04 juin 2012
} 


\section{B) LA COMMEMORATION DE LA GRANDE GUERRE, LE «RAPPORT ZIMET»}

L'année 2014 marquera les débuts du centenaire de la Première Guerre Mondiale. Dans la perspective de ce rendez-vous, un rapport de préfiguration "Commémorer la Grande Guerre (2014-2020) : propositions pour un centenaire international ", rédigé par Monsieur Joseph Zimet, adjoint au Directeur de la mémoire, du patrimoine et des archives au Ministère de la défense et des anciens combattants a été remis au Président de la République, le 11 novembre 2011.

\section{1) Les manifestations envisagées}

II propose une répartition des tâches entre l'État et les collectivités territoriales, avec une action des pouvoirs publics nationaux qui se concentrerait sur le début (2014) et la fin (2018) de la commémoration. Les collectivités territoriales interviendraient dans l'intervalle par un cycle de commémorations décentralisées qui marquera les grandes étapes de la première guerre mondiale sur le territoire national.

En 2014, l'État conduira un programme commémoratif qui insistera sur la transmission pédagogique de la mémoire de la Grande Guerre, le développement culturel et scientifique et le tourisme de mémoire. Il sera organisé autour de six grands rendez-vous prenant place entre le 28 juin et le 11 novembre 2014 :

$\Im 28$ juin : ouverture européenne du Centenaire à Sarajevo "de Sarajevo à Sarajevo ", regards croisés sur un siècle d'histoire européenne (grand rassemblement culturel européen et réunion exceptionnelle des chefs d'État et de gouvernement européens pour une commémoration de l'événement déclencheur de la Première Guerre mondiale) ;

$凶 13-14$ juillet : fête nationale mettant à l'honneur toutes les nations cobelligérantes de la Grande Guerre ;

\ 31 juillet : commémoration de l'assassinat de Jean Jaurès ;

$₫ 2$ août: commémoration décentralisée de la mobilisation générale et de l'entrée en guerre;

$\unlhd$ en septembre : commémoration de la première bataille de la Marne ;

$₫ 11$ novembre : entrée de Maurice Genevoix, écrivain et ancien combattant de la Grande Guerre, au Panthéon.

De 2015 à 2018, les collectivités territoriales, avec l'appui de l'État, seraient les hôtes d'une commémoration itinérante, intermittente, décentralisée et internationale.

En 2015, la France commémorera en Artois et en Champagne les deux principales offensives de l'année 1915.

L'année 2015 marquera également le centième anniversaire des combats des Vosges. Par ailleurs, un hommage sera rendu aux 4847 combattants indiens de I'Indian Corps morts au champ d'honneur lors de la bataille de Neuve-Chapelle en mars 1915. 
L'année 2016 sera marquée par deux importantes commémorations :

$\searrow$ le centième anniversaire de la bataille de Verdun ;

$\unlhd$ le 1er juillet, le centenaire de l'offensive de la Somme.

En 2017, auront lieu de nombreux événements locaux et nationaux comme par exemple :

$\Im$ le 9 avril, le gouvernement canadien viendra commémorer la bataille de Vimy ;

$₫$ le 4 juin, le département de l'Aisne commémorera le centenaire de l'offensive du Chemin des Dames ;

\ le 15 octobre, la Pologne viendra célébrer la création en France de l'armée polonaise.

En 2018 seront, entre autres, commémorées la seconde bataille de la Marne de juillet 1918 et la contre-offensive victorieuse des troupes alliées sous le commandement de Foch, qui mit un terme définitif aux combats du front de l'ouest.

L'État reprendra la conduite du processus commémoratif de la Première Guerre mondiale pour y mettre un terme avec l'organisation des commémorations du centenaire de l'Armistice du 11 novembre 1918.

Après le 11 novembre 2018, l'État pourrait accompagner, decrescendo, la fin du Centenaire, avec la commémoration de la paix de Versailles et des " sorties de guerres ", en 2019 et 2020.

Par ailleurs, à côté de ces six événements, l'État pourrait porter trois grandes initiatives culturelles et mémorielles :

$\Rightarrow$ la numérisation et la mise en ligne, durant le centenaire, de l'ensemble des registres matriculaires des huit millions de combattants de la Première Guerre mondiale ;

$\Rightarrow$ l'appui à l'inscription au patrimoine mondial de l'Unesco des "paysages et sites de mémoire de la Grande Guerre » proposée par treize départements du Front (sauf la Marne), constitués depuis juillet 2011 en association ;

$\Rightarrow$ la création d'une commission de réflexion sur la question des fusillés de la Grande Guerre.

\section{2) L’organisation au niveau national}

Afin d'assurer la conception et la mise en œuvre du programme commémoratif du centenaire, le gouvernement a créé, le 5 avril dernier, un groupement d'intérêt public (GIP) « Centenaire de 1914 ». Le général des armées Elrick Irastorza, ancien chef d'état major de l'armée de terre a été nommé président du conseil d'administration et Monsieur Joseph Zimet, directeur.

Par ailleurs, deux comités ont été constitués :

- un comité scientifique, chargé d'assister le groupement dans l'élaboration du programme commémoratif. Il est présidé par le Professeur Antoine Prost ;

- un comité des mécènes qui regroupe des personnes contribuant au financement du programme commémoratif. II est présidé par M. Jean-Claude Narcy. 


\section{3) Le financement du Centenaire}

Le financement du programme commémoratif du Centenaire ne reposera pas intégralement sur le budget de l'État. II devrait faire appel à des ressources privées, trouver des compléments de financement auprès de l'Union Européenne ${ }^{10}$ et monter des cofinancements avec les collectivités territoriales, parties prenantes de l'animation du Centenaire.

\section{C) La commemoration en Champagne-ARdenne}

\section{1) Les manifestations envisagées}

\section{a) dans le « rapport Zimet "}

Il est précisé, en page 71 , que la Champagne-Ardenne verra commémorer la première bataille de la Marne en septembre 2014. "A l'occasion du centenaire de la bataille de la Marne, une commémoration d'envergure pourrait être organisée à proximité de l'un des sites du champ de bataille ou près des monuments emblématiques bâtis pour perpétuer la mémoire de l'événement. Le monument de Mondement, élevé au sud des marais de Saint-Gond en souvenir de la Première bataille de la Marne, ou le Mémorial de la Marne de Dormans serait pleinement approprié pour l'organisation d'une telle commémoration ".

b) par les collectivités (non exhaustif)

\section{Dans la Marne :}

A Mondement, où la $1^{\text {ère }}$ bataille de la Marne sera commémorée début septembre 2014, des réflexions sont engagées pour préparer cet événement et laisser des traces (comme évoqué dans le rapport Zimet) en direction de la jeunesse : utilisation des nouvelles technologies, par exemple : reconstitution en 3D des événements sur le circuit de mémoire « Entre Marne et les deux Morins ", bornes interactives...

L'idée est également de travailler avec les personnes qui s'intéressent au bi-centenaire de la Campagne de France de Napoléon $1^{\text {er }}$ pour développer les nouvelles technologies. ${ }^{11}$

A Navarin, en 2015, les combats d’Argonne seront évoqués et une cérémonie mémorielle aura lieu.

A Saint Hilaire le Grand, en 2016, le corps expéditionnaire russe sera mis à l'honneur.

En 2017, les combats des Monts de Champagne seront fêtés.

A Dormans, en 2018, la $2^{\text {ème }}$ Bataille de la Marne ainsi que l'Armistice du 11 novembre seront commémorés.

A Sommepy Tahure, en 2018, des manifestations pour rendre hommage aux troupes américaines auront lieu.

\footnotetext{
${ }^{10}$ Par exemple : Programme Interreg IV France-Wallonie-Vlaanderen, Sous-programme franco-allemand/priorité 2/ Objectif opérationnel 1 - Développer et professionnaliser une offre touristique intégrée - Mémoire de la Grande Guerre

${ }^{11}$ Audition de Monsieur Michel Tellier - Président de Mondement 1914 « Les soldats de la Marne Joffre-Foch » le 11 mai 2012
} 


\section{2) Autres développements envisagés}

\section{Dans la Marne :}

L'association "Mondement 1914 " Les soldats de la Marne Joffre-Foch » travaille à :

- la création d'un parcours de mémoire, à partir des villes de Sézanne et de Montmirail, dans un rayon de 40 kilomètres. Les villages de Broyes, Mondement-Montgivroux, Reuves (à proximité des marais de Saint Gond), Oyes, Soizy-aux-Bois, Talus Saint Prix, Corfélix, Le Thoult Trosnay, Boissy-le-Repos, Bergère-sous-Montmirail sont riches d'histoire. De plus à proximité, se situent Champaubert, Vauchamps et Montmirail, lieux de bataille de la campagne de France qui ont vu la victoire de l'armée française de Napoléon $1^{\mathrm{er}}$;

- la construction d'un bâtiment d'accueil et d'histoire, d'une superficie d'environ $150 \mathrm{~m}^{2}$, « Marne 1914 » qui sera érigé à Soizy-aux-Bois (en dessous de la Nécropole nationale) ${ }^{12}$.

Le Fort de la Pompelle, qui connaît à l'heure actuelle un important programme de rénovation et de mise en valeur, verra, en 2014, l'ouverture d'une nouvelle galerie et d'une muséographie. Son esplanade connaîtra des aménagements.

Un partenariat est signé entre la Ville de Reims et le Musée Royal de l'Armée et d'Histoire Militaire de Bruxelles pour des actions culturelles.

La Ville de Reims a pris contact avec I'Inspection académique et le Centre départemental de documentation pédagogique pour des actions avec les établissements scolaires.

Le Comité départemental du tourisme envisage la création d'un site internet spécifiquement dédié à la Grande Guerre, la réalisation de publications, d'expositions, de conférences...

> Le Conseil Général de la Marne s’engagera sur un complément de signalétique spécifique au tourisme de mémoire. ${ }^{13}$

Les Archives départementales seront fortement impliquées dans la numérisation de documents historiques pour les rendre accessibles au grand public.

A Reims. $^{14}$ :

- un projet pédagogique, en lien avec l'Éducation nationale, est en cours d'élaboration ;

- une publication sur la Grande Guerre faisant référence aux communes alentours, dont le rôle a été crucial pour la défense de Reims, est en préparation ;

- en novembre 2013, un colloque international est envisagé, consécutivement à l'inauguration du Monument à l'Armée Noire.

A Châlons-en-Champagne, Mourmelon-le-Grand et Suippes, il est envisagé, à partir de septembre-octobre 2013, d'organiser annuellement un festival international des cinémas de guerre (toutes guerres confondues). Ce projet est porté par le Pays de Châlons-enChampagne et coordonné par la Scène nationale de Châlons-en-Champagne, la Comète.

\footnotetext{
${ }^{12}$ Audition de Monsieur Michel Tellier - Président de Mondement 1914 « Les soldats de la Marne Joffre-Foch » le 11 mai 2012

${ }^{13}$ Audition de Monsieur Christian Bruyen - Vice-Président du Conseil Général de la Marne le $1^{\text {er }}$ juin 2012

${ }^{14}$ Audition de Madame Catherine Martin - Chargée de mission à la Ville de Reims le $1^{\text {er }}$ juin 2012
} 


\section{En Haute-Marne :}

Il a été demandé que soit organisée une exposition au Mémorial Charles de Gaulle ${ }^{15}$.

Dans les Ardennes : ${ }^{16}$

Un colloque est prévu, en 2014, sur l'occupation. II pourrait être étendu à Châlons-enChampagne.

> Si le label « Ville d'art et d'histoire " est décerné fin 2012 à Charleville-Mézières, un circuit de visite guidée sur les traces de l'occupation allemande peut être étudié,

S'intéresser à la population civile dans les Ardennes peut être attrayant. Deux journaux, l'un français, l'autre allemand, font le récit de chaque jour de la guerre. Une lecture croisée des textes, voire un spectacle audiovisuel les mettant en scène, peuvent être imaginés, tout en allant au-delà en recherchant des ponts entre les guerres : un travail sur 1870 (Sedan), 14-18 et 39-45.

Une narration illustrée qui s'inscrirait dans un circuit touristique peut être par ailleurs étudiée.

\section{3) L'organisation mise en place}

Le "rapport Zimet » prévoit que, dans chaque département concerné, soit créé un comité départemental du souvenir dont la mission sera, entre autres, de coordonner l'action des collectivités locales.

Ainsi, dans la Marne, sous le pilotage de Monsieur le Sous-préfet de Reims, un Comité Départemental de la Commémoration du Centenaire de la Grande Guerre a été constitué. II rassemble le Président du Conseil Régional, le Président du Conseil Général, les grandes villes, les services de l'État (DRAC, ONAC, Services académiques et le Souvenir Français). ${ }^{17}$

II poursuivra quatre objectifs :

- voir reconnaître la place de la Marne dans le Centenaire,

- créer des liens intergénérationnels à l'occasion du Centenaire,

- viser à une pérennisation des actions au-delà des anniversaires,

- concourir à l'attractivité des territoires au travers du Centenaire.

Par ailleurs, il sera " la courroie de transmission » entre la Marne et le GIP national "Centenaire de 1914 " pour ce qui concerne la labellisation des actions. En effet, après avis du Préfet recueilli après consultation de ce Comité, l'État attribue des labels nationaux aux actions des collectivités organisatrices.

\section{Aussi, ont été formés :}

$\Rightarrow$ par le Conseil Général de la Marne, une Coordination Centenaire de la Grande Guerre.

Trois sous-comités la composent :

$\checkmark$ un sous-comité scientifique qui donne un avis sur l'ensemble des actions,

\footnotetext{
${ }^{15}$ Audition de Monsieur Alexandre Mora - Directeur Général du Mémorial Charles de Gaulle 7 juin 2012

${ }^{16}$ Auditions de Monsieur Raymond Stévenin - Marie-Adjoint en charge du patrimoine à la Ville de CharlevilleMézières et de Madame Carole Marquet-Morelle- attachée de conservation du patrimoine au Musée de Charleville-Mézières le 15 juin 2012

${ }^{17}$ Audition de Monsieur le Sous-Préfet de Reims, Michel Bernard le $1^{\mathrm{er}}$ juin 2012,
} 
un sous-comité "commémoration »: il établit un calendrier prévisionnel des commémorations sur les cinq années,

$\checkmark$ un sous-comité « internet » qui s'intéresse à la création d'un site dédié, porte d'entrée à l'ensemble des manifestations marnaises.

$\Rightarrow$ par la ville de Reims et Reims Métropole :

- un Comité de pilotage des Commémorations du Centenaire 14-18. II travaille sur trois angles :

o le souvenir,

- l'après-guerre, avec la reconstruction de Reims et de ses environs,

- la réconciliation (jusqu'au 8 juillet 1962, date de la cérémonie de la réconciliation entre la France et l'Allemagne en la cathédrale de Reims).

- un Comité scientifique qui émet un avis sur l'ensemble des commémorations de la métropole rémoise.

\section{D) LA COMMEMORATION DANS D'AUTRES REGIONS}

\section{1) En Picardie}

\section{a) Dans la Somme et dans l'Aisne}

Ces deux départements, qui ont la volonté de ne pas rater le grand rendez-vous de 2014-2018 pour leur territoire, ont des stratégies plus ou moins identiques. D'une part, ils souhaitent remettre à niveau leur offre culturelle et touristique. D'autre part, ils ambitionnent de proposer quelques grandes manifestations événementielles.

Le grand rendez-vous pour le département de la Somme sera juillet 2016 pour commémorer la grande offensive de la Somme du $1^{\mathrm{er}}$ juillet 1916. Le département accueillera des centaines de milliers de Britanniques et les hauts représentants des nations du Commonwealth.

Le grand rendez-vous de l'Aisne sera le 16 avril 2017 avec le centième anniversaire de I'Offensive Nivelle sur le Chemin des Dames.

Aussi, les deux collectivités organiseront d'autres manifestations, dès 2014 (veillées, marches, spectacles, colloques) puis en 2018.

Au-delà de ces dates, ces départements profiteront de la dynamique commémorative nationale pour procéder à une remise à niveau de leurs équipements mémoriels.

Dans la Somme, l'Historial de Péronne aura sa muséographie revue. Pour sa part, le département de l'Aisne devrait moderniser la Caverne du Dragon. Elle devrait être agrandie et concourir à l'octroi du label "Musée de France " en devenant le "Musée du Chemin des Dames ». Aussi, un centre de conférences et d'accueil devrait être construit à Craonne.

Le Département de l'Aisne reverra la signalétique et l'information pédagogique dispensée au long du Chemin des Dames et devrait créer un observatoire à l'extrémité orientale du Plateau de Californie, qui permettra au grand public d'embrasser la plaine de Reims d'un seul regard, depuis la montagne de Craonne.

Par ailleurs, ces deux collectivités souhaitent appuyer leurs politiques de développement mémoriel sur des sites internet de qualité pour relayer leur politique de mise en valeur touristique des territoires et offrir de l'information historique de qualité. Le département de la 
Somme dispose de plusieurs portails :

- www.somme14-18.com met en réseau les efforts des différents acteurs de la mémoire du département, notamment à travers un circuit du souvenir entre Albert et Péronne,

- www.sbpartner.fr (site Somme Battlefields'Partner). C'est un réseau de professionnels qui entend fédérer les acteurs du tourisme de mémoire dans la Somme,

- www.tourisme-paysducoquelicot.com: ce site offre des informations sur les sites historiques et mémoriels de la communauté de commune du pays des coquelicots.

L'Aisne, au travers de la Mission Chemin des Dames, a mis en place le portail www.chemindesdames.fr.

\section{b) Dans l'Oise}

Les importantes traces mémorielles de la Grande Guerre en Oise conduisent le Département à s'impliquer dans la valorisation du patrimoine 14-18 (début de la guerre de tranchées entre Noyon et Compiègne ; les armées allemandes et alliées se lancent, à l'automne 1914, dans « la course à la mer "; l'arrêt des combats et l'armistice sont signés dans une clairière en forêt de Compiègne ; le Grand Quartier Général des forces alliées est installé durant une grande partie de la guerre à Compiègne, Chantilly et Beauvais). Outre sa participation à l'initiative " paysages et sites de mémoire de la Grande Guerre ", portée par les treize "départements du front ", plusieurs projets devraient voir le jour dans l'Oise entre 2014 et 2018 :

- La création d'un musée-territoire "Front de l'Oise 14-18», portée par les cinq communautés de communes concernées par le front de l'Oise ${ }^{18}$ est envisagée. Ce projet consiste, entre autres, à mettre en valeur le patrimoine 14-18, à élaborer un circuit de mémoire suivant la ligne de front de l'Oise de 1914 à 1918,

- la restauration de l'abri du Kronprinz de Bavière,

- l'ouverture d'un musée de la mémoire franco-allemande, avec le soutien du Souvenir Français et du Volksbund Deutsche Kriegsgräberfürsorge (VDK),

- I'inauguration du jardin de la mémoire " Augustin Trébuchon » en 2014, dans la prairie qui jouxte la clairière de l'Armistice à Compiègne,

- L'extension des bâtiments d'accueil du public, pour 2018, du Mémorial de l'Armistice.

\section{2) En Lorraine}

Depuis le 3 juillet 2008, jour de la validation à l'unanimité du rapport «14-18 le temps de l'Histoire ", le département de la Meuse prépare le rendez-vous du centenaire de la Première Guerre mondiale. Un important programme de mise en valeur mémorielle du département a été décliné. Il est le fruit des réflexions du Contrôleur général des armées et Directeur de la Mission Histoire au Conseil Général de la Meuse, Serge Barcellini, synthétisées dans un document intitulé "La Meuse face au défi du centenaire de la Grande Guerre, 2014-2018, propositions pour une refondation de la politique mémorielle ". II repose sur la réalisation de trente-deux projets, répartis sur l'ensemble de la Meuse, divisés en cinq thématiques :

$>$ Le Champ de bataille de Verdun et l'arrière front allemand. "L'attractivité du champ de bataille de Verdun doit être accrue et son rôle de locomotive mémorielle privilégié ${ }^{19}$. Le mémorial musée de la bataille de Verdun doit demeurer le site de la connaissance de

\footnotetext{
${ }^{18}$ Les Communautés de communes du canton d'Attichy (porteuse du projet), de la Vallée de l'Aisne, du Pays Noyonnais, des Deux Vallées et du pays des Sources

${ }^{19}$ La Meuse, I'ambition de l'Histoire -14-18 Le temps de I'histoire, Conseil Général de la Meuse
} 
I'histoire et de la mémoire de Verdun. A l'échéance de 2016, le Département prévoit un appui à son projet d'extension d'une superficie de $750 \mathrm{~m}^{2}$ (nouvelles salles d'exposition, espaces pédagogiques...) et son classement au titre des musées de France sera sollicité. De son côté, l'Etat investit de façon significative sur le site de Douaumont, avec la rénovation complète de la nécropole de Fleury-devant-Douaumont d'ici 2014 (changement de l'ensemble des stèles) et le réaménagement de l'ensemble du site de la tranchée des Baïonnettes, à proximité de l'ossuaire.

Le Saillant de Saint Mihiel, formé en septembre 1914, était une avancée des lignes allemandes de plus de $20 \mathrm{kms}$ dans le dispositif français. Le village de Marbotte constituera un site "locomotive " qui dynamisera l'ensemble du Saillant. Son église sera rénovée. Son musée sera modernisé. Un ensemble de circuits de découverte sera défini et banalisé au départ de Marbotte.

L'Argonne (site locomotive: Varennes). Le musée de Varennes regroupe trois types de collections : Louis XVI, I'histoire régionale et la Grande Guerre. Un projet consiste à séparer les collections et à créer un musée de la grande Guerre en Argonne.

L'arrière du front français (site locomotive Souilly). Le quartier général du général Pétain durant la bataille de Verdun et du général américain Pershing, en 1918, lors de l'offensive lancée par les Américains en Meuse est devenu un lieu d'exposition temporaire. Sa transformation en musée de l'arrière front est programmée.

Verdun, "capitale mondiale de la Grande Guerre ". Verdun est la ville référence de la Grande Guerre dans le monde. Elle joue un double rôle national et mondial. Cette double fonction sera renforcée. Actuellement, la muséographie de la Grande Guerre est dispersée sur plusieurs sites. Il est proposé de créer un pôle unique autour de la citadelle basse de Verdun. Aussi, sont envisagées les créations :

- d'un centre généalogique de la Grande Guerre où chacun pourra rechercher sur internet son ancêtre qui a combattu en 14-18,

- d'un centre d'accueil des enseignants et des élèves.

En appui à ces actions mémorielles, le Conseil Général prévoit, à l'échelle du département, la mise en place d'une nouvelle signalétique routière, l'installation de panneaux d'information historique et la réalisation de dépliants qui guideront le visiteur à travers les différentes richesses mémorielles des champs de bataille de la Meuse.

\section{3) En Nord-Pas-de-Calais}

La région Nord-Pas-de-Calais a adopté en 2010 un ambitieux programme de mise en valeur mémorielle de son territoire au travers des "Chemins de mémoire en Nord-Pas-de-Calais".

Quatre-vingt-dix lieux de mémoire de la région, structurés en "chemins de mémoire " autour de quatre itinéraires thématiques :

- le Front,

- la guerre de mouvement et la première occupation allemande,

- le littoral, base arrière des armées alliées,

- la reconstruction dans les territoires dévastés,

sont mis en réseau. Le portail internet www.cheminsdememoire-nordpasdecalais.fr apporte des éléments de contexte historique sur chacun des sites et des éléments de compréhension globale sur la Grande Guerre. Par ailleurs, ces informations sont accessibles aux visiteurs, durant 
leurs déplacements sur les sites via leurs téléphones portables.

Le 7 juillet 2012, un premier circuit cyclotouristique « des Hauts-lieux de la Grande Guerre en Artois, labellisé "Chemins de mémoire en Nord-Pas-de-Calais» a été inauguré sur le site de Notre-Dame-de-Lorette. II a pour objectif d'inviter à la découverte des grands sites de mémoire des collines de l'Artois tout en pratiquant une activité sportive. Un guide d'accompagnement, consultable en ligne, de 24 pages en français ainsi qu'une édition anglaise permettent aux visiteurs de mieux appréhender les événements de la Grande Guerre sur le territoire. Une version en allemand et en néerlandais sera effective d'ici la fin de l'année. D'autres circuits de ce type verront le jour, d'ici à 2018, pour découvrir les sites de souvenir du Nord-Pas-de-Calais.

Le Conseil Régional du Nord-Pas-de-Calais est porteur de deux réalisations :

à Souchez, un centre d'interprétation de la Grande Guerre en Nord-Pas-de-Calais, (maîtrise d'ouvrage assurée par la Communauté d'agglomération de Lens-Liévin) qui offrira aux visiteurs du champ de bataille les clés de lecture des différentes phases de la Grande Guerre dans la région durant quatre ans,

à Ablain-Saint-Nazaire, au sommet du plateau de Notre-Dame-de-Lorette, face à la nécropole nationale, un mémorial international de la Grande Guerre sera érigé sur un terrain de 2,2 hectares, cédé à la Région par le Ministère de la Défense dans le cadre d'une convention signée le 13 avril 2011. La maîtrise d'ouvrage est assurée par le Conseil régional, avec le soutien de la Direction de la Mémoire du patrimoine et des archives du Ministère de la Défense.

"L'objectif de ce mémorial, qui sera l'un des plus grands de la planète, est d'ancrer le souvenir de la mort de masse qui a frappé les sociétés européennes ". "I s'agira d'inscrire les noms des quelques 600000 soldats de toutes nationalités, tombés en Flandre française et en Artois entre 1914 et 1918. Les noms seront disposés par ordre alphabétique, toutes nationalités mélangées, amies et ennemies d'hier » indique le Conseil régional (coût : 5,4M€).

Par ailleurs, le Conseil régional propose, en 2014, à Lille, une exposition sur le thème de la Grande Guerre en Nord-Pas-de-Calais.

\section{E) LA COMMEMORATION A L'ETRANGER}

\section{1) En Flandre belge}

Le Gouvernement flamand, après les Australiens, s'est très vite intéressé au Centenaire de la Grande Guerre, qu'il a identifié comme un événement majeur de nature à dynamiser son développement touristique, culturel et son image internationale. Au travers de ses actions, il aspire à mettre sur pied un programme humanitaire et international ciblé, durablement lié au thème "Plus jamais la Guerre » et " entend sensibiliser les générations actuelles et futures aux thèmes que sont la tolérance et l'entente internationale ». ${ }^{20}$

\footnotetext{
${ }^{20}$ Kris Peeters - Ministre-Président du Gouvernement flamand et Ministre flamand de l’Economie, de la Politique extérieure, de l'Agriculture et de la Ruralité.
} 
Son projet "Le Grand Centenaire 2014-18», porté par le Vice-Ministre-Président du Gouvernement flamand, Monsieur Geert Bourgeois, vise à inscrire le territoire flamand au cœur des commémorations internationales du centenaire de la Grande Guerre et être à l'initiative de quelques grands rendez-vous internationaux de référence organisés sur son territoire.

Pour ce faire, un fonds d'impulsion du Grand Centenaire 2014-18, doté de 15M€, a été mis en place. Il permet d'ores et déjà de soutenir 44 projets, dont :

- le financement d'une nouvelle exposition permanente au sein du musée In Flanders Fields d'Ypres,

- la rénovation du monument du Roi Albert $1^{\mathrm{e}}$,

- la création d'un centre d'interprétation près du complexe d'écluses du Ganzenpoot à Nieuport.

En 2013, le gouvernement flamand organisera à Ypres "le colloque international sur la Paix », auquel sont conviés des lauréats du Prix Nobel de la Paix.

Dès le 11 novembre 2012, le Gouvernement flamand souhaite faire adopter une déclaration internationale sur la paix "Flanders Fields Declaration ${ }^{21}$.

De plus, plusieurs projets portés par le secrétariat du Centenaire, proposent des coopérations avec la France. Outre un jardin du souvenir formé de terre prélevée sur des champs de bataille situés en Flandre, que le Gouvernement flamand souhaiterait offrir à la France, le Gouvernement flamand partage avec treize départements français l'ambition de faire classer au patrimoine mondial de l'Humanité les champs de bataille de la Grande Guerre.

\section{2) Au Luxembourg}

Envahi par l'Allemagne le 2 août 1914, le Luxembourg a vécu durant quatre années sous un régime d'occupation, sans être annexé. Le pays est resté cantonné dans une stricte neutralité durant tout le conflit.

Cette situation peut expliquer que le Luxembourg ne prévoit pas d'actions commémoratives spécifiques pour le centenaire de la Grande Guerre. Seul, un projet de plaque commémorative que des associations d'anciens combattants souhaiteraient voir apposée aux Invalides, en souvenir des combattants volontaires luxembourgeois engagés dans les armées françaises, dans la Légion étrangère notamment, est envisagé.

\footnotetext{
${ }^{21}$ Le texte a été présenté par le Gouvernement flamand à un groupe « noyau » de douze pays, parmi lesquels : I'Australie, le Canada, l'Allemagne, la France, l'Inde, le Maroc, la Nouvelle-Zélande, la Pologne, la Russie et le Royaume-Uni.
} 


\section{À RETENIR}

\section{EN 100 ANS LA GRANDE GUERRE PASSE DE LA MEMOIRE A L'HISTOIRE}

- le temps du souvenir : temps des deux générations qui suivent la guerre (environ 50 ans) : la connaissance de l'événement est enracinée dans le quotidien des Français ;

- le temps de la mémoire : temps des deux générations suivantes : les anciens combattants disparaissent et le monument aux morts devient un lieu de mémoire ;

- le temps de l'histoire s'ouvre avec la cinquième génération d'après guerre (à partir de 2010/2020) : les champs de bataille deviennent des lieux de tourisme de mémoire.

\section{4-2018 : LE CENTENAIRE DE LA GRANDE GUERRE}

- L'État français conduit un programme national commémoratif du souvenir ;

- En Champagne-Ardenne, des manifestations sont organisées par des collectivités et des associations dans les départements des Ardennes, de la Marne et de la Haute-Marne ;

- La commémoration prend place aussi dans d'autres régions françaises: Picardie (Somme, Aisne et Oise), Lorraine (Meuse) et Nord-Pas-de-Calais ;

- et à l'étranger : Flandre belge et Luxembourg. 
champaghe ardenne

\section{AVIS}

Président : Philippe GERMAIN

Séance plénière du 7 décembre 2012
LE TOURISME DE MEMOIRE

« LA Champagne-ARDENNE :

UNE TERRE D'HISTOIRE QUI SE TOURNE VERS L'AVENIR ॥
Rapporteur : Christophe GIRARDIN

Avis adopté à l'unanimité

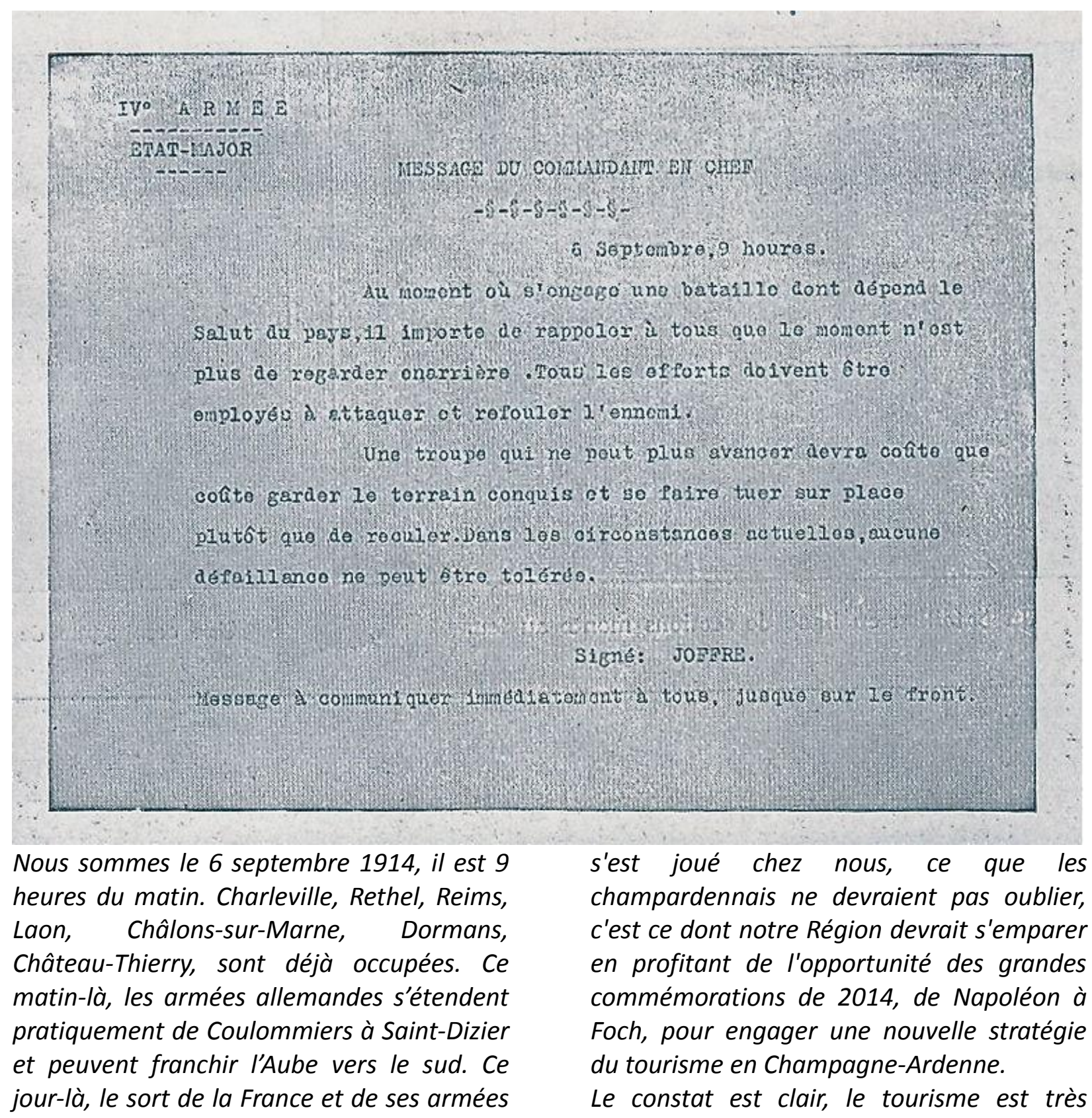


insuffisamment développé en ChampagneArdenne sous toutes ses dimensions, au regard, notamment de ses potentialités. Ainsi, nous disposons d'un patrimoine conséquent mais bien trop méconnu, y compris par nos propres habitants, que ce patrimoine soit naturel, gastronomique, architectural ou culturel. Parmi cet ensemble patrimonial, celui de l'histoire doit être distingué. Notre territoire régional présente, en effet, la particularité de conjuguer son histoire avec la grande histoire nationale et internationale. La vulgarisation participe de l'intérêt pour cette discipline. Cela se vérifie du public scolaire aux générations les plus anciennes, témoins ou non de grands événements, ou d'une vie quotidienne ordinaire. L'histoire est un vecteur de développement touristique. Le rapport du CESER qui est loin d'être exhaustif montre que partout où des villes, des départements et des régions se sont investis dans ce domaine, mettant en relation les populations avec l'histoire de leur territoire, communiquant à l'échelle nationale et internationale, se crée ou se recrée une identité.

À cet égard, 2014 va être une année de commémoration de deux évènements qui ont fortement touché notre région :

\section{4 et les batailles napoléoniennes ;}

1914 et le début de la Grande Guerre.

La Région pourrait-elle passer à côté de ces opportunités?

Pourrait-il ne rien se passer en ChampagneArdenne en 2014 qui fût organisé, proposé, mis en cohérence par la Région?

Des acteurs locaux, publics et privés se sont d'ores et déjà investis (Pays rémois, Mondement, Montmirail, Brienne-leChateau, Ardennes, offices de tourisme etc.). D'autres vont se mettre en mouvement. Mais, si nous voulons que ces initiatives aient les répercussions qu'elles méritent, il est primordial que la Région se place comme coordinatrice de ces initiatives, avec pour objectif de préparer une véritable stratégie du tourisme de mémoire en Champagne
Ardenne.

Cette stratégie doit s'inscrire dans un cadre éducatif pour la population régionale, particulièrement les scolaires, avec le but de dépasser la commémoration de 2014.

La Région est très investie dans les nouvelles technologies; c'est un domaine à explorer dans toutes ses dimensions y compris sur le terrain pour la mise en place des commentaires et explications sur les sites (réalité augmentée,etc.); par ailleurs, cela peut aussi être une opportunité pour permettre l'installation d'entreprises spécialisées.

Élaborer une stratégie pour la Région: quelles propositions?

Poser, à la Région, le problème de la coordination nécessaire pour les aspects notamment de circuits, communication et signalétique.

Devant la quasi absence actuelle de communication, le manque de publicité, une signalétique non ordonnée, la Région devrait se poser en coordinatrice des différents événements pour en faciliter et optimiser la fréquentation.

Dans ce cadre, la Région pourrait proposer une harmonisation des signalétiques départementales des différents sites pour qu'ils soient immédiatement identifiables par chaque touriste et ainsi créer une dynamique régionale autour du tourisme de mémoire.

Mettre en place une politique éditoriale régionale ambitieuse et coordonnée.

- Éditer un recueil, avec un fil conducteur régional, de toutes les manifestations qui vont être initiées par les Départements et les différents acteurs du territoire.

- Éditer un corpus documentaire, en collaboration avec l'Éducation Nationale, 
avec des objectifs pédagogiques, qui pourrait être distribué à tous les professeurs d'histoire du second degré tant dans les lycées que les collèges. Afin de ne pas séparer les jeunes champardennais par niveau d'enseignement, un exemplaire devrait aussi être adressé à chacune des écoles de la région.

- Éditer, en collaboration avec les autorités académiques, un site pédagogique dédié. La mise à disposition d'un corpus documentaire régional devrait faciliter le travail sur site des enseignants, champardennais ou non, avec leurs élèves. Il est nécessaire que ce corpus puisse être accessible par l'internet (collaboration avec l'Éducation Nationale, diffusion par le réseau CNDP, sites pédagogiques,etc.) Ce corpus doit permettre de travailler et de rappeler que nombreux sont les hommes venant de continents différents à avoir sacrifié leur vie sur notre territoire.

- Éditer un ouvrage sur les événements militaires en Champagne-Ardenne, éventuellement période par période, avec une cartographie et des propositions de circuits, en liaison avec les cafés, hôtels, restaurants et les professionnels du tourisme.

Accorder un soutien spécifique aux établissements scolaires.

- Faciliter la mise en place de cours d'histoire in situ, par une aide au transport des classes.

- Organiser un concours régional type concours de la résistance.

Faciliter l'accès aux fiches matricules des combattants.

La Champagne-Ardenne pourrait offrir l'accès à toutes les fiches numérisées (existantes ou à venir) des militaires inhumés en Champagne-Ardenne, en utilisant l'internet, avec la création d'un site dédié. Cela peut faire l'objet d'un programme ou de travaux de recherche en collaboration avec les établissements d'enseignements supérieurs de la région.

Quelques-unes de ces fiches devraient pouvoir être éditées dans le corpus documentaire à destination des élèves et des touristes, voire utilisées dans les informations sur sites (réalité augmentée,etc.).

\section{Accompagner quelques sites.}

Beaucoup d'associations font vivre la mémoire sur le terrain, mais la faiblesse de l'accueil en hébergement et restauration est un véritable problème. II s'agit d'identifier les sites potentiels, puis d'établir des priorités, et d'inciter à l'aménagement: en effet, ce n'est pas à la Région de faire à la place des entreprises (au sens large), ni des autres collectivités. Cette aide pourrait, par exemple, en fonction des lieux, porter sur l'entretien, la rénovation, l'amélioration de l'aménagement, de l'accueil ou encore apporter une meilleure signalétique au site, et diriger les touristes vers les lieux de restauration et d'hébergement les plus proches. II s'agit de rendre les lieux accessibles, actifs et attractifs pour les touristes.

À titre d'exemples :

- Le Fort des Ayvelles: lieu en partie détruit en 1918 qui, aujourd'hui, est restauré par des bénévoles et par un chantier d'insertion dans le cadre, notamment, de l'Association de sauvegarde du Fort et de la Batterie des Ayvelles (nécessité de renforcer la communication et l'accueil).

- Valoriser les sites du circuit "Campagne de France " élaboré par le PNR de la Forêt d'Orient et le musée Napoléon de Brienne le Château.

- Le camp Moreau à Vienne Le Château: lieu pédagogique pour comprendre la vie 
d'un camp mais qui nécessite un aménagement et une restauration.

- Le site de Mondement: incontournable, car la France y a remporté sa première victoire, et qui, dans les grandes commémorations à venir, devrait accueillir le Président de la République. Mais, ce site souffre de l'absence complète d'infrastructures pour accueillir le public.

- Le centre d'interprétation Marne 14/18 de Suippes: site remarquable mais qui rencontre une difficulté de localisation, faute de signalétique, et une absence d'infrastructures pour accueillir les touristes.

- La Main de Massiges : endroit susceptible de se présenter comme une continuité pédagogique après la visite du centre d'interprétation de Suippes. II est important, après avoir acquis toutes les connaissances de la Grande Guerre, de se rendre sur le terrain pour mieux comprendre (signalétique et fonctionnement en réseau avec les autres sites).

- Les villages détruits qui se trouvent actuellement dans le camp militaire de Suippes. II serait essentiel de convenir avec l'armée de la préservation, voire d'une sanctuarisation des lieux avec des ouvertures planifiées de visites plus fréquentes et de créer des liens avec les villages reconstruits (circuits).

\section{Développer les compétences en matière d'accueil}

En vue du centenaire de la Grande Guerre et $d u$ bicentenaire des batailles napoléoniennes, il est indispensable de faire vivre les sites de mémoire. Pour cela, le rôle des guides professionnels ou bénévoles apparaît comme essentiel. Pour cela, il faut inciter à l'organisation de formations dans le cadre du programme régional de formation professionnelle afin de disposer de personnes plus compétentes en matière d'accueil des touristes, tant français qu'étrangers.

Proposer des offres de visites à thèmes croisés incluant le tourisme de mémoire (package)

Le tourisme doit s'ancrer sur le territoire, ses ressources et ses habitants, son calendrier (ex: marché du terroir à l'occasion de la célébration d'événements historiques). Une action spécifique est aussi à mener à destination des Champardennais qui doivent être considérés eux aussi comme des touristes potentiels, mais aussi comme des habitants d'un territoire qui doivent se réapproprier leur histoire pour ensuite en devenir les ambassadeurs et participer à l'accueil des touristes extérieurs et à la promotion de la région (déclinaison du Pass Ambassadeur mis en place par le CRT sur la thématique de l'histoire nationale dans notre région).

Le tourisme de mémoire peut s'intégrer dans le tourisme rural (évolution du tourisme, tourisme de terroir, etc.). Le CRT pourrait construire un questionnaire destiné aux organismes privés du tourisme, en et hors région (autocaristes), pour savoir ce qu'ils attendent en termes de produits pour organiser un parcours.

Le Comité régional du tourisme pourrait, en partenariat avec les CDT et OT, créer au moins un produit sur plusieurs jours en Champagne-Ardenne, en lien avec l'Aisne (Chemin des Dames), la Meuse (Verdun) et la Seine et Marne (musée de la Grande Guerre), avec proposition d'hébergement.

Le CRT pourrait également proposer des circuits spécifiques pour les étrangers qui se rendront en France durant ces 5 ans pour venir sur les traces de leurs ancêtres. De nombreuses nationalités, notamment Russes et Chinoises, se sont retrouvées en Champagne-Ardenne pendant la $1^{\text {ère }}$ guerre mondiale. L'aéroport de Paris-Vatry est une opportunité supplémentaire du développement du tourisme. 
Actualiser et compléter la carte touristique de la Champagne-Ardenne

Utiliser les nouvelles technologies sans contact avec l'un ou l'autre des opérateurs.

En conclusion, le CESER propose d'utiliser les commémorations comme tremplin pour un développement du tourisme de mémoire et plus généralement du tourisme régional et interrégional.
Bien évidemment, notre région est particulièrement concernée par ce double anniversaire, de 1814 et 1914, en 2014 et jusqu'en 2018.

Le CESER considère comme un devoir d'interpeller la Région pour ne pas passer à côté de notre histoire qui doit être envisagée comme un réel facteur de développement et afin de ne pas perdre la mémoire. 


\section{SIGLES ET ABREVIATIONS UTILISES}

$\begin{array}{ll}\text { C.D.T. } & \text { Comité Départemental du Tourisme } \\ \text { C.E.S.E.R. } & \text { Conseil Économique, Social et Environnement Régional } \\ \text { C.F.D.T. } & \text { Confédération Française Démocratique du Travail } \\ \text { C.G.C. } & \text { Confédération Générale des Cadres } \\ \text { C.G.T. } & \text { Confédération Générale du Travail } \\ \text { C.G.T.-F.O. } & \text { Confédération Générale du Travail - Force Ouvrière } \\ \text { C.R.A.J.E.P. } & \text { Comité Régional des Associations de Jeunesse et d'Éducation Populaire } \\ \text { C.R.E.S.C.A. } & \text { Chambre Régionale de l'Économie Sociale en Champagne-Ardenne } \\ \text { C.R.T. } & \text { Comité Régional du Tourisme } \\ \text { D.R.A.C. } & \text { Direction Régionale des Affaires Culturelles } \\ \text { F.S.U. } & \text { Fédération Syndicale Unitaire } \\ \text { O.N.A.C. } & \text { Office National des Anciens Combattants } \\ \text { O.T. } & \text { Office du Tourisme }\end{array}$




\section{BIBLIOGRAPHIE}

Insee Flash n 135 Mai 2011 « Le tourisme en Champagne-Ardenne »

Le Schéma Régional pour l'Aménagement, le Développement et l'Organisation Touristique \& le Plan Marketing 2006/2010 Région Champagne-Ardenne \& Comité Régional du Tourisme

"Les lieux de mémoire de la Résistance en région Rhône-Alpes face à de nouveaux enjeux culturels et touristiques » - Mémoire professionnel - Loriane Gouaille

Enquête tourisme de mémoire - Champagne-Ardenne Tourisme - Cabinet Planeth- 2009

Évaluation du poids économique de la filière du "Tourisme de mémoire " - Ministère de la Défense et des Anciens Combattants, Ministère de l'Économie, des Finances et de l'Innovation, réalisée par Atout France

Tourisme de mémoire Région Champagne-Ardenne - Schéma de développement du tourisme de mémoire en Champagne-Ardenne - Mérimée Conseil - novembre 2001

Intervention de Monsieur Serge Barcellini à l'Assemblée Nationale, le 21 mars 2009 « Réflexions sur la politique de mémoire de la Grande Guerre »

Veille Info Tourisme - René Ressouches, Direction du tourisme, 17 juillet 2008

Le Grand Centenaire (2014-2018) - Autorité flamande - Bruxelles

Le Grand Centenaire en Flandre - Secrétariat du projet Le Grand Centenaire (2014-18)

Les chemins de mémoire 14-18 - Région-Nord-Pas-de-Calais

La Meuse, l'ambition de l'Histoire - 14-18 Le temps de l'histoire - Conseil Général de la Meuse

La Meuse face au défi du centenaire de la grande Guerre 2014-2018 - Serge Barcellini 


\section{ANNEXES}

Annexe 1 Composition du groupe de travail

Annexe 2 Les personnes auditionnées

Annexe 3 Critères d'évaluation

Annexe 4 Fiches descriptives des sites de mémoire de la Grande Guerre 
Pour mener à bien cette autosaisine, le CESER a mis en place un groupe de travail composé de 15 membres et un comité de pilotage composé de six membres du groupe de travail.

Le groupe de travail était composé des personnes suivantes :

Membre

Christian BLANCKAERT

François CLAVERIE

Michel DEHU

Coraline FURIGO

Hervé GABET

Philippe GERMAIN

Christophe GIRARDIN

Jack GRODARD

Gérard LABRUNE

Bruno MALTHET

Francis PAILLARD

Jean-Claude RENARD

Michel RUDENT

Michèle SEVERS

Armande SPILMANN

Patrick TASSIN

\section{Organisme représenté au CESER}

Union Professionnelle Artisanale Régionale

Comité Régional C.G.T.

C.R.A.J.E.P.

Union Régionale C.G.T.-F.O.

Comité Régional de Liaison de la Mutualité

Personnalité Qualifiée

Comité Régional de la F.S.U.

Chambre Régionale de Commerce et d'Industrie

Union Régionale C.G.C.

Union Régionale C.F.D.T.

Chambre Régionale de Métiers et de l'Artisanat

Association Régionale des Industries Agro-alimentaires et Fédération Régionale des Coopératives Agricoles

Section Régionale de l'Union Nationale des Associations des Professions Libérales et Section Régionale de la Chambre Nationale des Professions Libérales

C.R.E.S.C.A.

Personnalité Qualifiée - compétence en matière d'environnement et de développement durable

Président du CESER - Invité permanent

Le comité de pilotage réunissait :

Philippe GERMAIN, Président

Michel DEHU

Christophe GIRARDIN, Rapporteur

Gérard LABRUNE

Christian BLANCKAERT

Michel RUDENT

Patrick TASSIN, Invité permanent

Martine BERCAIRE, chargée de mission, Stéphane GALLOU, documentaliste et Evelyne MARTIN, assistante au CESER ont soutenu le Groupe de travail et le Comité de pilotage dans leurs travaux.

Clémentine JUMEL a accompagné le Groupe de travail pendant les mois de juillet et août 2012 sur l'état des lieux dans le cadre d'un emploi d'été. 


\section{Annexe 2 Les personnes auditionnées}

Le Groupe de travail a rencontré :

Monsieur Serge BARCELLINI

Monsieur Michel BERNARD

Madame Hélène BERTHAUT

Monsieur Eric BLANCHEGORGE

Monsieur Christian BRUYEN

Monsieur Guy CARRIEU

Monsieur Bruno DUPUIS

Madame Carole MARQUET-MORELLE

Madame Catherine MARTIN

Monsieur Alexandre MORA

Madame Laurence PREVOT

Monsieur Joseph PUZO

Monsieur Raymond STEVENIN

Monsieur Michel TELLIER
Directeur de la mission histoire au Conseil Général de la Meuse

Sous-Préfet de Reims

Chef de mission - Appui tourisme à la Direction Régionale des Entreprises, de la concurrence, de la consommation, du travail et de l'emploi de Champagne-Ardenne

Directeur du service " culture » - Région ChampagneArdenne

Vice-président du Conseil général de la Marne

Président de la Commémoration de la Campagne de France de 1814

Directeur de l'Office National des Anciens Combattants et Victimes de Guerre de la Marne

Attachée du patrimoine au Musée de l'Ardenne

Chargée de mission à la Ville de Reims

Directeur Général du Mémorial Charles de Gaulle

Directrice du Comité Régional du Tourisme

Président de « 1814V4 » (1814 des 4 victoires)

Maire-adjoint au Maire de Charleville-Mézières, chargé du patrimoine

Président de Mondement 1914 "Les soldats de la Marne-Joffre-Foch » 
Clémentine JUMEL a auditionné :

Madame Clémentine BILLET

Monsieur Eric BLANCHEGORGE

Monsieur Simon DODANE

Monsieur Bruno DUPUIS

Madame Delphine GARNOTREL

Madame Hélène MEHAULT

Madame Laurence PADIOU

Monsieur Michel TELLIER

Monsieur Thomas WAUTHIER
Directrice du Musée Napoléon \& Trésor des églises à Brienne-le-Château

Directeur du service "culture » - Région Champagne-Ardenne

Chargé de communication à la Maison de l'outil et de la pensée ouvrière à Troyes

Directeur de l'Office National des Anciens Combattants et Victimes de Guerre de la Marne

Chargée de mission - Comité Régional du Tourisme

Directrice du Centre d'Interprétation «Marne 1418 » à Suippes

Directrice de l'Office de Tourisme de Châlons-enChampagne

Président de Mondement 1914 « Les soldats de la Marne-Joffre-Foch »

Responsable d'accueil au Mémorial Charles de Gaulle 
Annexe 3 Les critères d'évaluation

Évolution de l'offre de tourisme

Mise en place de formations

Édition de publications spécifiques

Création d'un site internet dédié au tourisme de mémoire 


\section{Camp de la Vallée Moreau}

Localisation GPS :

$\mathrm{N} 49^{\circ} 11.509^{\prime} \mathrm{E} 4^{\circ}$

53. $156^{\prime}$

\begin{tabular}{|l|l|l|l|}
\hline & & 03.26 .60 .49 .40 & \\
RD 63 Entre Vienne le Château & $\begin{array}{l}\text { Roger Berdold président } \\
\text { et Binarville }\end{array}$ & $\begin{array}{l}\text { maison du pays } \\
\text { du Comité franco-Argonne } \\
\text { dllemand }\end{array}$ & Non renseigné \\
& & Of.26.60.85.83 \\
& Office de Tourisme & \\
\hline
\end{tabular}

\section{Ouverture :}

Tous les samedis matins de $9 \mathrm{~h}$ à $12 \mathrm{~h}$; De juillet à septembre : les 2èmes et 4èmes dimanches de chaque mois de $14 \mathrm{~h}$ à $18 \mathrm{~h}$; En semaine sur réservation

\section{Propriétaire :}

Commune de Vienne-le-Château

Budget :

Non renseigné
Emplois :

Aucun uniquement des bénévoles adhérents)

\section{Français :}

Non renseigné

Étrangers :

Non renseigné

\begin{tabular}{|c|c|c|c|c|}
\hline Camp allemand & $\begin{array}{l}\text { Superficie } \\
: \\
\text { Non } \\
\text { renseigné }\end{array}$ & $\begin{array}{l}\text { Nombre de salles: } \\
\text { Il y a vraiment } \\
\text { beaucoup de choses } \\
\text { à voir sur le camp : } \\
\text { douches, centrale } \\
\text { électrique, le lavoir, } \\
\text { le cinéma, les } \\
\text { cabanes, le grand } \\
\text { tunnel... }\end{array}$ & Non renseigné & $\begin{array}{l}\text { Grande capacité } \\
\text { d'accueil mais } 25 \\
\text { personnes environ par } \\
\text { guide dont le nombre } \\
\text { n'est pas extensible }\end{array}$ \\
\hline
\end{tabular}

\begin{tabular}{|c|c|c|c|}
\hline \multirow[b]{3}{*}{ Visites } & Libre : Non & \multirow[b]{3}{*}{$\begin{array}{l}\text { Langues : } \\
\text { Français, Allemand }\end{array}$} & \multirow{3}{*}{$\begin{array}{l}\text { Tarifs: } \\
\text { Particuliers : } 5 € ; \text { Gratuit pour les } \\
\text { moins de 12ans ; Groupes : (15 } \\
\text { personnes minimum) : } 3 € \text {; Primaire } \\
\text { et collège : } 1 € ; \text { Lycée : } 2 € \\
\text { Lieux d'achat : } \\
\text { Maison du pays d'Argonne à Vienne- } \\
\text { Le-Château ; Office du tourisme du } \\
\text { pays d'Argonne à Sainte-Ménehould }\end{array}$} \\
\hline & $\begin{array}{l}\text { Organisée: Guide physique. } \\
\text { Possible d'acheter un fascicule } \\
\text { de visite à } 5 €\end{array}$ & & \\
\hline & Virtuelle : Non & & \\
\hline
\end{tabular}

\begin{tabular}{|l|l|}
\hline $\begin{array}{l}\text { Accès : } \\
\text { Voiture }\end{array}$ & Accès handicapés : Non \\
\hline $\begin{array}{l}\text { Stationnement : } \\
\text { Oui environ 15 VL }\end{array}$ \\
\hline $\begin{array}{l}\text { Commodités : } \\
\text { Aire de pique nique }\end{array}$ \\
\hline
\end{tabular}

\section{Hébergement à proximité :}

Chambre d'hôtes La Madeleine; Hôtel Le Tulipier

Restauration à proximité :

Restaurant le Tulipier

Organisation de séjours : Non renseigné 


\section{Activités et initiatives annexes :}

25/26 août 2012 reconstitution avec présences de soldats déguisés comme à l'époque.

Musée de la Maison du pays d'Argonne à Vienne le Château. Nécropole nationale de La Harazée

Reconstruction de la " Kantine " détruite après la

\section{Circuit :}

Non concentrer toute son énergie pour le projet de restauration de la Feste Kronpriz.

\section{Actions :}

Non renseigné 


\begin{tabular}{|l|l|l|l|}
\hline $\begin{array}{l}\text { RD } 21-\text { L'Espérance - 51600 } \\
\text { Saint-Hilaire-le-Grand }\end{array}$ & Mr et Mme Mathe & 03.26 .66 .17 .25 & mathe.d@neuf.fr \\
\hline $\begin{array}{l}\text { Ouverture : } \\
\text { Se concerter avec le responsable }\end{array}$ & $\begin{array}{l}\text { Budget : } \\
\text { non fixé }\end{array}$ & $\begin{array}{l}\text { Emplois : } \\
\text { uniquement } \\
\text { bénévoles }\end{array}$ \\
\hline $\begin{array}{l}\text { Propriétaire : } \\
\begin{array}{l}\text { Association du souvenir du corps expéditionnaire russe en } \\
\text { France (ASCERF) }\end{array}\end{array}$ & $\begin{array}{l}\text { Nombre } \\
\text { visiteurs : } \\
300 \text { environ }\end{array}$ & $\begin{array}{l}\text { Français : } \\
0,95\end{array}$ \\
\cline { 2 - 3 } & $\begin{array}{l}\text { Étrangers : } \\
5 \% \text { de russes }\end{array}$ \\
\hline
\end{tabular}

\begin{tabular}{|c|c|c|c|c|}
\hline $\begin{array}{l}\text { Chapelle } \\
\text { commémorative } \\
\text { orthodoxe dédiée à la } \\
\text { mémoire des soldats } \\
\text { russes tombés en } \\
\text { France (1916/1918). } \\
\text { Cimetière militaire } \\
\text { attenant où repose un } \\
\text { millier de soldats } \\
\text { russes appartenant } \\
\text { aux brigades venues } \\
\text { combattre sur le front } \\
\text { français à partir de } \\
\text { 1916. }\end{array}$ & $\begin{array}{l}\text { Superficie : } \\
100 \mathrm{~m}^{2}\end{array}$ & $\begin{array}{l}\text { Nombre de salles: } \\
1\end{array}$ & $\begin{array}{l}\text { Expositions } \\
\text { temporaires } \\
\text { variable }\end{array}$ & Une trentaine \\
\hline
\end{tabular}

\begin{tabular}{|l|l|l|l|}
\hline \multirow{3}{*}{$\begin{array}{l}\text { Visites } \\
:\end{array}$} & Libre : non & $\begin{array}{l}\text { Tarifs : } \\
\text { A l'appréciation des visiteurs }\end{array}$ \\
\cline { 2 - 3 } & Organisée : non & $\begin{array}{l}\text { Langues : } \\
\text { français }\end{array}$ & $\begin{array}{l}\text { Lieux d'achat : } \\
\text { non }\end{array}$ \\
\hline
\end{tabular}

\begin{tabular}{|l|l|}
\hline $\begin{array}{l}\text { Accès : } \\
\text { voiture }\end{array}$ & Accès handicapés : Oui \\
\hline $\begin{array}{l}\text { Stationnement : } \\
\text { Une vingtaine de place pour les VL }\end{array}$ \\
\hline $\begin{array}{l}\text { Commodités : } \\
\text { non }\end{array}$ \\
\hline
\end{tabular}

Hébergement à proximité :

Une chambre d'hôtes : Les charbaudières 03.26.70.00.96

\section{Restauration à proximité :}

Aucun à Saint-Hilaire-le Grand. 1 restaurant à Aubérive, Mourmelon-le-Grand etPlusieurs à Suippes.

Organisation de séjours : Non renseigné 
RD 944 (direction Châlons-enChampagne)

\section{Ouverture :}

Ouverture du 1er novembre au 31 mars, de 10h à 17h.

Du 1 er avril au 31 octobre, en semaine de $11 \mathrm{~h}$ à $18 \mathrm{~h}$, les week-ends et jours fériés de $11 \mathrm{~h}$ à $19 \mathrm{~h}$.

Fermé le mardi et du 24/12 au 06/01.

\section{Propriétaire :}

ville de Reims

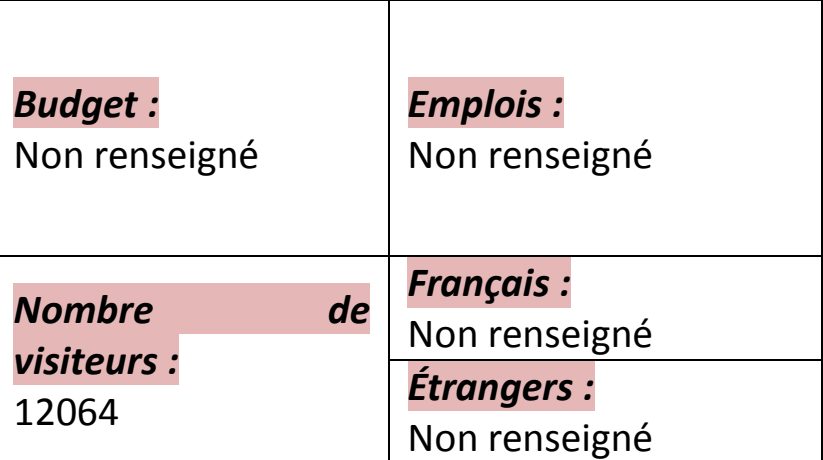

\begin{tabular}{|l|l|l|l|l|}
\hline Musée & $\begin{array}{l}\text { Superficie : } \\
2 \text { ha } 31\end{array}$ & $\begin{array}{l}\text { Nombre de salles : } \\
\text { Non renseigné }\end{array}$ & Non renseigné & Non renseigné \\
\hline
\end{tabular}

\begin{tabular}{|c|c|c|c|}
\hline & Libre :Non renseigné & & Tarifs : \\
\hline & Organisée : Non renseigné & & \\
\hline $\begin{array}{l}\text { Visites } \\
\text { : }\end{array}$ & Virtuelle : Non renseigné & $\begin{array}{l}\text { Langues : } \\
\text { Non renseigné }\end{array}$ & $\begin{array}{l}3 € \text { pour les groupes (à partir de } 15 \\
\text { personnes) } \\
\text { gratuit pour les jeunes jusqu'à } 16 \\
\text { ans, pour les étudiants sur } \\
\text { présentation de leur carte et pour } \\
\text { les scolaires (lycées, collèges et } \\
\text { écoles primaires de la Marne), les } \\
\text { bénéficiaires du CCAS, les } \\
\text { chômeurs, les journalistes et les } \\
\text { conservateurs. } \\
\text { Lieux d'achat: } \\
\text { Office de tourisme de Reims avec le } \\
\text { Pass' Mémoire }\end{array}$ \\
\hline
\end{tabular}

\begin{tabular}{|c|c|c|}
\hline $\begin{array}{l}\text { Accès : } \\
\text { voiture }\end{array}$ & $\begin{array}{l}\text { Accès handicapés : Non } \\
\text { renseigné }\end{array}$ & $\begin{array}{l}\text { Hébergement à proximité : } \\
\text { Non renseigné }\end{array}$ \\
\hline $\begin{array}{l}\text { Stationnement : } \\
\text { Non renseigné }\end{array}$ & & $\begin{array}{l}\text { Restauration à proximité : } \\
\text { Non renseigné }\end{array}$ \\
\hline $\begin{array}{l}\text { Commodités : } \\
\text { Non renseigné }\end{array}$ & & Organisation de séjours : Non renseigné \\
\hline
\end{tabular}

\begin{tabular}{|l|l|}
\hline $\begin{array}{l}\text { Activités et initiatives annexes : } \\
\text { la visite de Reims }\end{array}$ & $\begin{array}{l}\text { Circuit : } \\
\text { Non renseigné }\end{array}$ \\
\hline
\end{tabular}

Actions : Non renseigné 


\begin{tabular}{|l|l|l|l|}
\hline $\begin{array}{l}\text { Rue Louise Michel } \\
08000 \text { Villers-Semeuse }\end{array}$ & Non renseigné & 0324334897 & $\begin{array}{l}\text { domaine.ayvelles } \\
\text { @orange.fr }\end{array}$ \\
\hline
\end{tabular}

\section{Ouverture :}

Ouvert de Pâques à la Toussaint, tous les jours, sauf le lundi.En semaine, de $9 \mathrm{~h}$ à $17 \mathrm{~h}$ et le samedi et dimanche de $9 \mathrm{~h}$ à $18 \mathrm{~h}$.

\section{Propriétaire :}

Conseil général des Ardennes

\section{Budget :}

Non renseigné

Nombre

visiteurs :

Environ 4000

\section{Emplois :}

Non renseigné

Français :

Non renseigné

Étrangers :

Non renseigné

\begin{tabular}{|l|l|l|l|l|}
\hline Non renseigné & $\begin{array}{l}\text { Superficie : } \\
\text { Domaine de } \\
37 \text { hectares }\end{array}$ & $\begin{array}{l}\text { Nombre de salles : } \\
\text { Non renseigné }\end{array}$ & $\begin{array}{l}\text { Visite du fort et du } \\
\text { domaine }\end{array}$ & Non renseigné \\
\hline
\end{tabular}

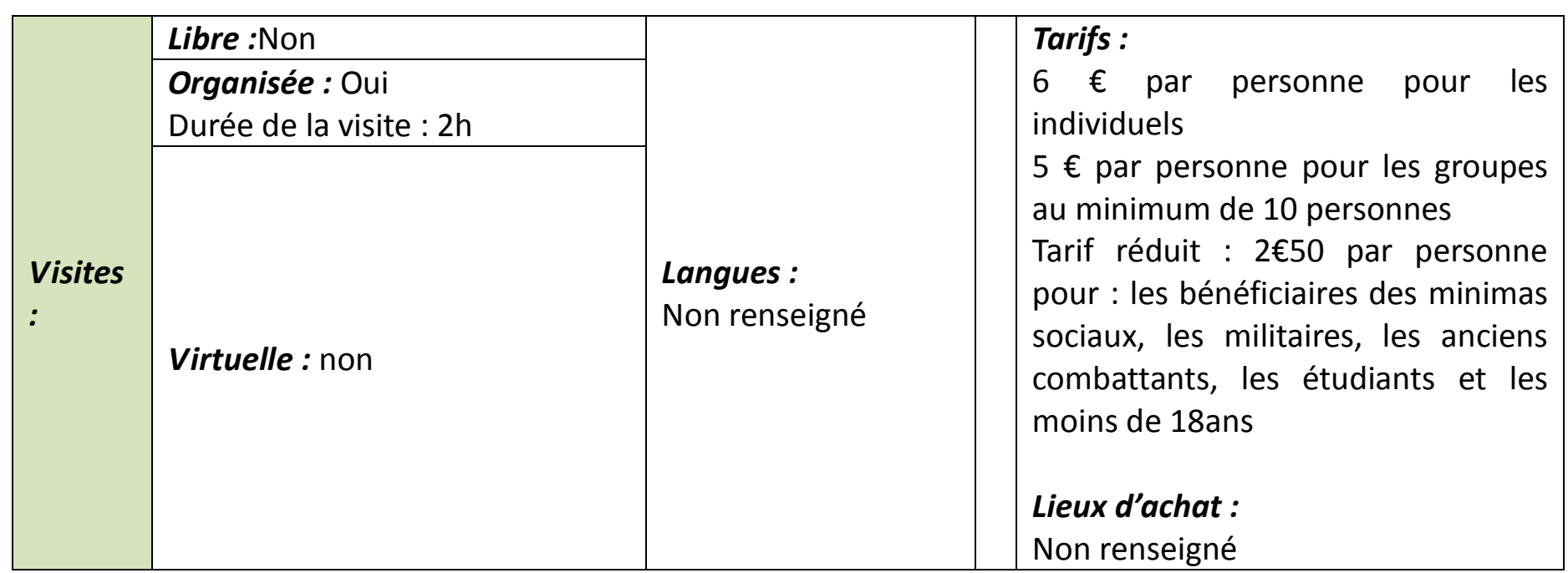

\begin{tabular}{|l|l|}
\hline Accès : & Accès handicapés : non \\
\hline voiture & Stationnement : \\
Parking pour 100 véhicules \\
Accès facile pour les bus \\
Râteliers pour cycles \\
\hline Commodités : \\
Aires de repos et de pique nique ont été aménagées \\
\hline
\end{tabular}

\begin{tabular}{|l|}
\hline $\begin{array}{l}\text { Hébergement à proximité : } \\
\text { Hôtel - restaurant à Villers-Semeuse }\end{array}$ \\
\hline $\begin{array}{l}\text { Restauration à proximité : } \\
\text { Non renseigné }\end{array}$ \\
\hline Organisation de séjours : Non renseigné \\
\hline
\end{tabular}




\begin{tabular}{|l|l|l|}
\hline $\begin{array}{l}\text { Activités et initiatives annexes : } \\
\text { Journées du patrimoine }\end{array}$ & \\
\hline $\begin{array}{l}\text { Fort de Villy-la-Ferté } \\
\text { Musée mai - juin } 1940 \text { à Margut }\end{array}$ & \\
$\begin{array}{l}\text { Ville de Rocroi et ses fortifications } \\
\text { Maison de la dernière cartouche à Bazeilles }\end{array}$ & $\begin{array}{l}\text { Circuit : } \\
\text { En attente de signature d'un contrat avec un } \\
\text { prescripteur }\end{array}$ \\
$\begin{array}{ll}\text { D'importantes restaurations sont en cours. Elles sont } \\
\text { l'œuvre conjointe des bénévoles de l'Association du Fort } \\
\text { et de la Batterie des Ayvelles, qui gère le domaine } \\
\text { appartenant au Conseil général des Ardennes, et des } \\
\text { salariés d'une structure d'insertion. }\end{array}$ & \\
\hline
\end{tabular}

\section{Actions :}

Non renseigné 
Marne 14-18 Centre d'interprétation

\begin{tabular}{|l|l|l|l|}
\hline $\begin{array}{l}4 \text { ruelle Bayard (accès place de } \\
\text { I'Hôtel de Ville) BP 31. } \\
\text { 51601 Suippes cedex }\end{array}$ & Mme Méhault Hélène & $\begin{array}{l}03.26 .68 .24 .09 \\
03.26 .68 .24 .09\end{array}$ & $\begin{array}{l}\text { contact@marne14- } \\
18 . f r\end{array}$ \\
\hline
\end{tabular}

\section{Ouverture :}

Du mardi au dimanche :

- de février à juin et de septembre à novembre: $13 \mathrm{~h}$ à $18 \mathrm{~h}$ -de juillet à août : $10 \mathrm{~h}$ à $19 \mathrm{~h}$

Fermé 1er mai, 14 juillet et 1er novembre

\section{Propriétaire :}

Communauté de communes de la région de Suippes

\section{Budget :}

$190000 €$ de budget général dont 65 $000 €$ de fonctionnement et $12000 €$ pour la communication

\section{Nombre} visiteurs : 6000 visiteurs en 2011 et en hausse pour 2012

\section{Emplois :}

3 emplois permanents et 1 saisonnier

\section{Français :}

$80 \%$ de nationaux dont $45 \%$ de Champardennais (avec $78 \%$ de Marnais et 14 $\%$ d'Aubois).

Étrangers :

$20 \%$ d'étrangers

\begin{tabular}{|c|c|c|c|c|}
\hline $\begin{array}{l}\text { Centre } \\
\text { d'interprétation }\end{array}$ & $\begin{array}{l}\text { Superficie : } \\
600 \mathrm{~m}^{2}\end{array}$ & $\begin{array}{l}\text { Nombre de salles: } \\
7\end{array}$ & $\begin{array}{l}\text { Exposition } \\
\text { permanente, } \\
\text { Expositions } \\
\text { temporaires } \\
\text { régulièrement }\end{array}$ & $\begin{array}{l}300 \text { personnes environ } \\
25 \text { personnes } \\
\text { maximum par groupe }\end{array}$ \\
\hline
\end{tabular}

\begin{tabular}{|c|c|c|c|}
\hline \multirow[b]{3}{*}{$\begin{array}{l}\text { Visites } \\
\text { : }\end{array}$} & Libre :oui & \multirow{3}{*}{$\begin{array}{l}\text { Langues: } \\
\text { Français, anglais et } \\
\text { allemand dans tout } \\
\text { le musée Français et } \\
\text { anglais pour la visite } \\
\text { guidée }\end{array}$} & \multirow{3}{*}{$\begin{array}{l}\text { Tarifs: } \\
\text { Adultes : } 6,50 € / / \text { tarif réduit : } 4,50 € \\
\text { Jeunes de } 6 \text { à } 18 \text { ans : } 3 € / / \text { Gratuit } \\
\text { pour les moins de 6ans } \\
\text { Groupes (>10 personnes) : Adultes : } \\
4,50 € / / \text { Jeunes : } 2,50 € \\
\text { Lieux d'achat : } \\
\text { Office de tourisme de Reims } \\
\text { Centre départemental du tourisme } \\
\text { de la Marne }\end{array}$} \\
\hline & $\begin{array}{l}\text { Organisée : guide physique (sur } \\
\text { réservation), parcours de visite, } \\
\text { brochure, guide et audio guide }\end{array}$ & & \\
\hline & $\begin{array}{l}\text { Virtuelle : visite virtuelle sur le } \\
\text { site www.marne14-18.fr } \\
\text { flash code sur la brochure } \\
\text { audio guide téléchargeable } \\
\text { disponible pour le circuit ( } 8000 \\
\text { téléchargements depuis 2011) }\end{array}$ & & \\
\hline
\end{tabular}




\begin{tabular}{|c|c|c|}
\hline $\begin{array}{l}\text { Accès : } \\
\text { Essentiellement accès en } \\
\text { voiture. } \\
\text { Très difficile avec les horaires } \\
\text { des trains. }\end{array}$ & $\begin{array}{l}\text { Accès handicapés : Accès } \\
\text { handicapés (4 formes } \\
\text { d'handicap) } \quad \text {;Label } \\
\text { tourisme et handicap. }\end{array}$ & $\begin{array}{l}\text { Hébergement à proximité : } \\
\text { Hôtel de Champagne 03.26.69.81.17 } \\
\text { Hôtellerie du café de la gare }\end{array}$ \\
\hline \multicolumn{2}{|c|}{$\begin{array}{l}\text { Stationnement: } \\
\text { Possibilité suffisante pour stationner les voitures comme } \\
\text { les bus. Mais attention parking sous zone bleue. }\end{array}$} & $\begin{array}{l}\text { Restauration à proximité : } \\
\text { Restaurant de la gare 03.26.70.10.98 } \\
\text { L'écluse 03.26.66.47.40 } \\
\text { Speed'Zeria 03.26.63.89.65 }\end{array}$ \\
\hline $\begin{array}{l}\text { Commodités : } \\
\text { WC, Air de pique nique mais } \mathrm{s} \\
\text { En hiver possibilité de réserve } \\
\text { pour les scolaires. }\end{array}$ & $\begin{array}{l}\text { une salle de restauration }\end{array}$ & $\begin{array}{l}\text { Organisation de séjours : Le centre a intégré } \\
\text { les circuits proposés par le CRT. } \\
\text { Pass' Mémoire de Reims } \\
\text { Circuits avec l'office de tourisme du pays } \\
\text { d'Argonne champenoise } \\
\text { Forfait Histoire en champagne : à partir de } \\
62 € / \text { pers. } 2 \text { jours, } 1 \text { nuit } \\
1 / 2 \text { pension en chambre d'hôte, visite du } \\
\text { champagne N.Potié à Condé-sur-Marne, } \\
\text { Visite du centre d'interprétation Marne 14- } \\
18 \text { à Suippes }\end{array}$ \\
\hline
\end{tabular}

\section{Activités et initiatives annexes :}

Participation aux journées du patrimoine et à la nuit des musées mais chaque année reconstitution avec son et lumières sur un site différent. Randonnée historique si possible dans les camps militaires

Le circuit sur les pas des armées de Champagne 1914 1918.

Le village fleuri de Baconnes (chaque été "Baconnes village en lumière" - circuit lumineux à travers le village).

Proposition d'une extension consacrée aux villages détruits du secteur. En pour parler.

\section{Circuit :}

Centre départemental du tourisme et Lastminute.com

\section{Actions :}

En août ouverture à Reims à la maison du département de l'expo sur les villages détruits. Puis l'expo sera itinérante ; et passera notamment par le centre d'interprétation de Suippes.Avec le budget annuel : les actions suivent la logique chronologique :

2013 : Elaboration d'expositions autour du thème : L'art et la guerre Festival international des films de Guerre avec en 2014 des films recentrés sur la première Guerre Mondiale.

2014 : actions autour des évacuations des civils et de la mobilisation

2015 : autour de septembre et de l'offensive de Navarin et de Massiges

2016 : actions portant sur le corps expéditionnaire russe

2017 : batailles autour des monts de Champagne 2018 : thèmes autour des troupes américaines 


\begin{tabular}{|l|l|l|l|}
\hline $\begin{array}{l}\text { Parc du château- } \\
51700 \text { Dormans }\end{array}$ & Non renseigné & 0326591418 & $\begin{array}{l}\text { memorialdormans141 } \\
\text { 8@orange.fr }\end{array}$ \\
\hline
\end{tabular}

\section{Ouverture :}

Ouverture du 1er avril au 11 novembre, tous les jours de $14 \mathrm{~h}$ à $18 \mathrm{~h}$.

Dimanches et jours fériés de $10 \mathrm{~h}$ à $12 \mathrm{~h}$ et de $14 \mathrm{~h}$ à $18 \mathrm{~h}$.

Budget :

Non renseigné

Pour les groupes, visites guidées toute l'année sur rendezvous.

\section{Propriétaire :}

Commune de Dormans
Nombre

visiteurs :

15609

\section{Emplois :}

Non renseigné

\section{Français :}

Non renseigné

Étrangers :

Non renseigné

\begin{tabular}{|c|c|c|c|c|}
\hline Mémorial & $\begin{array}{l}\text { Superficie : } \\
\text { Parc de } \\
\text { 26ha }\end{array}$ & $\begin{array}{l}\text { Nombre de salles: } \\
\text { Une crypte, une } \\
\text { chapelle et un } \\
\text { ossuaire plus le parc } \\
\text { et le chemin de } \\
\text { ronde }\end{array}$ & $\begin{array}{l}\text { Exposition } \\
\text { permanente } \\
\text { Lieu de mémoire } \\
\text { Expositions } \\
\text { temporaires }\end{array}$ & Non renseigné \\
\hline
\end{tabular}

\begin{tabular}{|c|c|c|c|}
\hline \multirow[b]{3}{*}{$\begin{array}{l}\text { Visites } \\
\text { : }\end{array}$} & Libre :oui & \multirow[b]{3}{*}{$\begin{array}{l}\text { Langues : } \\
\text { Non renseigné }\end{array}$} & \multirow{3}{*}{$\begin{array}{l}\text { Tarifs: } \\
\text { Gratuit pour les individuels } \\
2 € \text { par personne pour les groupes } \\
\text { Lieux d'achat : } \\
\text { Non renseigné }\end{array}$} \\
\hline & Organisée : Non renseigné & & \\
\hline & Virtuelle : Non renseigné & & \\
\hline
\end{tabular}

\begin{tabular}{|l|l|}
\hline $\begin{array}{l}\text { Accès : } \\
\text { voiture }\end{array}$ & $\begin{array}{l}\text { Accès handicapés : Non } \\
\text { renseigné }\end{array}$ \\
\hline Stationnement:
\end{tabular}

\section{Stationnement :}

Non renseigné

Commodités :

Non renseigné

Hébergement à proximité :

Non renseigné

Restauration à proximité :

Non renseigné

Organisation de séjours : Non renseigné

\section{Activités et initiatives annexes :}

La visite de Reims

Cimetière italien de Bligny-Chambrecy

Cimetières militaires de Marfaux

Le moulin d'en haut (écomusée)

\section{Actions :}

17 septembre exposition "Le front invisible " 


\begin{tabular}{|l|l|l|l|}
\hline RD $977 \quad$ (entre Souain et & & \\
Sommepy-Tahure) & Souain-Perthe-les- \\
$51600 \quad$ Non renseigné & 0326668232 & Non renseigné \\
Hurlus & S & \\
\hline
\end{tabular}

\begin{tabular}{|l|l|l|}
\hline $\begin{array}{l}\text { Ouverture : } \\
\text { Chapelle ouverte de mars à mi-octobre les vendredis de } \\
\begin{array}{l}14 \mathrm{~h} \text { à } 18 \mathrm{~h}, \text { les week-ends et jours fériés de 10h à 12h et de } \\
14 \mathrm{~h} \text { à } 18 \mathrm{~h} .\end{array}\end{array}$ & $\begin{array}{l}\text { Budget : } \\
\text { Non renseigné }\end{array}$ & $\begin{array}{l}\text { Emplois : } \\
\text { Non renseigné }\end{array}$ \\
\hline $\begin{array}{l}\text { Propriétaire : } \\
\text { Non renseigné }\end{array}$ & $\begin{array}{l}\text { Nombre } \\
\text { visiteurs : } \\
\text { Non renseigné }\end{array}$ & $\begin{array}{l}\text { Français : } \\
\text { Non renseigné }\end{array}$ \\
\cline { 2 - 3 } & $\begin{array}{l}\text { Étrangers : } \\
\text { Non renseigné }\end{array}$ \\
\hline
\end{tabular}

\begin{tabular}{|l|l|l|l|l|}
\hline Lieu de mémoire & $\begin{array}{l}\text { Superficie : } \\
\text { Non } \\
\text { renseigné }\end{array}$ & $\begin{array}{l}\text { Nombre de salles : } \\
1 \text { chapelle }\end{array}$ & Non renseigné & Non renseigné \\
\hline
\end{tabular}

\begin{tabular}{|l|l|l|l|}
\hline \multirow{4}{*}{$\begin{array}{l}\text { Visites } \\
:\end{array}$} & \multicolumn{4}{|l|}{ Libre :oui pour le monument } & $\begin{array}{l}\text { Tarifs : } \\
\text { gratuit }\end{array}$ \\
\cline { 2 - 3 } & Organisée : non & Langues : \\
Non renseigné & Virtuelle : non & $\begin{array}{l}\text { Lieux d'achat : } \\
\text { Par le biais du CRT }\end{array}$ \\
\hline
\end{tabular}

\begin{tabular}{|l|l|l|}
\hline $\begin{array}{l}\text { Accès : } \\
\text { oui }\end{array}$ & Accès handicapés : Oui & $\begin{array}{l}\text { Hébergement à proximité : } \\
\text { Non renseigné }\end{array}$ \\
\cline { 1 - 1 } $\begin{array}{l}\text { Stationnement : } \\
\text { Oui parkings au pied du monument de chaque côté de la } \\
\text { route }\end{array}$ & $\begin{array}{l}\text { Restauration à proximité : } \\
\text { Non renseigné }\end{array}$ \\
\cline { 1 - 1 } $\begin{array}{l}\text { Commodités : } \\
\text { Aire de pique nique }\end{array}$ & Organisation de séjours : Non renseigné \\
\hline
\end{tabular}

\begin{tabular}{|c|c|}
\hline $\begin{array}{l}\text { Activités et initiatives annexes: } \\
\text { Géocaching sur place car plusieurs caches ont été } \\
\text { placées à proximité du site. } \\
\text { Salle mémorial \& le monument du Blanc Mont de } \\
\text { Sommepy-Tahure, Centre d'interprétation Marne 14-18 } \\
\text { de SuippesMusée et cimetières militaires de Souain- } \\
\text { Perthes-les-Hurlus }\end{array}$ & $\begin{array}{l}\text { Circuit : } \\
\text { Non }\end{array}$ \\
\hline
\end{tabular}

Actions :

Non renseigné 


\begin{tabular}{|l|l|l|l|}
\hline $\begin{array}{l}51 \quad 600 \quad \text { Souain-Perthe-les- } \\
\text { Hurlus }\end{array}$ & Non renseigné & 0326701198 & Non renseigné \\
\hline \begin{tabular}{l|l|l|}
\hline $\begin{array}{l}\text { Ouverture : } \\
\text { On peut visiter le musée à la mairie les dimanches après- } \\
\text { midi des mois de juillet et d'août de 14 à 18 heures. }\end{array}$ & $\begin{array}{l}\text { Budget : } \\
\text { Non renseigné }\end{array}$ & $\begin{array}{l}\text { Emplois : } \\
\text { Non renseigné }\end{array}$ \\
\hline $\begin{array}{l}\text { Propriétaire : } \\
\text { Non renseigné }\end{array}$ & $\begin{array}{l}\text { Nombre } \\
\text { visiteurs : } \\
\text { Non renseigné }\end{array}$ & $\begin{array}{l}\text { Français : } \\
\text { Non renseigné }\end{array}$ \\
\cline { 2 - 4 } & $\begin{array}{l}\text { Étrangers : } \\
\text { Non renseigné }\end{array}$ \\
\hline
\end{tabular}
\end{tabular}

\begin{tabular}{|l|l|l|l|l|}
\hline Musée & $\begin{array}{l}\text { Superficie : } \\
\text { Non } \\
\text { renseigné }\end{array}$ & $\begin{array}{l}\text { Nombre de salles : } \\
2 \text { salles sur deux } \\
\text { étages }\end{array}$ & $\begin{array}{l}\text { Exposition } \\
\text { permanente }\end{array}$ & Non renseigné \\
\hline
\end{tabular}

\begin{tabular}{|l|l|l|l|l|}
\hline \multirow{4}{*}{$\begin{array}{l}\text { Visites } \\
:\end{array}$} & Libre :Non renseigné & $\begin{array}{l}\text { Tarifs : } \\
\text { Non renseigné }\end{array}$ \\
\cline { 2 - 2 } & Organisée : Non renseigné & Langues : \\
\cline { 2 - 3 } & Virtuelle : Non renseigné & $\begin{array}{l}\text { Non renseigné } \\
\text { Non d'achat : }\end{array}$ \\
\hline
\end{tabular}

\begin{tabular}{|l|l|l|}
\hline $\begin{array}{l}\text { Accès : } \\
\text { Non renseigné }\end{array}$ & $\begin{array}{l}\text { Accès handicapés : Non } \\
\text { renseigné }\end{array}$ & $\begin{array}{l}\text { Hébergement à proximité : } \\
\text { Non renseigné }\end{array}$ \\
\cline { 1 - 1 } $\begin{array}{l}\text { Stationnement : } \\
\text { Non renseigné }\end{array}$ & $\begin{array}{l}\text { Restauration à proximité : } \\
\text { Non renseigné }\end{array}$ \\
\hline $\begin{array}{l}\text { Commodités : } \\
\text { Non renseigné }\end{array}$ & & \begin{tabular}{l} 
Organisation de séjours : Non renseigné \\
\hline
\end{tabular}
\end{tabular}

\section{Activités et initiatives annexes :}

Musée de Sommpy-Tahure

Les nécropoles autour du village et celles autour Centre

Circuit :

d'interprétation Maner 14/18 à Suippes

Non renseigné

\section{Actions :}

Non renseigné 
Musée de Mondement - Monument

national de la victoire de la Marne

Localisation GPS :

$48^{\circ} 47^{\prime} 17^{\prime \prime}$ Nord $3^{\circ}$

$46^{\prime} 43^{\prime \prime}$ Est

\begin{tabular}{|l|l|l|l|}
\hline $\begin{array}{l}\text { Rue Général Humbert } \\
51120 \text { MONDEMENT }\end{array}$ & Michel TELLIER & 0326803730 & $\begin{array}{l}\text { contact@mondement1 } \\
\text { 914.asso.fr }\end{array}$ \\
\hline
\end{tabular}

\begin{tabular}{|c|c|c|c|}
\hline \multicolumn{2}{|c|}{$\begin{array}{l}\text { Ouverture: } \\
\text { Musée : Ouvert chaque dimanche de juin à septembre, de } \\
15 \mathrm{~h} \text { à } 18 \mathrm{~h} .\end{array}$} & $\begin{array}{l}\text { Budget: } \\
\text { Le budget actuel de } \\
\text { l'association est de } \\
30000 €\end{array}$ & $\begin{array}{l}\text { Emplois : } \\
\text { Aucun uniquement des } \\
\text { bénévoles } \\
\text { L'Association } \\
\text { Mondement } 1914 \\
\text { compte } 480 \text { adhérents }\end{array}$ \\
\hline \multicolumn{2}{|c|}{$\begin{array}{l}\text { Propriétaire: } \\
\text { Musée : Mairie de Mondement est propriétaire du } \\
\text { bâtiment. Collection appartient à l'association. } \\
\text { Monument national : Conseil général de la Marne }\end{array}$} & $\begin{array}{l}\text { Nombre de } \\
\text { visiteurs : } \\
\text { Non renseigné }\end{array}$ & \begin{tabular}{l|} 
Français : \\
Non renseigné \\
Étrangers : \\
Non renseigné \\
\end{tabular} \\
\hline $\begin{array}{l}\text { Superficie : } \\
\text { Non } \\
\text { renseigné }\end{array}$ & $\begin{array}{l}\text { Nombre de salles: } \\
1\end{array}$ & $\begin{array}{l}\text { Exposition } \\
\text { permanente }\end{array}$ & $\begin{array}{l}25 \\
\text { maximum }\end{array}$ \\
\hline
\end{tabular}

\begin{tabular}{|c|c|c|c|}
\hline \multirow{3}{*}{ Visites : } & Libre : non & \multirow{3}{*}{$\begin{array}{l}\text { Langues: } \\
\text { Français }\end{array}$} & \multirow{3}{*}{$\begin{array}{l}\text { Tarifs: } \\
\text { Gratuit, pour les Groupes sur } \\
\text { rendez-vous } \\
\text { Lieux d'achat : } \\
\text { Non renseigné }\end{array}$} \\
\hline & $\begin{array}{l}\text { Organisée : Oui avec un } \\
\text { bénévole de l'association qui } \\
\text { est agréé par le rectorat de } \\
\text { l'Académie de Reims }\end{array}$ & & \\
\hline & Virtuelle : Non & & \\
\hline
\end{tabular}

\begin{tabular}{|c|c|c|}
\hline $\begin{array}{l}\text { Accès : } \\
\text { En voiture }\end{array}$ & $\begin{array}{l}\text { Accès handicapés: } \\
\text { Difficilement }\end{array}$ & $\begin{array}{l}\text { Hébergement à proximité : } \\
3 \text { hôtels - restaurants, } 1 \text { chambre d'hôtes \& } \\
1 \text { camping à Sézanne }\end{array}$ \\
\hline \multicolumn{2}{|c|}{$\begin{array}{l}\text { Stationnement : } \\
\text { Oui sur le parking au pied du monument environ } 20 \mathrm{VL} .\end{array}$} & $\begin{array}{l}\text { Restauration à proximité : } \\
\text { Restaurants à Villevenard et à Sézanne }\end{array}$ \\
\hline \multicolumn{2}{|c|}{$\begin{array}{l}\text { Commodités : } \\
\text { Toilettes }\end{array}$} & Organisation de séjours : Non renseigné \\
\hline
\end{tabular}




\section{Activités et initiatives annexes :}

Monument national: Chaque année, la cérémonie commémorative de la première bataille de la Marne au pied du monument est célébrée le premier dimanche de septembre. Cérémonie internationale et nationale.

Projet de déplacer le musée à Soizy-aux-bois après la création d'un centre d'interprétation.

Musée: Nécropoles de Soizy-aux-bois, FèreChampenoise et Courgivaux,

Cimetière allemand de Connantre

Colonne commémorative à Champaubert

Abbaye Notre Dame du Reclus à Talus Saint Prix

Projet de déplacer le musée à Soizy-aux-bois après la création d'un centre d'interprétation

\section{Actions :}

Musée : Pour le centenaire, l'association Mondement 1914, souhaite travailler avec les Pyrénées pour rendre hommage aux trois généraux ayant combattus dans la Marne ; que sont Joffre, Foch et Galliéni.

Sinon pour 2013 création par les jeunes du secteur de Mondement d'une BD sur les blessés de guerre. II y aura la même année la création d'un livre sur la vie à l'arrière des combats.

Monument national : Pour 2014 l'association souhaite inaugurer le musée à Soizy-aux-bois.

Cérémonie officielle comme prévue par le rapport Zimmet 
Musée des guerres de $1914-1918$ et 1939 -

Localisation GPS : 1945

Non renseigné

\begin{tabular}{|l|l|l|l|}
\hline $\begin{array}{l}13 \text { rue de Poilcourt } \\
08190 \text { Brienne-sur-Aisne }\end{array}$ & M \& Mme Leriche & 0324729425 & Non renseigné \\
\hline
\end{tabular}

\begin{tabular}{|l|l|l|}
\hline $\begin{array}{l}\text { Ouverture : } \\
\text { Ouvert le week-end sur rendez-vous du 1er mars au } 11 \\
\text { novembre. }\end{array}$ & $\begin{array}{l}\text { Budget : } \\
\text { Non renseigné }\end{array}$ & $\begin{array}{l}\text { Emplois : } \\
\text { Aucun }\end{array}$ \\
\hline $\begin{array}{l}\text { Propriétaire : } \\
\text { Particulier }\end{array}$ & $\begin{array}{l}\text { Nombre } \\
\text { visiteurs : } \\
\text { Non renseigné }\end{array}$ & $\begin{array}{l}\text { Français : } \\
\text { Non renseigné }\end{array}$ \\
\cline { 3 - 4 } & $\begin{array}{l}\text { Étrangers : } \\
\text { Non renseigné }\end{array}$ \\
\hline
\end{tabular}

\begin{tabular}{|l|l|l|l|l|}
\hline Musée & $\begin{array}{l}\text { Superficie : } \\
\text { Non } \\
\text { renseigné }\end{array}$ & $\begin{array}{l}\text { Nombre de salles : } \\
\text { Non renseigné }\end{array}$ & $\begin{array}{l}\text { Exposition } \\
\text { permanente }\end{array}$ & Non renseigné \\
\hline
\end{tabular}

\begin{tabular}{|l|l|l|l|l|}
\hline \multirow{4}{*}{$\begin{array}{l}\text { Visites } \\
:\end{array}$} & \multicolumn{1}{|l|}{ Libre :Non renseigné } & $\begin{array}{l}\text { Tarifs : } \\
\text { Visite gratuite }\end{array}$ \\
\cline { 2 - 3 } & Organisée : Non renseigné & Langues : \\
\cline { 2 - 3 } & Von renseigné & $\begin{array}{l}\text { Lieux d'achat : } \\
\text { Non renseigné }\end{array}$ \\
\hline
\end{tabular}

\begin{tabular}{|c|c|c|}
\hline $\begin{array}{l}\text { Accès : } \\
\text { Voiture }\end{array}$ & $\begin{array}{l}\text { Accès handicapés : Non } \\
\text { renseigné }\end{array}$ & $\begin{array}{l}\text { Hébergement à proximité : } \\
\text { Non renseigné }\end{array}$ \\
\hline $\begin{array}{l}\text { Stationnement : } \\
\text { Non renseigné }\end{array}$ & & $\begin{array}{l}\text { Restauration à proximité : } \\
\text { Non renseigné }\end{array}$ \\
\hline $\begin{array}{l}\text { Commodités : } \\
\text { Non renseigné }\end{array}$ & & Organisation de séjours : Non renseigné \\
\hline
\end{tabular}

\begin{tabular}{|c|c|}
\hline $\begin{array}{l}\text { Activités et initiatives annexes: } \\
\text { Non renseigné }\end{array}$ & rimgi \\
\hline $\begin{array}{l}\text { Actions : } \\
\text { Non renseigné }\end{array}$ & Non renseigné \\
\hline
\end{tabular}




\section{Salle mémorial}

\begin{tabular}{|l|l|l|l|}
\hline 20 rue Foch & & $\begin{array}{l}03.26 .66 .81 .30 \\
\text { ou } 0326668007 \\
\text { ou } 0326668004 \\
03.26 .66 .81 .30\end{array}$ & Mme GUYOT Marie-Jo
\end{tabular}$\quad$\begin{tabular}{l}
$\mathrm{http}$ fr/sommepy-tahure/ \\
\hline
\end{tabular}

\begin{tabular}{|c|c|c|}
\hline $\begin{array}{l}\text { Ouverture: } \\
\text { Visite individuelle ou groupe sur demande toute l'année. }\end{array}$ & $\begin{array}{l}\text { Budget : } \\
\text { Non renseigné }\end{array}$ & $\begin{array}{l}\text { Emplois : } \\
\text { Aucun. Uniquement } 4 \\
\text { bénévoles } \\
\text { l'association } \\
\text { souvenir }\end{array}$ \\
\hline $\begin{array}{l}\text { Propriétaire : } \\
\text { Commune de Sommepy-Tahure }\end{array}$ & $\begin{array}{l}\text { Nombre } \\
\text { visiteurs : } \\
\text { peu }\end{array}$ & $\begin{array}{l}\text { Français : } \\
0,9 \\
\text { Étrangers : } \\
10 \% \text { d'étrangers } \\
\text { (Américains, Danois, } \\
\text { Allemands, ...) }\end{array}$ \\
\hline
\end{tabular}

\begin{tabular}{|l|l|l|l|l|}
\hline $\begin{array}{l}\text { Musée / Salle de } \\
\text { mémoire }\end{array}$ & $\begin{array}{l}\text { Superficie : } \\
\begin{array}{l}60 \mathrm{~m}^{2} \\
\text { environ }\end{array}\end{array}$ & $\begin{array}{l}\text { Nombre de salles : } \\
1\end{array}$ & $\begin{array}{l}\text { Salle d'exposition } \\
\text { permanente }\end{array}$ & $\begin{array}{l}25 \\
\text { maximum }\end{array}$
\end{tabular}

\begin{tabular}{|l|l|l|l|}
\hline \multirow{4}{*}{$\begin{array}{l}\text { Visites } \\
:\end{array}$} & \begin{tabular}{l} 
Libre $:$ non \\
\cline { 2 - 3 }
\end{tabular} & $\begin{array}{l}\text { Organisée : Visite guidée } \\
\text { uniquement }\end{array}$ & $\begin{array}{l}\text { Langues : } \\
\text { français }\end{array}$ \\
\cline { 2 - 3 } & Virtuelle : non & $\begin{array}{l}\text { Participation demandée de 2€ } \\
\text { non d'achat : }\end{array}$ \\
\hline
\end{tabular}

\begin{tabular}{|l|l|}
\hline $\begin{array}{l}\text { Accès : } \\
\text { voiture }\end{array}$ & Accès handicapés : non \\
\hline $\begin{array}{l}\text { Stationnement : } \\
\text { Parking gratuit devant le musée. Arrêt possible pour les } \\
\text { bus. }\end{array}$ \\
\hline $\begin{array}{l}\text { Commodités : } \\
\text { WC }\end{array}$ \\
\hline
\end{tabular}

Hébergement à proximité :

Gîte La Chanvière - 03.26.64.95.05

Restauration à proximité :

La source du Py 03.26.67.06.25

Organisation de séjours : Non renseigné 


\section{Activités et initiatives annexes :}

Participation aux journées des villages détruits (13 et 14 octobre 2012)Ballade dans Sommepy-Tahure avec 6 points de rendez-vous audiovisuel (ne fonctionne plus aujourd'hui mais l'association veut relancer cette visite L'église ,Nécropole nationale, Monument du Blanc Mont - Mémorial de Navarin et le Centre d'interprétation de Suippes.

Projet de rénovation de la façade.

Création dans l'autre pièce libre à l'étage d'une salle pouvant permettant la diffusion de films. Réorganisation de l'exposition surtout dans certaines vitrines (faire un tri, mieux exposer, ...)

\section{Circuit :}

Non

\section{Actions :}

Organisation de la journée des villages détruits 


\section{Tranchées de la main de Massiges}

\begin{tabular}{|l|l|l|l|}
\hline $\begin{array}{l}\text { D } 566 \\
51800 \text { Massiges }\end{array}$ & Non renseigné & 0326604400 & Non renseigné \\
\hline
\end{tabular}

\begin{tabular}{|l|l|l|}
\hline Ouverture : & $\begin{array}{l}\text { Budget : } \\
\text { Non renseigné }\end{array}$ & $\begin{array}{l}\text { Emplois : } \\
\text { Non renseigné }\end{array}$ \\
\hline Propriétaire : & $\begin{array}{l}\text { Nombre de de } \\
\text { visiteurs : } \\
\text { Municipalité }\end{array}$ & $\begin{array}{l}\text { Français : } \\
\text { Non renseigné }\end{array}$ \\
\cline { 3 - 4 } & $\begin{array}{l}\text { Étrangers : } \\
\text { Non renseigné }\end{array}$ \\
\hline
\end{tabular}

\begin{tabular}{|l|l|l|l|l|}
\hline Lieu de mémoire & $\begin{array}{l}\text { Superficie : } \\
\text { Non renseigné }\end{array}$ & $\begin{array}{l}\text { Nombre de } \\
\text { salles : } \\
\text { Non renseigné }\end{array}$ & Non renseigné & Non renseigné \\
\hline
\end{tabular}

\begin{tabular}{|c|c|c|c|}
\hline \multirow{3}{*}{ Visites : } & $\begin{array}{l}\text { Libre :Accès libre aux } \\
\text { tranchées }\end{array}$ & \multirow{3}{*}{$\begin{array}{l}\text { Langues : } \\
\text { Non } \\
\text { renseigné }\end{array}$} & \multirow{3}{*}{$\begin{array}{l}\text { Tarifs : } \\
\text { Non renseigné } \\
\text { Lieux d'achat : } \\
\text { Non renseigné }\end{array}$} \\
\hline & $\begin{array}{l}\text { Organisée : } \quad \text { Visite } \\
\text { guidée sur rendez-vous }\end{array}$ & & \\
\hline & $\begin{array}{l}\text { Virtuelle : } \\
\text { renseigné }\end{array}$ & & \\
\hline
\end{tabular}

\begin{tabular}{|l|l|l|}
\hline $\begin{array}{l}\text { Accès : } \\
\text { En voiture par la D 982 }\end{array}$ & Accès handicapés : non & $\begin{array}{l}\text { Hébergement à proximité : } \\
\text { Non renseigné }\end{array}$ \\
\hline $\begin{array}{ll}\text { Stationnement : } \\
\text { Non renseigné }\end{array}$ & $\begin{array}{l}\text { Restauration à proximité : } \\
\text { L'auberge du Pont de Marson à } \\
\text { Minacourt-le-Mesnil-lès-Hurlus à 2,5km } \\
\text { de Massiges }\end{array}$ \\
\hline $\begin{array}{ll}\text { Commodités : } \\
\text { non }\end{array}$ & $\begin{array}{l}\text { Organisation de séjours : Non } \\
\text { renseigné }\end{array}$ \\
\hline
\end{tabular}

\section{Activités et initiatives annexes :}

Cimetière militaire de Minaucourt-le-Mesnil-les-HurlusLe camp de la vallée Moreau à Vienne-le-château

L'atelier de Raymond Kneip : spécialiste dans la fabrication des coqs de clocher, girouettes et autres ornements de

Circuit :

toiture.

Non renseigné

\section{Actions :}

Non renseigné 

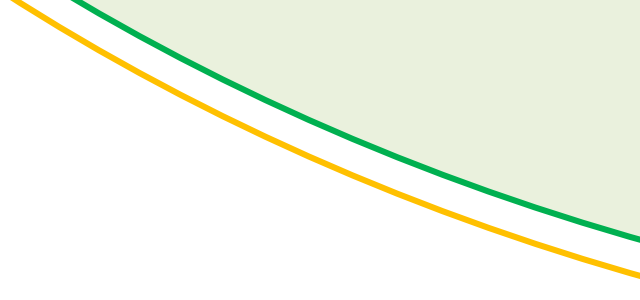

Conseil Économique, Social et EnVIRonnemental Regional

DE Champagne-ARdenNe

HOTEL DE REGION

5 RUE DE JERICHO

51037 CHALONS-EN-ChAMPAGNE

TEL : 0326703179

FAX : 0326216976

MAIL : ceser@cr-champagne-ardenne.fr

SITE WEB : http://www.ceser-champagne-ardenne.fr 